\title{
Low Emission Feed
}

Using feed additives to decrease methane production in dairy cows

Geronda Klop 


\section{Thesis committee}

\section{Promotor}

Prof. Dr W.H. Hendriks

Professor of Animal Nutrition

Wageningen University

\section{Co-promotors}

\section{Dr J. Dijkstra}

Associate professor, Animal Nutrition Group

Wageningen University

Dr A. Bannink

Senior researcher, Wageningen UR Livestock Research

\section{Other members}

Prof. Dr I. J. M. de Boer, Wageningen University

Dr H. B. Perdok

Dr P. Lund, Aarhus University, Tjele, Denmark

Dr D. R. Yáñez-Ruiz, Spanish National Research Council, Madrid, Spain

This research was conducted under the auspices of the Graduate School of Wageningen Institute of Animal Science (WIAS). 


\title{
Low Emission Feed
}

\section{Using feed additives to decrease methane production in dairy cows}

\author{
Geronda Klop
}

\section{Thesis}

submitted in fulfilment of the requirements for the degree of doctor

at Wageningen University

by the authority of the Rector Magnificus

Prof. Dr A.P.J. Mol,

in the presence of the

Thesis Committee appointed by the Academic Board

to be defended in public

on Wednesday 5 October 2016

at 1.30 p.m. in the Aula. 
Geronda Klop

Low Emission Feed - Using feed additives to decrease methane production in dairy cows 168 pages.

PhD thesis, Wageningen University, Wageningen, NL (2016)

With references, with summary in English

ISBN 978-94-6257-894-4

DOI $10.18174 / 387944$ 


\section{SUMMARY}

Research into manipulating methane $\left(\mathrm{CH}_{4}\right)$ production as a result of enteric fermentation in ruminants currently receives global interest. Using feed additives may be a feasible strategy to mitigate $\mathrm{CH}_{4}$ as they are supplied in such amounts that the basal diet composition will not be largely affected. The latter is relevant because ruminants have the capacity to convert human inedible feedstuffs into human edible energy and protein. However, the application of $\mathrm{CH}_{4}$ mitigation feed additives may be hampered by several negative side effects including trade-offs with other environmental impacts, negative effects on animal performance, and lack of persistency of the mitigating effect. The research described in this thesis addresses both the mitigating effect of feed additives as well as its persistency. The main focus was on investigating additivity of the $\mathrm{CH}_{4}$ mitigating effect of feed additives, on the adaptation of rumen microbes to long term feeding of feed additives, and on exploring the potential of rotational feeding of additives to avoid (or reduce) microbial adaptation.

In an experiment with lactating dairy cows in climate respiration chambers to study potential interactions between the effects of feeding nitrate and docosahexaenoic acid (DHA; $\mathrm{C} 22: 6 \mathrm{n}-3$ ) on enteric $\mathrm{CH}_{4}$ production, the effects of nitrate and $\mathrm{DHA}$ on $\mathrm{CH}_{4}$ yield [g/kg dry matter intake (DMI)] and $\mathrm{CH}_{4}$ intensity $[\mathrm{g} / \mathrm{kg}$ fat- and protein- corrected milk (FPCM)], were additive (Chapter 2). Nitrate decreased $\mathrm{CH}_{4}$ irrespective of the unit in which it was expressed, and the average decline in $\mathrm{CH}_{4}$ emission corresponds to $85 \%$ of the stoichiometric potential of nitrate to decrease $\mathrm{CH}_{4}$. Feeding $\mathrm{DHA}$ had no effect on $\mathrm{CH}_{4}$ yield, but resulted in a higher $\mathrm{CH}_{4}$ intensity, because of milk fat depression. The interaction effect between nitrate and DHA on fiber digestibility indicated that negative effects of nitrate on apparent total tract digestibility of nutrients were alleviated by DHA, probably due to an altered feed intake pattern.

Using an isotope measurement protocol in the same study, it was demonstrated that effects of nitrate as a $\mathrm{CH}_{4}$ mitigating feed additive on fiber degradation in the rumen can be detected by evaluating diurnal patterns of ${ }^{13} \mathrm{C}$ enrichment of exhaled $\mathrm{CO}_{2}$ (Chapter 3 ). 
Feeding nitrate, but not DHA, resulted in a pronounced increase in ${ }^{13} \mathrm{C}$ enrichment of $\mathrm{CO}_{2}$ in the first 3 to $4 \mathrm{~h}$ after feeding only. Results support the hypothesis that effects of a feed additive on the rate of fiber degradation in the rumen can be detected by evaluating diurnal patterns of ${ }^{13} \mathrm{C}$ enrichment of $\mathrm{CO}_{2}$. A prerequisite for this detection method is that the main ration components differ in natural ${ }^{13} \mathrm{C}$ enrichment (e.g., $\mathrm{C} 3$ and $\mathrm{C} 4$ plants), and in content of the nutrients that are expected to be involved in a shift in fermentation (e.g., starch and fiber) or in degradability of a nutrient.

In a combined in vivo and in vitro trial, the adaptation to $\mathrm{CH}_{4}$ mitigating feed additives, viz. an essential oil blend or lauric acid (C12:0), compared with a control diet was first investigated using the in vitro gas production technique during the period that lactating cows were adapting to certain feed additives (Chapter 4). Rumen fluid was collected from each cow at several days relative to the introduction of the additives in the diets and used as inoculum for the gas production experiment with each of the three different substrates that reflected the treatment diets offered to the cows. The feed additives in the donor cow diet had a stronger effect on in vitro gas and $\mathrm{CH}_{4}$ production than the same additives in the incubation substrate. From day 4 onwards, the C12:0 diet persistently reduced gas and $\mathrm{CH}_{4}$ production, total volatile fatty acid concentration, acetate molar proportion and in vitro organic matter degradation, and increased propionate molar proportion. In contrast, in vitro $\mathrm{CH}_{4}$ production was reduced by the essential oils diet on day 8, but not on days 15 and 22. In line with these findings, the molar proportion of propionate in fermentation fluid was higher, and that of acetate smaller, for the essential oils diet than for the control diet on day 8, but not on days 15 and 22. Overall, the data indicate a transient effect of the essential oils on $\mathrm{CH}_{4}$ production, which may indicate microbial adaptation, whereas the $\mathrm{CH}_{4}$ mitigating effect of $\mathrm{C} 12: 0$ persisted. It is recommended that this phenomenon is considered in the planning of future studies on the mitigation potential of feed additives in vitro.

In a follow-up in vivo study, it was investigated whether the alternate feeding of two $\mathrm{CH}_{4}$ mitigating feed additives with a different mode of action (viz. C12:0 and a blend of essential oils) would result in a persistently lower $\mathrm{CH}_{4}$ production compared to feeding a 
single additive over a period of 10 weeks. The experiment comprised a pre-treatment period and three two-week measurement periods, with two periods of 2 weeks in between in which $\mathrm{CH}_{4}$ emission was not measured. Cows received either continuously the essential oil blend, or both the essential oil blend and C12:0 following a weekly rotation schedule (Chapter 5). Both $\mathrm{CH}_{4}$ yield and $\mathrm{CH}_{4}$ intensity changed over time, but were not affected by treatment. Methane yield and intensity were significantly lower (12 and 11\%, respectively) in period 1 compared with the pre-treatment period, but no significant difference relative to the pre-treatment period was observed in period 3 (numerically 9 and $7 \%$ lower, respectively) and in period 5 (numerically 8 and $4 \%$ lower, respectively). These results indicate a transient decrease in $\mathrm{CH}_{4}$ yield and intensity in time, but no improvement in extent or persistency of $\mathrm{CH}_{4}$ reduction due to rotational feeding of essential oils and C12:0 in lactating dairy cows. However, there were indications that the concept of rotation may be effective and warrants further investigation.

The additives and concepts tested in this thesis are applied under specific experimental conditions. More mechanistic understanding is required to predict the response of the same additives when supplemented to other basal diets or cows in a different physiological state. Trade-offs in environmental impact, and effects on cow health and performance, and on milk processing parameters and food safety are important aspects to consider in future research on the application of feed additives as $\mathrm{CH}_{4}$ mitigation strategy. 


\section{Table of contents}

Summary

Chapter 1

General introduction

11

Chapter 2 Feeding nitrate and docosahexaenoic acid affects enteric

methane production and milk fatty acid composition in

lactating dairy cows

31

Chapter 3 Using diurnal patterns of ${ }^{13} \mathrm{C}$ enrichment of $\mathrm{CO}_{2}$ to evaluate

the effects of nitrate and docosahexaenoic acid on fiber

degradation in the rumen of lactating dairy cows

59

Chapter 4 Changes in in vitro gas and methane production from

rumen fluid from dairy cows during adaptation to feed

71

additives in vivo

Chapter 5 Effects of continuous feeding of essential oils or rotational

feeding of essential oils and lauric acid on enteric methane

production in lactating dairy cows

95

Chapter 6

General discussion

123

Chapter 7

Co-authored peer-reviewed publications related to this

155

thesis

Curriculum vitae

158

Overview of scientific publications

159

Training and Supervision Plan

162

Acknowledgements

164 
Chapter 1

General introduction 


\section{GENERAL INTRODUCTION}

\section{Methane research}

Research into manipulating methane $\left(\mathrm{CH}_{4}\right)$ production as a result of enteric fermentation in ruminants currently receives global interest (Hristov et al., 2013b). Approximately 90\% of total enteric $\mathrm{CH}_{4}$ production in ruminants, originates from rumen fermentation of feedstuffs, which implies that nutrition can have a large impact on total $\mathrm{CH}_{4}$ emissions. For this reason, the topic of nutritional strategies to reduce $\mathrm{CH}_{4}$ emissions from ruminants has been the subject of several qualitative and quantitative reviews (see Hristov et al., 2013b,c for a recent overview in which more than 900 studies on the mitigation of direct nitrous oxide $\left(\mathrm{N}_{2} \mathrm{O}\right)$ and $\mathrm{CH}_{4}$ emissions were reviewed).

Metabolizable energy (ME) and Net energy (NE) systems are widely used in feed evaluation for cattle. The ME is the heat of combustion (gross energy; GE) of feed, minus the energy in faeces, urine and gases. To accurately determine $\mathrm{ME}$, losses of energy in $\mathrm{CH}_{4}$ have to be measured. Methane represents, on average, a loss of $6.5 \%$ of GE, but with a wide range (2-12\% of GE; Johnson and Johnson 1995). Initially, research into manipulating $\mathrm{CH}_{4}$ production was related to the loss of $\mathrm{GE}$ represented by $\mathrm{CH}_{4}$. However, more recently the research focus shifted from enteric $\mathrm{CH}_{4}$ as an inefficiency in animal production, towards the contribution of $\mathrm{CH}_{4}$ to global greenhouse gas emissions (see Hristov et al., 2013b,c).

\section{Metrics to express enteric methane production in ruminants}

The effect of a mitigation strategy may vary across different units in which enteric $\mathrm{CH}_{4}$ production can be expressed. As discussed by Hristov et al. (2013b), metrics used to quantify emissions should be standardized. The commonly used $\mathrm{CH}_{4}$ yield factor that expresses $\mathrm{CH}_{4}$ production as a percentage of $\mathrm{GE}$ intake (GEI) does for example not adequately describe the impact of changes in nutrient composition of the diet. Ellis et al. (2010) explained that using a GEI based calculation cannot distinguish between an increased dry matter intake (DMI) or increased dietary fat content. Both scenarios may result in the same GEI value, but the effect on $\mathrm{CH}_{4}$ production may differ. 
As most of the $\mathrm{CH}_{4}$ production originates from rumen fermentation, less fermentation will consequently lower the total $\mathrm{CH}_{4}$ production per day. Less fermentation of feed in the rumen may lower the amount of available nutrients to the animal, and consequently animal productivity. Thus, if a mitigation strategy negatively affects animal performance then $\mathrm{CH}_{4}$ production rate in $\mathrm{g} / \mathrm{d}$ may decrease whilst $\mathrm{CH}_{4}$ production in $\mathrm{g} / \mathrm{kg} \mathrm{DMI}$ and $\mathrm{g} / \mathrm{kg}$ fat- and protein-corrected milk (FPCM) may actually increase. In the context of global food supply and efficient use of resources, it is important to consider the latter two units, which are often referred to with the terms $\mathrm{CH}_{4}$ yield and intensity, respectively. The focus in this thesis will also be on lowering $\mathrm{CH}_{4}$ production per $\mathrm{kg} \mathrm{DMI}$ and per $\mathrm{kg}$ FPCM produced.

\section{Function of methanogenesis in ruminants}

Before proposing any $\mathrm{CH}_{4}$ mitigation strategy, it is important to understand the function of methanogenesis in ruminant animals. For digestion of the fibrous feedstuffs that are typical for ruminant diets, the animals largely depend on the rumen microbial ecosystem. Microbial fermentation in the rumen yields volatile fatty acids (VFA) and microbial protein, which are quantitatively important sources of energy and protein for the animal.

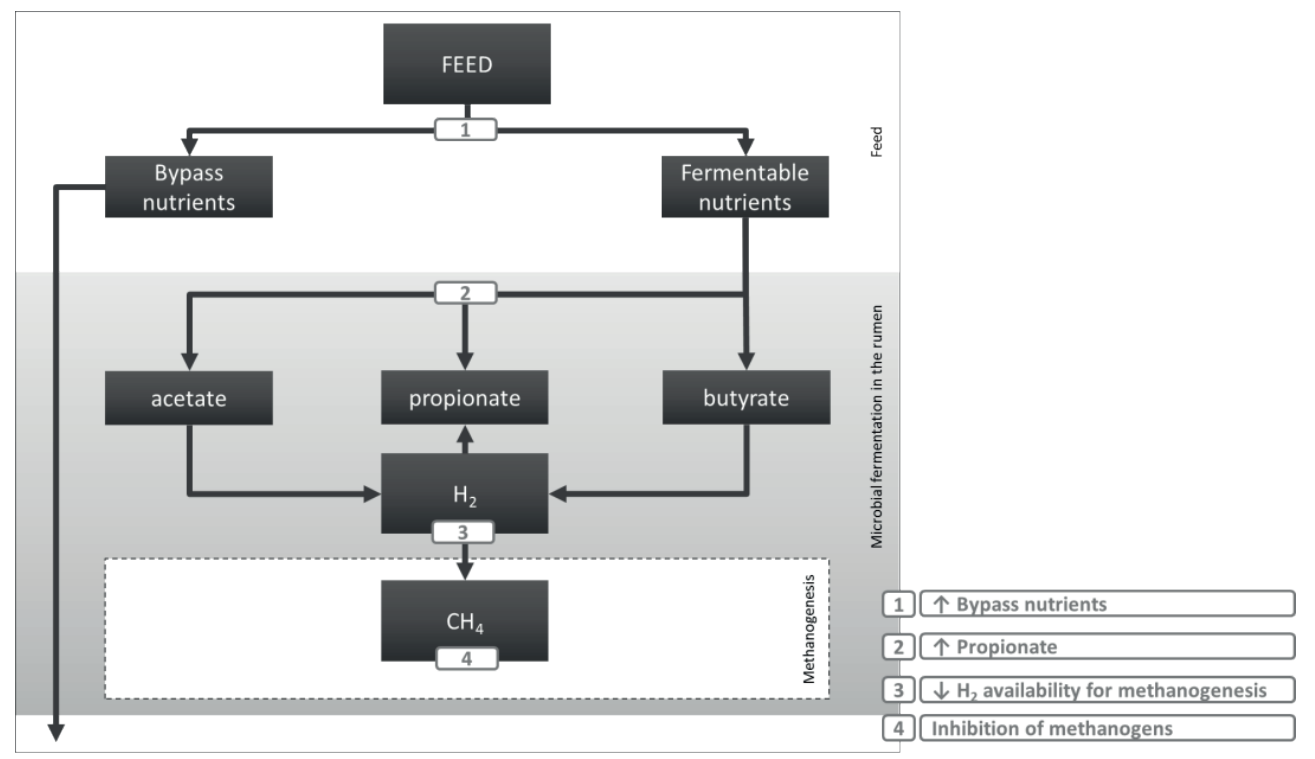

Figure 1.1. Simplified representation of causal factors to decrease methane production in the rumen. 
During microbial fermentation of feedstuffs, also hydrogen $\left(\mathrm{H}_{2}\right)$ is produced. Methanogens (Archaea) are a specific group of rumen microbes that use carbon sources like carbon dioxide $\left(\mathrm{CO}_{2}\right)$, formate and methyl groups together with $\mathrm{H}_{2}$ to form $\mathrm{CH}_{4}$. By doing so, a low redox potential is maintained in the rumen. The latter is important to maintain proper rumen fermentation, because an increased $\mathrm{H}_{2}$ pressure in the rumen would inhibit reoxidation of reduced enzymatic co-factors (NADH, NADPH and FADH). As a consequence, the rate of rumen fermentation would cease as well (McAllister and Newbold, 2008). Given the crucial role of methanogenesis in supporting adequate conditions for rumen fermentation, any strategy that inhibits the production of $\mathrm{CH}_{4}$ should provide an alternative $\mathrm{H}_{2}$ removal pathway (McAllister and Newbold, 2008; Van Zijderveld et al., 2010) or lead to less $\mathrm{H}_{2}$ being produced.

\section{Mechanisms to decrease ruminal methane production}

As most of the $\mathrm{CH}_{4}$ is produced following fermentation of feed in the rumen, nutrition is the factor with the largest impact on $\mathrm{CH}_{4}$ production. Several options for lowering the production of $\mathrm{CH}_{4}$ in the rumen are presented in Figure 1.1. The first option is to increase the proportion of nutrients in the diet that bypass rumen fermentation. An example of this strategy is supplementation of fat (Grainger and Beauchemin, 2011) or increasing the amount of bypass starch or protein. Both fat and bypass starch or protein remain unfermented in the rumen but are enzymatically digested in the small intestine. By feeding more bypass starch and protein, less use is made however of the unique capacity of ruminants to convert human inedible biomass into human edible energy and protein.

An option not indicated in Figure 1.1 is the increase of the formation of microbial mass per unit of organic matter fermented, as this will lower VFA and $\mathrm{CH}_{4}$ production. Volatile fatty acids are the most important end products of rumen fermentation, as these provide approximately two-third of the required energy for maintenance, production and/or growth. Acetate, propionate and butyrate are quantitatively the most important VFA formed in the rumen. A shift in the profile of VFA formed towards more propionate is the second option indicated in Figure 1.1, as production of acetate and butyrate releases $\mathrm{H}_{2}$ in the rumen environment, whereas propiogenesis is a $\mathrm{H}_{2}$ consuming process. Rumen 
degradable starch is mainly a propionate precursor, thus increasing the amount of rumen degradable starch could in theory lower $\mathrm{CH}_{4}$ production. However, both Hassanat et al. (2013) and Van Gastelen et al. (2015) suggested that based on their experimental observations, a minimum starch level is required to achieve a reduction in $\mathrm{CH}_{4}$ production. Effects of dietary starch on $\mathrm{CH}_{4}$ emissions in dairy cows were extensively investigated in the PhD work of Hatew (2015) who also concluded that starch contents were too low to obtain a reduced methane yield.

Another way to stimulate propionate formation connects to option number 3 indicated in Figure 1.1, which is lowering the amount of $\mathrm{H}_{2}$ available for methanogenesis. This can be achieved by directing fermentation processes towards alternative $\mathrm{H}_{2}$ consuming pathways other than by altering dietary fermentable substrates, such as by propiogenesis, reduction of carboxylic acids, nitrate- or sulfate reduction, and biohydrogenation of fatty acids. However, the quantitative importance of these pathways is variable (Ellis et al., 2008; Martin et al., 2010).

The fourth option indicated in Figure 1.1 is the inhibition of methanogens, not indirectly by lowering substrate availability, but directly upon feeding compounds that are inhibitory to methanogens. Recently, the compound 3-nitrooxypropanol (3NOP) received a lot of attention as a newly developed mitigation strategy. The compound was specifically designed to inhibit methyl coenzyme-M reductase, which is the enzyme that catalyzes the last step of methanogenesis in the rumen. As reviewed by Latham et al. (2016), several in vivo experiments have been conducted to evaluate the effect of $3 \mathrm{NOP}$ on $\mathrm{CH}_{4}$ production in dairy and beef cattle. There seems to be a strong and repeatable mitigating effect, although the size of this effect varies across studies. As this additive was not yet available for research at the start of this PhD project, it could not be considered as mitigation strategy to study in the experiments described here.

\section{Why feed additives?}

Feed additives may be a viable mitigation strategy as they are usually only supplied in small amounts to the animal. In this way, the basal diet composition will not be largely 
affected. The latter is relevant, because ruminants have the capacity to convert human inedible feedstuffs into human edible energy and protein. According to Regulation (EC) No $1831 / 2003$ on additives for use in animal nutrition, feed additives can be defined as substances, micro-organisms or preparations, other than feed material and premixtures, which are intentionally added to feed or water in order to perform, in particular, one or more of the following functions:

1. favourably affect the characteristics of feed,

2. favourably affect the characteristics of animal products,

3. favourably affect the colour of ornamental fish and birds,

4. satisfy the nutritional needs of animals,

5. favourably affect the environmental consequences of animal production,

6. favourably affect animal production, performance or welfare, particularly by affecting the gastro-intestinal flora or digestibility of feedingstuffs, or

7. have a coccidiostatic or histomonostatic effect.

In the context of this thesis, the fifth characteristic is the target function of the feed additives, but obviously a mitigating feed additive should not negatively affect the characteristics listed under 1, 2, 4, and 6.

\section{Feed additives with potential to decrease methane production}

The focus in this thesis will be on three categories of feed additives with potential to decrease $\mathrm{CH}_{4}$ production:

1. Alternative electron sinks

2. Fat/fatty acids

3. Essential oils

\section{Alternative electron sinks}

Chemical reactions, whether carried out by microbes or not, are in general subject to kinetic, or thermodynamic regulation. Kinetic regulation is based on the presence and concentration of the required substrate, whereas thermodynamic regulation can be described as the formation of reaction (end) products based on the ratio between substrate and end product. Kinetic advantage of an alternative $\mathrm{H}_{2}$ consuming pathway to 
methanogenesis in the rumen depends on the $\mathrm{H}_{2}$ affinity constant $\left(\mathrm{K}_{\mathrm{m}}\right)$, which should be low (Ellis et al., 2008). Thermodynamic regulation of chemical reactions in the rumen is based on the question whether it is energetically favourable for the reaction to occur. This can be quantified as the change in Gibbs free energy $(\Delta G)$. The change in energy under standardized conditions is expressed as $\Delta \mathrm{G}^{\circ}$. A negative $\Delta \mathrm{G}^{\circ}$ value indicates that a reaction may occur spontaneously.

Theoretically, the pathway in which carboxylic acids like malate and fumarate are reduced by rumen microbes as precursors of propionate is energetically more favourable $\left(\Delta G^{0}=-\right.$ $63.6 \mathrm{KJ} / \mathrm{mole}_{2}$ ) than methanogenesis (Ungerfeld et al., 2007; Ellis et al., 2008) ${ }^{1}$. Although the reduction of carboxylic acids is energetically more favourable, the $K_{m}$ related to these reduction pathways is much higher compared to the $\mathrm{K}_{m}$ of methanogens (Asanuma et al., 1999; Ungerfeld and Kohn, 2006). Moreover, it was demonstrated by Van Zijderveld et al. (2011b) that dietary supplementation of calcium fumarate in concentrations that could be fed in practice did not reduce enteric $\mathrm{CH}_{4}$ production. It was discussed by the authors that calcium fumarate is not completely converted to propionate but also to acetate, with the latter conversion being a $\mathrm{H}_{2}$ producing pathway that makes the reduction of fumarate less $\mathrm{H}_{2}$ consuming. Given the costs and poor palatability of calcium fumarate, it was concluded that the dietary concentrations of fumarate that would be required to achieve a significant $\mathrm{CH}_{4}$ reduction are too high for practical use. It was also discussed by Van Zijderveld et al. (2011b) that only a few studies had observed a lower $\mathrm{CH}_{4}$ production upon feeding fumarate (Bayaru et al., 2001; Wallace et al, 2006), but that their results actually were in line with several other studies in which also no effect of fumarate on $\mathrm{CH}_{4}$ production was found (Beauchemin and McGinn, 2006; Kolver and Aspin, 2006; Molano et al., 2008).

Other pathways with potential of outcompeting methanogenesis are the reduction pathways of sulfate and nitrate. Sulfate-reducing microbes in the rumen have a lower $\mathrm{K}_{\mathrm{m}}$ and $\mathrm{H}_{2}$-threshold compared to methanogens and the sulfate reduction pathway is also

\footnotetext{
${ }^{1}$ Note: The standardized conditions used to calculate $\Delta G^{\circ}$ differ from the rumen environment, and caution should be taken in drawing firm conclusions related to reaction processes in the rumen based on $\Delta \mathrm{G}^{\circ}$.
} 
energetically slightly more favorable $\left(\Delta \mathrm{G}^{0}=-21.1 \mathrm{KJ} /\right.$ mole $\mathrm{H}_{2}$ ) (Ungerfeld and Kohn, 2006; Ellis et al., 2008). However, the limiting factor in this pathway is the Sulfur (S) concentration of the ration that would be required to substantially reduce $\mathrm{CH}_{4}$. A potential risk of high S intake is S-associated polioencephalomalacia. This neurological condition is caused by excessive production and absorption of ruminal hydrogen sulphide $\left(\mathrm{H}_{2} \mathrm{~S}\right)$, which is the final product of sulfate reduction. Production and absorption of ruminal $\mathrm{H}_{2} \mathrm{~S}$ are influenced by S source, total $\mathrm{S}$ intake and state of S-reducing ruminal microbes (Dewhurst et al., 2007). Excess $\mathrm{H}_{2} \mathrm{~S}$ in the rumen head space is released by eructation and subsequent inhalation and systemic absorption can occur (Gould, 1998). The necessary dietary amount of sulfate, required to substantially reduce $\mathrm{CH}_{4}$ production (Van Zijderveld et al., 2010), exceeds the safety limits set for ruminant diets (NRC, 2001), and, therefore, sulfate is not suitable as a sole $\mathrm{H}_{2}$ sink.

The use of nitrate as alternative $\mathrm{H}_{2}$ acceptor was proven to effectively reduce $\mathrm{CH}_{4}$ production in vivo in sheep (Van Zijderveld et al., 2010), and a persistent effect was also shown in vivo in lactating dairy cows (Van Zijderveld et al., 2011c). However, its use as a mitigating additive may also result in undesirable side effects, which will be discussed later.

\section{Fat and fatty acids}

A mitigating effect of fat on $\mathrm{CH}_{4}$ production has been observed in a large number of studies, but the duration of this effect is not consistent across studies (Grainger and Beauchemin, 2011). Dietary fat is thought to have an influence on $\mathrm{CH}_{4}$ production by several mechanisms (Martin et al., 2010). Indirect effects of dietary fat on $\mathrm{CH}_{4}$ production may be found as a result of a reduction in DMI or a dilution of the fermentable organic matter, as fat is not fermented in the rumen but after outflow from the rumen highly digestible in the intestine. Moreover, specific fatty acids may have a direct negative effect on methanogens (medium chain fatty acids) or on cellulolytic bacteria and protozoa (polyunsaturated fatty acids). Utilization of $\mathrm{H}_{2}$ with biohydrogenation of unsaturated fatty acids reduces the amount of $\mathrm{H}_{2}$ available for methanogens, but this is quantitatively of minor importance. The meta-analysis of Patra (2013) showed that fat supplementation 
also resulted in a linear increase in propionate as proportion of total VFA. As propionate acts as a $\mathrm{H}_{2}$ sink, this contributes to the mitigating effect of fat supplementation.

A meta-analysis, in which data from in vivo studies in the practical range of dietary fat concentration in ruminant diets $(<80 \mathrm{~g}$ fat $/ \mathrm{kg} \mathrm{DM})$ were used to investigate the effects of dietary fat on $\mathrm{CH}_{4}$ production, showed a strong negative relationship between dietary fat concentration and production of $\mathrm{CH}_{4}\left(-1 \mathrm{~g} \mathrm{CH}_{4} / \mathrm{kg}\right.$ DMI per $1 \%$ increase of fat in feed DM), but no effect of the fatty acid profile of dietary fat on $\mathrm{CH}_{4}$ production could be established (Grainger and Beauchemin, 2011). However, the meta-analysis by Patra (2013) showed that $\mathrm{CH}_{4}$ emissions were not affected by saturated fatty acid concentration in the diet, whereas concentrations of mono- and polyunsaturated fatty acids significantly decreased $\mathrm{CH}_{4}$ emissions (g/kg DM). It was noted that lauric acid (C12:0) and linolenic acid (C18:3) exerted a strong inhibitory effect on $\mathrm{CH}_{4}$ production $(\mathrm{g} / \mathrm{kg} \mathrm{DM})$ compared with other fatty acids. The extent of $\mathrm{CH}_{4}$ reduction by $\mathrm{C} 12: 0$ was affected by the non-fiber carbohydrate content of the diet. The dataset of Patra (2013) comprised a larger number of observations than the one of Grainger and Beauchemin (2011), which may explain the contrasting results of both studies. The magnitude of the $\mathrm{CH}_{4}$ supressing effect of fat supplementation may vary across species and the mitigation effect is likely to be stronger in sheep than in cattle (Grainger and Beauchemin, 2011; Patra, 2014).

\section{Essential oils}

Essential oils are plant secondary metabolites that are responsible for specific plant characteristics as flavour and fragrance (Benchaar and Greathead, 2011). The precise mode of action may vary between different essential oils but, generally speaking, they all exhibit some antimicrobial activity. In a recent review by Benchaar and Greathead (2011), it was concluded that some essential oils (derived from garlic and cinnamon) show in vitro a reduction of $\mathrm{CH}_{4}$ production, but these results have not been confirmed in vivo. Although no $\mathrm{CH}_{4}$ was measured, Benchaar et al. (2008) observed for example no effect of cinnamaldehyde $(1 \mathrm{~g} / \mathrm{cow} / \mathrm{d} ; 43 \mathrm{mg} / \mathrm{kg} \mathrm{DMI})$ on $\mathrm{pH}$, total VFA concentration and molar proportions of individual VFA in the rumen of lactating dairy cows. In a recent study by Benchaar (2015), feeding cinnamon oil, cinnamaldehyde, or monensin to dairy cows did 
not lower $\mathrm{CH}_{4}$ production determined with the $\mathrm{SF}_{6}$ technique. In vitro, promising results have been obtained using other plant extracts and essential oils with potential to be added to a concentrate-based diet (Durmic et al. 2014). Hristov et al. (2013a) observed an in vivo decrease in $\mathrm{CH}_{4}$ production upon feeding oregano leaves to dairy cattle, but measurements were only taken until $8 \mathrm{~h}$ after feeding. Therefore, it is not known if the effect was of the same size on a $24 \mathrm{~h}$ basis. If oregano caused a shift in the moment and rate of fermentation after feeding and a more equally divided $\mathrm{CH}_{4}$ emissions over a $24 \mathrm{~h}$ period, the overall $\mathrm{CH}_{4}$ production may still have remained rather unaffected.

In summary, mixed results have been reported in the scientific literature and mechanisms underlying the (absence of) effects of essential oils on $\mathrm{CH}_{4}$ production have not been fully elucidated. Therefore, these compounds require further study before deciding if they have potential to be applied in mitigation strategies.

\section{Issues related to the application of additives with potential to mitigate methane production}

\section{General issues}

Although all three categories of feed additives, as discussed above, show potential for $\mathrm{CH}_{4}$ mitigation, it is important to consider potential adverse effects and/or trade-offs before applying them in practice. One of the most evident issues is that a decrease in $\mathrm{CH}_{4}$ production should not be accompanied by a lower DMI, milk production or milk quality. In this respect it is also important to express $\mathrm{CH}_{4}$ production not only in $\mathrm{g} / \mathrm{d}$, but also relative to DMI and milk production (as discussed earlier in the section on metrics to express $\mathrm{CH}_{4}$ production).

Another issue is that persistency of a mitigating effect of a feed additive often has not been established in vivo (Hristov et al. 2013b). As noted in the general discussion of the PhD thesis of Van Zijderveld (2011), there is a possibility that the effect of feed additives on $\mathrm{CH}_{4}$ production is amplified in an in vitro test compared to effects obtained with the same level of feed additive applied in vivo (g additive/kg feed or substrate), because of a 
higher concentration of additive relative to the microbial density applied in the in vitro test. Moreover, the microbial population used in in vitro systems may have had insufficient time to adapt to the feed additives as occurs in the in vivo situation, or lack adaptive capacity at all, resulting in a larger $\mathrm{CH}_{4}$ reduction in vitro than observed in the in vivo situation. Recently, Yáñez-Ruiz et al. (2016) published a review on design, implementation and interpretation of in vitro batch culture experiments to assess enteric $\mathrm{CH}_{4}$ mitigation in ruminants. Aspects like e.g. donor animal species, use of adapted or nonadapted rumen fluid, composition of the buffer, and buffer:medium ratio all have such a strong influence on the results, that these require a well-described protocol. They also argued that in most cases the research question determines the protocol that is adopted for an in vitro study. Therefore, there may not be a standard protocol for evaluating $\mathrm{CH}_{4}$ production in ruminants using the in vitro gas production technique. Consequently, effects found in in vitro experiments, need to be interpreted with care, as they may differ from the effects observed in vivo.

Besides factors to be considered at the animal level, also factors along the animal production chain should be taken into account when evaluating feed additive-based mitigation strategies. For example, if a mitigating feed additive reduces $\mathrm{CH}_{4}$ production at the expense of increased nitrogen emissions into the environment, 'pollution swapping' occurs. As shown by Van Middelaar et al. (2013), conclusions on the potential of a mitigation strategy depend on the level of analysis (animal, farm or chain level). This can be explained by trade-offs in environmental pollution between $\mathrm{CH}_{4}$ production and other emissions along the production chain. Moreover, Van Middelaar et al. (2014) also determined the cost-effectiveness of three mitigating feeding strategies (viz. feeding linseed oil, feeding nitrate, or feeding grass at an earlier stage of maturity) using a chain level approach, and concluded that all these strategies involve additional costs to the farmer. The economic aspects are important factor adopting mitigation strategies in practice. 


\section{Issues related to feeding nitrate}

Although nitrate persistently reduces $\mathrm{CH}_{4}$ production, its use as a feed additive also has some disadvantages. Mixed results have been reported regarding the effect of nitrate on DMI (Lee et al., 2014; Newbold et al., 2014), but it may lower voluntary intake. Moreover, nitrite is an intermediate in the process of reduction of nitrate to ammonia. The process of converting nitrate to nitrite in the rumen occurs rapidly whereas the conversion of nitrite to ammonia occurs at a slower rate in non-adapted animals (Allison and Reddy, 1984). Nitrite in the rumen is absorbed through the rumen wall into the bloodstream, where it may cause oxidation of hemoglobin to methemoglobin, thereby inhibiting oxygen transport. However, gradual adaptation to increasing levels of dietary nitrate may prevent the accumulation of nitrite and the occurrence of methemoglobinemia (Van Zijderveld et al., 2010; Van Zijderveld et al., 2011c). As mentioned in the previous paragraph, nitrate is currently not cost-effective as a mitigation strategy, and also pollution swapping is a concern (Van Middelaar et al., 2014). Furthermore, Petersen et al. (2015) found that increasing dietary nitrate, also increases $\mathrm{N}_{2} \mathrm{O}$ emission in cows, which is considered to be a more potent greenhouse gas than $\mathrm{CH}_{4}$.

\section{Issues related to feeding fat and fatty acids}

As discussed by Hristov et al. (2013b), expressing the response to dietary fat as $\mathrm{CH}_{4} / \mathrm{kg}$ DMI (Grainger and Beauchemin, 2011) does not account for reduced DMI or milk production upon fat supplementation. In case of negative DMI and milk production responses, more (replacement) animals would be required to produce the same amount of milk which increases emissions, making fat supplementation a less effective mitigation strategy. Increasing dietary fat concentrations above 5-6\% of dietary DM increases the risk of negative effects on DMI, fiber digestion, milk production and milk composition (NRC, 2001). If fiber degradation is impaired, both DMI and milk fat concentration might decrease, and such adverse effects upon feeding fat have been reported from quantitative reviews (Grainger and Beauchemin, 2011; Patra, 2013).

Van Middelaar et al. (2014) investigated the cost-effectiveness of feeding linseed oil as a mitigation strategy. It was concluded by the latter authors that the method was the least 
cost-effective for current practice compared to the other strategies that were evaluated (feeding grass harvested at a lower stage of maturity, or nitrate), and that the uncertainty range was large.

\section{Issues related to feeding essential oils}

The levels of essential oil addition required to effectively reduce $\mathrm{CH}_{4}$ production in vivo are likely to inhibit overall rumen fermentation as well. Moreover, microbial adaptation to the presence of essential oils may result in a transient effect on $\mathrm{CH}_{4}$ only (Cardozo et al., 2004).

Another noteworthy aspect is that essential oils may easily be transferred into the animal product. For example, in the study of Van Zijderveld et al. (2011b) feeding diallyl disulfide (a component of garlic oil) at a level of $200 \mathrm{mg} / \mathrm{kg}$ DM resulted in a distinctive garlic taint in the milk whereas $\mathrm{CH}_{4}$ production was not affected. Such effects relate to another important general aspect that needs to be considered before adopting any feed additivebased mitigation strategy, which is consumer acceptance of animal products.

\section{Search for solutions}

Negative effects of feed additives on DMI, milk production and/or milk composition are frequently reported in scientific literature. Therefore, a positive interaction of two mitigating additives would be of interest, as it would allow for a similar decrease in $\mathrm{CH}_{4}$ emissions using lower doses of the separate additives. Subsequently, the risk of negative effects of the additives on cow health and performance will be alleviated too.

Another complication in the search for feed additive-based mitigation strategies is that the rumen microbial ecosystem may adapt to the use of a certain feed additive. In that case, only a transient reduction of $\mathrm{CH}_{4}$ emissions can be achieved. This process of adaptation is an important aspect that requires further study. Cardozo et al. (2004) reported a transient effect of plant extracts on fermentation characteristics that disappeared after six days. This result indicates that microbial adaptation can occur after short term exposure. The alternating use of two or more $\mathrm{CH}_{4}$ reducing feed additives with a different mode of action may alleviate the problem of microbial adaptation in the rumen. 
This concept is similar to what is used with agronomical applications, where herbicide rotations are applied as a strategy to prevent or to delay the resistance of weeds against herbicides (Beckie, 2006). Similarly, shuttle programmes with two or more anticoccidial compounds, usually with different modes of action, are widely used to reduce resistance of protozoan parasites in broilers (Chapman, 2001).

If the concept of rotational feeding of additives would also be effective in $\mathrm{CH}_{4}$ mitigation, a persistent lower $\mathrm{CH}_{4}$ production could be achieved without the need for a persistent $\mathrm{CH}_{4}$ reduction by a single feed additive. However, several knowledge gaps need to be addressed before this concept can be tested in vivo. First of all, suitable additives need to be selected based on available knowledge from the scientific literature and in vitro screening of their effect. Second, more information is needed on the size and duration of the mitigating effect of these additives to determine the optimal rotation interval for the inclusion of these additives in the diet.

\section{Research objectives}

Development of feed additive-based mitigation strategies has been subject of many research efforts, which will likely continue during the next years. To increase our understanding of the $\mathrm{CH}_{4}$ reducing potential of feed additives, more detailed information regarding the dynamics and effectiveness of these additives to mitigate $\mathrm{CH}_{4}$ is required than currently available. Moreover, application of feed additives as mitigation strategy may have negative side effects, in particular reduced animal health and performance, and a lack of persistency of the mitigating effect. The overall aim of the work presented in this thesis is, therefore, to investigate possible solutions to those frequently reported problems in relation to feed additive-based mitigation strategies. The effectiveness and side effects of feed additives may vary depending on the mode of action of the additive, the way it is provided to the animal and whether a single additive is fed or additives are fed in combination. Therefore, the specific research objectives of this PhD project are:

1. To investigate if the effects of two different additives, with different modes of action on $\mathrm{CH}_{4}$ production and dairy cow performance, are additive or not.

2. To study the in vivo adaptation to potential $\mathrm{CH}_{4}$ reducing feed additives, using the 
in vitro gas production technique.

3. To compare $\mathrm{CH}_{4}$ production and performance of dairy cows, fed either a single feed additive or two different additives following a rotation schedule.

\section{Outline of this thesis}

The work described in this thesis was part of the Low Emission Feed project (Dutch project 'EmissieArm Veevoer'). This project comprised research related to the effects of source and quantity of dietary starch, grass silage and grass herbage quality and feed additives on enteric $\mathrm{CH}_{4}$ production in dairy cows. As outlined above, the research in this thesis focuses on the effect of feed additives on $\mathrm{CH}_{4}$ production. Chapter $\mathbf{2}$ describes an experiment with the aim to determine whether the effects of nitrate and docosahexaenoic acid (DHA) on $\mathrm{CH}_{4}$ production and animal performance in lactating dairy cows are additive. Methane reducing feed additives, including nitrate, may adversely affect fiber degradation. Chapter $\mathbf{3}$ deals with the hypothesis that negative effects of a feed additive on fiber degradation in the rumen can be detected by evaluating diurnal patterns of ${ }^{13} \mathrm{C}$ enrichment of $\mathrm{CO}_{2}$. The main ration components should then differ in starch and non-fiber carbohydrate content as well as in natural ${ }^{13} \mathrm{C}$ enrichment, as achieved in this trial. In Chapter $4, \mathrm{CH}_{4}$ production was evaluated at different time points during the course of microbial adaptation to $\mathrm{CH}_{4}$ reducing feed additives in vivo, using the in vitro gas production technique and inoculum from cows in the in vivo trial. Chapter $\mathbf{5}$ outlines an in vivo study that was conducted to compare $\mathrm{CH}_{4}$ production of dairy cows that were assigned to either continuous feeding of a commercial blend of essential oils or to a weekly rotation in feeding the essential oil blend and C12:0. In Chapter 6, the outcomes of the experiments described in the previous chapters are discussed together to derive some overall conclusions and implications of this research project. Chapter 7 provides an overview of other scientific output, related to the research discussed in this thesis.

\section{REFERENCES}

Allison, M. J., and C. A. Reddy. 1984. Adaptations of gastrointestinal bacteria in response to changes in dietary oxalate and nitrate. In: Klug, M. J., and C. A. Reddy (eds.) Current perspectives in 
microbial ecology. Proceedings of the Third International Symposium on Microbial Ecology, Michigan State University. American Society for Microbiology, Washington, D.C. ,USA.

Asanuma, N., M. Iwamoto, and T. Hino. 1999. Effect of the addition of fumarate on methane production by ruminal microorganisms in vitro. J. Dairy Sci. 82:780-787.

Bayaru, E., S. Kanda, T. Kamada, H. Itabashi, N. Andoh, T. Nishida, M. Ishida, T. Itoii, K. Nagara, and Y. Isobe. 2001. Effect of fumaric acid on methane production, rumen fermentation and digestibility of cattle fed roughage alone. Anim. Sci. J. 72:139-146.

Beauchemin, K. A., and S. M. McGinn. 2006. Methane emissions from beef cattle: Effects of fumaric acid, essential oil, and canola oil. J. Anim. Sci. 84:1489-1496.

Beauchemin, K. A., M. Kreuzer, F. O'Mara, and T. A. McAllister. 2008. Nutritional management for enteric methane abatement: a review. Austr. J. Exp. Agric. 48:21-27.

Beckie, H. J. 2006. Herbicide-resistant weeds: management tactics and practices. Weed Technol. 20:793-814.

Benchaar, C., S. Calsamiglia, A. V. Chaves, G. R. Fraser, D. Colombatto, T. A. McAllister, and K. A. Beauchemin. 2008. A review of plant-derived essential oils in ruminant nutrition and production. Anim. Feed Sci. Technol. 145:209-228.

Benchaar, C. 2015. Diet supplementation with cinnamon oil, cinnamaldehyde, or monensin does not reduce enteric methane production of dairy cows. Animal 1:418-425.

Benchaar, C., and H. Greathead. 2011. Essential oils and opportunities to mitigate enteric methane emissions from ruminants. Anim. Feed Sci. Technol. 166-167:338-355.

Cardozo, P. W., S. Calsamiglia, A. Ferret, and C. Kamel. 2004. Effects of natural plant extracts on ruminal protein degradation and fermentation profiles in continuous culture. J. Anim. Sci. 82:3230-3236.

Chapman, H. D. 2001. Use of anticoccidial drugs in broiler chickens in the USA: Analysis for the years 1995 to 1999. Poultry Sci. 80:572-580.

Dewhurst, R. J., E. J. Kim, R. T. Evans, A. R. J. Cabrita, and A. J. M. Fonseca. 2007. Effects of dietary sulphur sources on concentrations of hydrogen sulphide in the rumen head-space gas of dairy cows. Animal 1:531-535.

Durmic, Z., P. J. Moate, R. Eckard, D. K. Revel, R. Williams, and P. E. Vercoe. 2014. In vitro screening of selected feed additives, plant essential oils and plant extracts for rumen methane mitigation. J. Sci. Food Agric. 94:1191-1196.

Ellis, J. L., J. Dijkstra, E. Kebreab, A. Bannink, N. E. Odongo, B. W. McBride, and J. France. 2008. Aspects of rumen microbiology central to mechanistic modelling of methane production in cattle. J. Agric. Sci. 146:213-233. 
Ellis, J. L., A. Bannink, J. France, E. Kebreab, and J. Dijkstra. 2010. Evaluation of enteric methane prediction equations for dairy cows used in whole farm models. Global Change Biol. $16: 3246-3256$.

Gould, D. H. 1998. Polioencephalomalacia. J. Anim. Sci. 76:309-314.

Grainger, C., and K. A. Beauchemin. 2011. Can enteric methane emissions from ruminants be lowered without lowering their production? Anim. Feed Sci. Technol. 166-167:308-320.

Hassanat, F., R. Gervais, C. Julien, D. I. Massé, A. Lettat, P. Y. Chouinard, H. V. Petit, and C. Benchaar,. 2013. Replacing alfalfa silage with corn silage in dairy cow diets: Effects on enteric methane production, ruminal fermentation, digestion, $\mathrm{N}$ balance, and milk production. J. Dairy Sci. 96:4553-4567.

Hatew, B. 2015. Low Emission Feed: Opportunities to Mitigate Enteric Methane Production of Dairy Cows. PhD thesis, Wageningen University, Wageningen, the Netherlands (228 pages).

Hatew, B., S. C. Podesta, H. Van Laar, W. F. Pellikaan, J. L. Ellis, J. Dijkstra, and A. Bannink. 2015. Effects of dietary starch content and rate of fermentation on methane production in lactating dairy cows. J. Dairy Sci. 98:486-499.

Hristov, A. N., C. Lee, T. Cassidy, K. Heyler, J. A. Tekippe, G. A. Varga, B. Corl, and R. C. Brandt. $2013 a$. Effect of Origanum vulgare L. leaves on rumen fermentation, production, and milk fatty acid composition in lactating dairy cows. J. Dairy Sci. 96:1189-1202.

Hristov, A. N., J. Oh, J. Firkins, J. Dijkstra, E. Kebreab, G. Waghorn, A. Adesogan, W. Yang, J. Tricarico, C. Lee, P. J. Gerber, B. Henderson, and H. P. S. Makkar. 2013b. Mitigation of methane and nitrous oxide emissions from animal operations: I. A review of enteric methane mitigation options. J. Anim. Sci. 91:5045-5069.

Hristov, A. N., J. Oh, C. Lee, R. Meinen, F. Montes, T. Ott, J. Firkins, A. Rotz, C. Dell, A. Adesogan, W. Yang, J. Tricarico, E. Kebreab, G. Waghorn, J. Dijkstra, and S. Oosting. 2013c. Mitigation of greenhouse gas emissions in livestock production - A review of technical options for nonCO2 emissions. In: Gerber, P.J., B. Henderson, and H.P.S. Makkar (eds). FAO Animal Production and Health Paper No. 177. FAO, Rome, Italy.

Johnson, K. A., and D. E. Johnson. 1995. Methane emissions from cattle. J. Anim. Sci. 73:2483-2492.

Kolver, A. S., and P. W. Aspin. 2006. Supplemental fumarate did not influence milk solids or methane production from dairy cows fed high quality pasture. Proc. N. Z. Soc. Anim. Prod. 66:409-415.

Latham, E. A., R. C. Anderson, W. E. Pinchak, and D. J. Nisbet. 2016. Insight on alterations to the rumen ecosystem by nitrate and nitrocompounds. Front. Microbiol. 7:228. 
Lee, C., and K. A. Beauchemin. 2014. A review of feeding supplementary nitrate to ruminant animals: Nitrate toxicity, methane emissions, and production performance. Can. J. Anim. Sci. 94:557570.

Martin, C., D. P. Morgavi, and M. Doreau. 2010. Methane mitigation in ruminants: from microbe to the farm scale. Animal 4:351-365.

McAllister, T. A., and Newbold, C. J. 2008. Redirecting rumen fermentation to reduce methanogenesis. Austr. J. Exp. Agric. 48:7-13.

Molano, G., T. W. Knight, H. Clark. 2008. Fumaric acid supplements have no effect on methane emissions per unit of feed intake in wether lambs. Aust. J. Exp. Agric. 48:165-168.

Newbold, J. R., S. M. Van Zijderveld, R. B. A. Hulshof, W. B. Fokkink, R. A. Leng, P. Terencio, W. J. Powers, P. S. J. Van Adrichem, N.D. Paton, and H. B. Perdok. 2014. The effect of incremental levels of dietary nitrate on methane emissions in Holstein steers and performance in Nelore bulls. J. Anim. Sci. 92:5032-5040.

NRC. 2001. Nutrient Requirements of Dairy Cattle. 7th revised edition. Natl. Acad. Sci., Washington DC.

Patra, A. K. 2013. The effect of dietary fats on methane emissions, and its other effects on digestibility, rumen fermentation and lactation performance in cattle: A meta-analysis. Livest. Sci. 155:244-254.

Patra, A. K. 2014. A meta-analysis of the effect of dietary fat on enteric methane production, digestibility and rumen fermentation in sheep, and a comparison of these responses between cattle and sheep. Livest. Sci. 162:97-103.

Petersen S. O., A. L. F. Hellwing, M. Brask. O. Højberg, M. Poulsen, Z. Zhu, K. R. Baral, and P. Lund. 2015. Dietary nitrate for methane mitigation leads to nitrous oxide emissions from dairy cows. J. Environ. Qual. 44:1063-1070.

Ungerfeld, E. M., and R. A. Kohn. 2006. The role of thermodynamics in the control of ruminal fermentation. Ruminant Physiology. Wageningen Academic Publishers, Wageningen, The Netherlands.

Ungerfeld, E. M., R. A. Kohn, R. J. Wallace, and C. J. Newbold. 2007. A meta-analysis of fumarate effects on methane production in ruminal batch cultures. J. Anim. Sci. 85:2556-2563.

Van Gastelen, S., E. C. Antunes-Fernandes, K. A. Hettinga, G. Klop, S. J. J. Alferink, W. H. Hendriks, and J. Dijkstra. 2015. Enteric methane production, rumen volatile fatty acid concentrations, and milk fatty acid composition in lactating Holstein-Friesian cows fed grass silage- or corn silage-based diets. J. Dairy Sci. 98:1915-1927. 
Van Middelaar, C. E., P. M. Berentsen, J. Dijkstra, and I. J. M. De Boer. 2013. Evaluation of a feeding strategy to reduce greenhouse gas emissions from dairy farming: The level of analysis matters. Agric. Sys. 121:9-22.

Van Middelaar, C. E., J. Dijkstra, P. M. Berentsen, and I. J. M. De Boer. 2014. Cost-effectiveness of feeding strategies to reduce greenhouse gas emissions from dairy farming. J. Dairy. Sci. 97: 2427-2439.

Van Zijderveld, S.M. 2011. Dietary Strategies to Reduce Methane Emissions from Ruminants. PhD thesis., Wageningen University, Wageningen, the Netherlands (132 pages).

Van Zijderveld, S. M., W. J. J. Gerrits, J. A. Apajalahti, J. R. Newbold, J. Dijkstra, R. A. Leng, and H. B. Perdok. 2010. Nitrate and sulfate: Effective alternative hydrogen sinks for mitigation of ruminal methane production in sheep. J. Dairy Sci. 93:5856-5866.

Van Zijderveld, S. M., B. Fonken, J. Dijkstra, W. J. J. Gerrits, H. B. Perdok, W. Fokkink, and J. R. Newbold. 2011a. Effects of a combination of feed additives on methane production, diet digestibility, and animal performance in lactating dairy cows. J. Dairy Sci. 94:1445-1454.

Van Zijderveld, S. M., J. Dijkstra, H. B. Perdok, J. R. Newbold, and W. J. J. Gerrits. 2011b. Dietary inclusion of diallyl disulfide, yucca powder, calcium fumarate, an extruded linseed product, or medium-chain fatty acids does not affect methane production in lactating dairy cows. J. Dairy Sci. 94:3094-3104.

Van Zijderveld, S. M., W. J. J. Gerrits, J. Dijkstra, J. R. Newbold, R. B. A. Hulshof, and H. B. Perdok. 2011c. Persistency of methane mitigation by dietary nitrate supplementation in dairy cows. J. Dairy Sci. 94:4028-4038.

Yáñez-Ruiz, D. R., A. Bannink, J. Dijkstra, E. Kebreab, D. P. Morgavi, P. O’Kiely, C. K. Reynolds, A. Schwarm, K. J. Shingfield, Z. Yu, and A. N. Hristov. 2016. Design, implementation and interpretation of in vitro batch culture experiments to assess enteric methane mitigation in ruminants - a review. Anim. Feed Sci. Technol. 216:1-18.

Wallace, R. J., T. A. Wood, A. Rowe, J. Price, D. R. Yanez, S. P. Williams, C. J. Newbold. 2006. Encapsulated fumaric acid as a means of decreasing ruminal methane emissions. Int. Congr. Ser. 1293:148-151. 


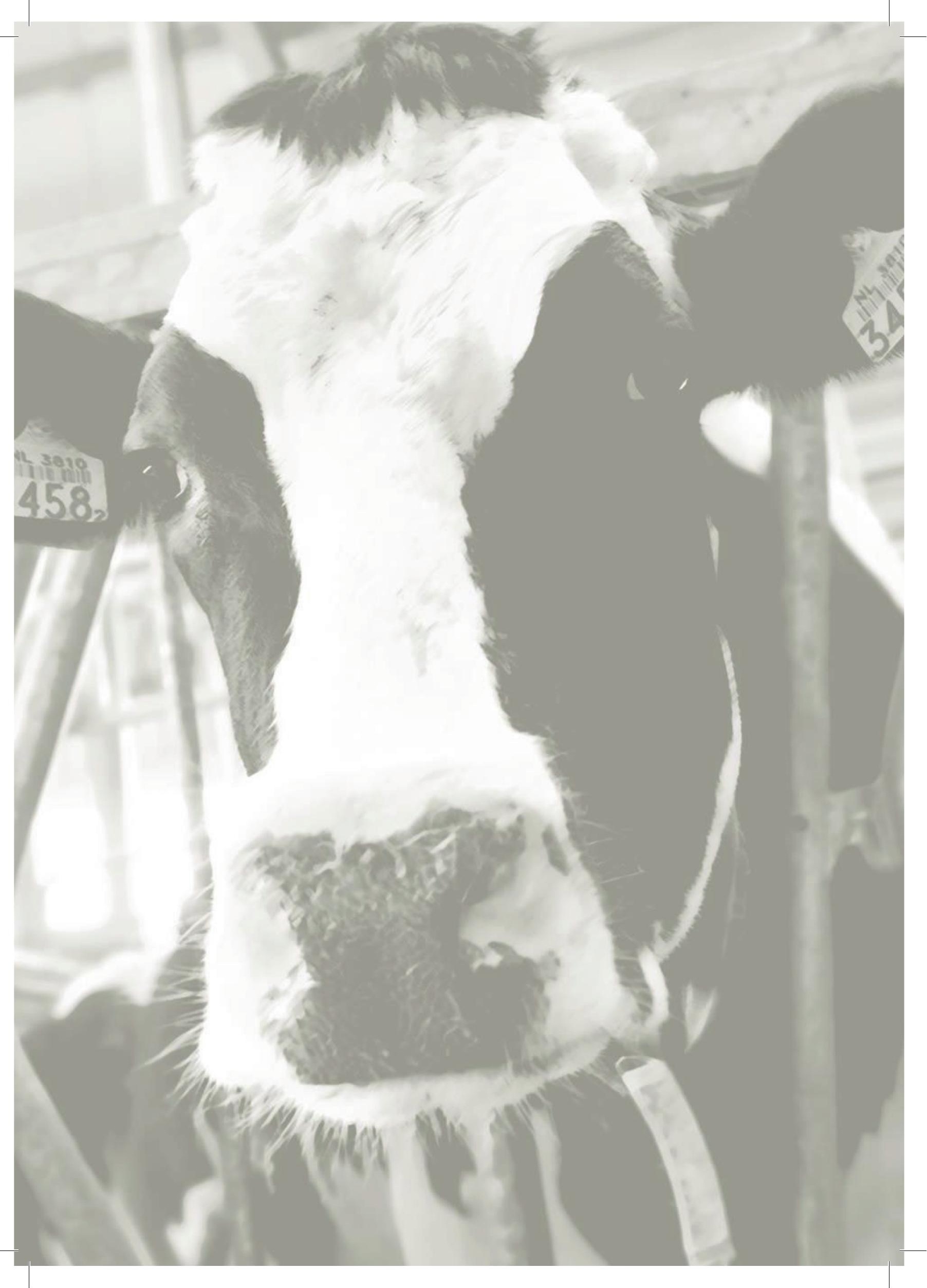




\title{
Chapter 2
}

Feeding nitrate and docosahexaenoic acid affects enteric methane production and milk fatty acid composition in lactating dairy cows

\author{
G. Klop ${ }^{*}$, B. Hatew ${ }^{*}$, A. Bannink ${ }^{\dagger}$, J. Dijkstra ${ }^{*}$ \\ * Animal Nutrition Group, Wageningen University, PO Box 338, 6700 AH Wageningen, The \\ Netherlands \\ ' Wageningen UR Livestock Research, PO Box 338, 6700 AH Wageningen, The Netherlands
}

(Journal of Dairy Science 99:1161 - 1172) 


\begin{abstract}
An experiment was conducted to study potential interaction between the effects of feeding nitrate and docosahexaenoic acid (DHA; $\mathrm{C} 22: 6 \mathrm{n}-3$ ) on enteric $\mathrm{CH}_{4}$ production and performance of lactating dairy cows. Twenty-eight lactating Holstein dairy cows were grouped into 7 blocks of 4 cows. Within blocks, cows were randomly assigned to 1 of 4 treatments: control (CON; urea as alternative nonprotein $\mathrm{N}$ source to nitrate), $\mathrm{NO}_{3}$ [ $21 \mathrm{~g}$ of nitrate/kg of dry matter (DM)], DHA (3 g of DHA/kg of DM and urea as alternative nonprotein N source to nitrate), or $\mathrm{NO}_{3}$ + DHA (21 g of nitrate/kg of DM and $3 \mathrm{~g}$ of DHA/kg of DM, respectively). Cows were fed a total mixed ration consisting of $21 \%$ grass silage, $49 \%$ corn silage, and $30 \%$ concentrates on a DM basis. Feed additives were included in the concentrates. Cows assigned to a treatment including nitrate were gradually adapted to the treatment dose of nitrate over a period of $21 \mathrm{~d}$ during which no DHA was fed. The experimental period lasted $17 \mathrm{~d}$, and $\mathrm{CH}_{4}$ production was measured during the last $5 \mathrm{~d}$ in climate respiration chambers. Cows produced on average 363, 263, 369, and $298 \mathrm{~g}$ of $\mathrm{CH}_{4} /$ d on $\mathrm{CON}, \mathrm{NO}_{3}, \mathrm{DHA}$, and $\mathrm{NO}_{3}+\mathrm{DHA}$ treatments, respectively, and a tendency for a nitrate $\times$ DHA interaction effect was found where the $\mathrm{CH}_{4}$-mitigating effect of nitrate decreased when combined with DHA. This tendency was not obtained for $\mathrm{CH}_{4}$ production relative to dry matter intake (DMI) or to fat- and protein corrected milk (FPCM). The $\mathrm{NO}_{3}$ treatment decreased $\mathrm{CH}_{4}$ production irrespective of the unit in which it was expressed, whereas DHA did not affect $\mathrm{CH}_{4}$ production per kilogram of DMI, but resulted in a higher $\mathrm{CH}_{4}$ production per kilogram of fat- and protein-corrected milk (FPCM) production. The FPCM production $\left(27.9,24.7,24.2\right.$, and $23.8 \mathrm{~kg} / \mathrm{d}$ for CON, $\mathrm{NO}_{3}, \mathrm{DHA}$, and $\mathrm{NO}_{3}+\mathrm{DHA}$, respectively) was lower for $\mathrm{DHA}$-fed cows because of decreased milk fat concentration. The proportion of saturated fatty acids in milk fat was decreased by DHA, and the proportion of polyunsaturated fatty acids was increased by both nitrate and DHA. Milk protein concentration was lower for nitrate-fed cows. In conclusion, nitrate but not DHA decreased enteric $\mathrm{CH}_{4}$ production and no interaction effects were found on $\mathrm{CH}_{4}$ production per kilogram of DMI or per kilogram of FPCM.
\end{abstract}

Key words: methane, nitrate, docosahexaenoic acid, milk fatty acid 


\section{INTRODUCTION}

Enteric $\mathrm{CH}_{4}$ production in ruminants has received global interest (Hristov et al., 2013), and various feed additives have been suggested as a nutritional mitigation strategy. Feeding nitrate as alternative electron receptor effectively decreases $\mathrm{CH}_{4}$ production in sheep (Van Zijderveld et al., 2010), and a persistent effect was shown in lactating dairy cows (Van Zijderveld et al., 2011). A sudden inclusion of high concentrations of nitrate in ruminant diets may result in a condition known as methemoglobinemia, which decreases the oxygen carrying capacity of the blood. Symptoms of nitrate toxicity depend on the level of methemoglobin in the blood and may include reduced intake and performance, brown discoloration of mucosae, and even death (Bruning-Fann and Kaneene, 1993). When animals are gradually adapted to higher concentrations of nitrate in their diets, no signs of (sub)clinical methemoglobinemia were observed (Van Zijderveld et al., 2010, 2011; Lee and Beauchemin, 2014).

Supplementation of fat to ruminant diets also lowers $\mathrm{CH}_{4}$ production (Grainger and Beauchemin, 2011). Specific fatty acids (FA) have been evaluated for their effect on rumen fermentation, and docosahexaenoic acid (DHA; an n-3 FA; C22:6 n-3) has been shown to have a particularly marked effect on microbial metabolism in the rumen (Boeckaert et al., 2008a). Micro-algae enriched in DHA have been shown to decrease $\mathrm{CH}_{4}$ production in vitro (Fievez et al., 2007), but this could not be confirmed in vivo (Moate et al., 2013).

The VFA profile in rumen fluid may shift toward more acetate when nitrate is fed, whereas DHA may cause a shift toward a larger relative proportion of propionate (Boeckaert et al., 2008b; Guyader et al., 2015). Propionate production is an $\mathrm{H}_{2}$-consuming process and can therefore decrease $\mathrm{CH}_{4}$ production. Because nitrate and DHA have different mechanisms of affecting ruminal methanogenesis, we hypothesize that their effects on $\mathrm{CH}_{4}$ production are additive. An additive, or positive, interaction effect of the 2 additives would be of interest because it would allow for a similar decrease in $\mathrm{CH}_{4}$ emissions using lower doses of the separate additives. The latter would alleviate the risk of negative effects of the additives on cow health and performance. Moreover, feeding DHA to lactating dairy cows 
has been reported to increase the proportions of CLA and DHA in milk fat and decrease the SFA proportion (Boeckaert et al., 2008b). From a human health perspective, such an alteration in milk FA composition is of interest (Shingfield et al., 2013). To the best of our knowledge, the effect of feeding nitrate on milk FA profile is unknown.

The main objective of this study was to investigate whether the effects of nitrate and DHA on $\mathrm{CH}_{4}$ production and animal performance in lactating dairy cows are additive or not. Milk FA profile is a potential indicator of $\mathrm{CH}_{4}$ production (van Lingen et al., 2014), and, therefore, the effects of nitrate and DHA fed alone or in combination on milk FA composition were also evaluated.

\section{MATERIALS AND METHODS}

\section{Experimental design, animals, and housing}

All experimental procedures were approved by the Animal Care and Use Committee of Wageningen University (Wageningen, the Netherlands). The experiment was set up as a completely randomized block design with 4 treatments. Eight primiparous and 20 multiparous lactating Holstein cows (125 \pm 16 DIM at the start of the experimental period; mean \pm SD) were blocked according to parity, lactation stage, milk production and presence or absence of a previously fitted rumen cannula. Within blocks, animals were randomly assigned to 1 of the 4 experimental diets. One of the 8 cows with a rumen cannula had to be culled because of foot injuries and was replaced by a nonfistulated reserve animal already adapted to the same experimental diet $\left(\mathrm{NO}_{3}\right)$.

Animals were housed in a freestall barn from which blocks of 4 cows consecutively entered a 17-d experimental period. This 17-d period consisted of $12 \mathrm{~d}$ in tie-stalls, and from $1500 \mathrm{~h}$ on $\mathrm{d} 13$ until $0900 \mathrm{~h}$ on $\mathrm{d} 17$, cows were housed individually in climate respiration chambers (CRC). 


\section{Diets and feeding}

The experimental diets consisted of $49 \%$ corn silage, $21 \%$ grass silage, and $30 \%$ concentrates on a DM basis. Treatments consisted of a control treatment (CON; no nitrate or DHA added), a nitrate treatment $\left(\mathrm{NO}_{3} ; 21 \mathrm{~g}\right.$ of nitrate/kg of total DM), a DHA treatment (DHA; $3 \mathrm{~g}$ of DHA/kg of total DM), and a treatment including both nitrate and DHA in the diet $\left(\mathrm{NO}_{3}+\mathrm{DHA} ; 21 \mathrm{~g}\right.$ of nitrate/kg of total DM and $3 \mathrm{~g}$ of $\mathrm{DHA} / \mathrm{kg}$ of total DM). Nitrate, $\mathrm{DHA}$, or both were included in the concentrates (Table 2.1). Diets were balanced for $\mathrm{N}$ content by isonitrogenous exchange of nitrate and urea. Cellulose and limestone were added to balance DM and Ca content of the concentrate mixtures. DHAgold (DSM Nutritional Products, Columbia, MD) was exchanged against wheat because of the similar CP content. The chemical composition of DHAgold was described by Boeckaert et al. (2007) where the DHA content was $198 \mathrm{~g} / \mathrm{kg}$ of DM. In the present study, DHA content of DHAgold was $254 \mathrm{~g} / \mathrm{kg}$ of DM. Chromium oxide (1.7 g/ kg of DM) was included in all concentrates to estimate total-tract diet digestibility of energy and nutrients. Diets were offered to the cows as TMR (Table 2.2). Drinking water was continuously available during the entire experiment.

All animals that were assigned to either the $\mathrm{NO}_{3}$ or the $\mathrm{NO}_{3}+\mathrm{DHA}$ treatment, including 2 reserve animals, were gradually adapted to the experimental level of dietary nitrate (21 $\mathrm{g} / \mathrm{kg}$ of DM) over a period of $21 \mathrm{~d}$. Cows were group-fed once daily around $0900 \mathrm{~h}$ and received $25 \%$ of the experimental dose of dietary nitrate during the first week, followed by incremental steps of $25 \%$ per week and thereafter all cows received the full experimental dose of dietary nitrate. No DHA was fed during this period of adaptation to increasing levels of dietary nitrate.

During the experimental periods, cows were fed individually with 2 equal portions offered twice daily (at 0600 and 1600 h). A mixture of grass silage and corn silage was prepared twice weekly and weighed into crates that were stored in a cooling room $\left( \pm 7^{\circ} \mathrm{C}\right)$. The concentrates were in meal form and weighed separately into buckets and manually mixed into the roughage mixture at the moment of feeding. Until d 9 of the tie-stall period, each block of cows had free access to feed. Thereafter, DMI within a block was restricted to $95 \%$ 
Table 2.1. Ingredient composition $(\mathrm{g} / \mathrm{kg}$ of $\mathrm{DM})$ of the experimental concentrates containing no treatment additive (CON), nitrate $\left(\mathrm{NO}_{3}\right)$, docosahexaenoic acid (DHA), or $\mathrm{NO}_{3}+\mathrm{DHA}$ as feed additives

\begin{tabular}{|c|c|c|c|c|}
\hline Ingredient & CON & $\mathrm{NO}_{3}$ & $\mathrm{DHA}$ & $\mathrm{NO}_{3}+\mathrm{DHA}$ \\
\hline Wheat & 194 & 194 & 155 & 155 \\
\hline Dry, ground corn & 145 & 145 & 145 & 145 \\
\hline Beet pulp & 165 & 165 & 165 & 165 \\
\hline Formaldehyde-treated soybean meal & 321 & 321 & 321 & 321 \\
\hline Molasses & 33 & 33 & 33 & 33 \\
\hline Trace mineral and vitamin premix & 9 & 9 & 9 & 9 \\
\hline Monocalcium phosphate & 17 & 17 & 17 & 17 \\
\hline $\mathrm{NaCl}$ & 17 & 17 & 17 & 17 \\
\hline $\mathrm{CaCO}_{3}$ & 57 & - & 57 & - \\
\hline Nitrate source $^{1}$ & - & 98 & - & 98 \\
\hline Urea & 39 & - & 39 & - \\
\hline DHAgold $^{2}$ & - & - & 39 & 39 \\
\hline Cellulose & 2 & - & 2 & - \\
\hline $\mathrm{Cr}_{2} \mathrm{O}_{3}$ & 1.7 & 1.7 & 1.7 & 1.7 \\
\hline
\end{tabular}

${ }^{1} 5 \mathrm{Ca}\left(\mathrm{NO}_{3}\right) 2 \mathrm{NH}_{4} \mathrm{NO}_{3} 10 \mathrm{H}_{2} \mathrm{O}$, containing $75 \%$ nitrate.

${ }^{2}$ DHAgold (DSM Nutritional Products, Columbia, MD) = dried, whole cell algae product (seaweed meal), containing 25.4\% DHA; trademark of Martek Biosciences Corporation, Royal DSM NV.

of that of the animal with the lowest voluntary DMI between $d 5$ and 8 , while ensuring that none of the animals in the block was restricted to less than $80 \%$ of its voluntary DMI.

\section{Measurements, sampling, and laboratory analyses}

Methane was measured in CRC with a volume of $35 \mathrm{~m}^{3}$ (for details of CRC, see van Gastelen et al., 2015). Briefly, temperature in the chambers was set at $16^{\circ} \mathrm{C}$ and the relative humidity was maintained at $65 \%$. The ventilation rate was $43 \mathrm{~m}^{3} / \mathrm{h}$ per chamber, inlet and exhaust air of each compartment was sampled at 10 min intervals, and the light schedule allowed for $16 \mathrm{~h}$ of light per $\mathrm{d}$, starting from $0530 \mathrm{~h}$ onward. Concentrations of $\mathrm{CH}_{4}, \mathrm{O}_{2}$, and $\mathrm{CO}_{2}$ in inlet and exhaust air of each compartment were sampled, and ventilation rates were corrected for air pressure, temperature, and humidity to arrive at standard temperature pressure dew point volumes of inlet and exhaust air. Heat production rates were calculated from gaseous exchange (Brouwer, 1965). Cows were weighed immediately after entering and just before leaving the CRC.

Representative samples of all individual TMR components were collected at the moments of feed preparation for measurement periods in the CRC. Orts were collected during the 
period that cows were in the CRC. If the amount composed more than $4 \%$ of the estimated DM supply, a representative subsample was analyzed for DM and ash content. If the amount was less than $4 \%$ of DM supply, composition of the orts was assumed to be similar to the composition of the offered diet. During CRC periods, the total amount of manure was collected and mixed, and a representative subsample was taken for analysis of DM, gross energy (GE), and $\mathrm{N}$ content. Fecal grab samples were collected at each milking in the CRC for analysis of DM, GE, N, crude fat, starch, NDF, ash, and chromium content to estimate apparent total-tract digestibility of nutrients. Samples were stored at $-20^{\circ} \mathrm{C}$ pending analysis. After thawing, samples were dried at $60^{\circ} \mathrm{C}$ until constant weight and ground to pass a 1-mm screen. The $\mathrm{N}$ concentrations in manure and of roughages were determined in fresh material. For the determination of $\mathrm{NH}_{3}$ content, fresh silage samples were deproteinized by the addition of $10 \%(\mathrm{wt} / \mathrm{vol})$ trichloroacetic acid solution followed by centrifugation. Subsequently, indophenol blue was formed using the Berthelot reaction with phenol and hypochlorite in an alkaline solution, which was determined spectroscopically at $623 \mathrm{~nm}$. The DM content of air dry samples was gravimetrically determined by drying at $103^{\circ} \mathrm{C}$ until constant weight (ISO 6496; ISO, 1999b). Ash was determined after combustion at $550^{\circ} \mathrm{C}$ (ISO 5984; ISO, 2002). Crude protein content was calculated as $\mathrm{N} \times 6.25$, where $\mathrm{N}$ was determined using the Kjeldahl method with $\mathrm{CuSO}_{4}$ as catalyst (ISO 5983; ISO, 2005). Based on findings of Guo et al. (2007), N content of nitrate containing concentrates was corrected assuming a nitrate- $\mathrm{N}$ recovery of $53 \%$ after Kjeldahl analysis. The nitrate concentrations in all concentrates were analyzed at the Eurofins laboratory (Barendrecht, the Netherlands). Briefly, nitrate was extracted from the feed using Milli-Q water and converted into nitrite using a cadmium/copper column. Subsequently, the reaction product formed after combination of nitrite and sulfanilamide in an acidic environment was combined with $\mathrm{N}$-1-naphtylethylene diamine dihydrochloride into a red/purple color, which was measured spectrophotometrically at $550 \mathrm{~nm}$. Nitrite concentration of the original sample was analyzed separately to correct the result for nitrate. Hydrolysis with $\mathrm{HCl}$ and extraction with light petroleum was used to determine crude fat content of samples (ISO 6492; ISO, 1999a). Starch was determined enzymatically (ISO 15914; ISO, 2004). The NDF content of samples was analyzed according to Van Soest et al. (1991) after pretreatment with $\alpha$-amylase, but without sodium sulfite. 
Table 1.2. Average analyzed chemical composition of TMR ingredients (corn silage, grass silage, and concentrates) and calculated composition of complete TMR for the control (CON) diet and diets with nitrate $\left(\mathrm{NO}_{3}\right)$, docosahexaenoic acid (DHA), or $\mathrm{NO}_{3}+\mathrm{DHA}$ as feed additives (g/ $\mathrm{kg}$ of DM unless otherwise stated)

\begin{tabular}{|c|c|c|c|c|c|c|c|c|c|c|}
\hline \multirow[b]{2}{*}{ Item } & \multicolumn{2}{|c|}{ Roughages } & \multicolumn{4}{|c|}{ Concentrates } & \multicolumn{4}{|l|}{ TMR } \\
\hline & Corn & Grass & CON & $\mathrm{NO}_{3}$ & DHA & $\mathrm{NO}_{3}+\mathrm{DHA}$ & CON & $\mathrm{NO}_{3}$ & DHA & $\mathrm{NO}_{3}+\mathrm{DHA}$ \\
\hline Inclusion & 490 & 210 & 300 & 300 & 300 & 300 & - & - & - & - \\
\hline DM (g/kg) & 326 & 586 & 884 & 874 & 894 & 881 & 454 & 452 & 455 & 453 \\
\hline Gross energy & 18.6 & 18.5 & 16.4 & 15.7 & 16.8 & 16.1 & 17.9 & 17.7 & 18.0 & 17.8 \\
\hline Crude Ash & 36 & 76 & 134 & 135 & 135 & 134 & 74 & 74 & 74 & 74 \\
\hline $\mathrm{CP}$ & 78 & 109 & 347 & 345 & 341 & 349 & 165 & 165 & 163 & 166 \\
\hline Crude fat & 33 & 30 & 22 & 21 & 40 & 31 & 29 & 29 & 34 & 32 \\
\hline NDF & 380 & 561 & 165 & 163 & 155 & 177 & 354 & 356 & 351 & 357 \\
\hline ADF & 221 & 327 & 72 & 70 & 70 & 69 & 199 & 198 & 198 & 198 \\
\hline ADL & 21 & 25 & 7 & 8 & 7 & 9 & 18 & 18 & 18 & 18 \\
\hline Starch & 353 & NA & 239 & 231 & 209 & 209 & 245 & 242 & 236 & 236 \\
\hline Sugar & 6 & 130 & 16 & 13 & 16 & 16 & 35 & 34 & 35 & 35 \\
\hline Nitrate & $N A^{3}$ & NA & 0 & 71 & 0 & 72 & 0 & 21 & 0 & 21 \\
\hline
\end{tabular}

${ }^{1} \mathrm{NE}_{\mathrm{L}}=6.2 \mathrm{MJ} / \mathrm{kg}$ of DM.

${ }^{2} \mathrm{NE}_{\mathrm{L}}=6.9 \mathrm{MJ} / \mathrm{kg}$ of $\mathrm{DM}$.

${ }^{3} \mathrm{NA}=$ not analyzed.

Methods described by Van Soest et al. (1991) were also used for analysis of ADF content and ADL was analyzed using sulfuric acid (Robertson and Van Soest, 1981). An adiabatic bomb calorimeter (IKA-C700, Janke and Kunkel, Heitersheim, Germany) was used for determination of GE content (ISO 9831; ISO, 1998). Chromium contents of concentrates and feces were analyzed using atomic absorption spectrophotometry (Williams et al., 1962).

\section{Milk Production and Milk Composition}

Cows were milked twice daily (0600 and $1600 \mathrm{~h}$ ) throughout the entire experiment. Milk production was recorded at each milking. A subsample of milk from each milking in the CRC was analyzed for fat, protein, lactose, and GE, and N and MUN content were analyzed in a pooled sample from all milkings in the CRC ( $5 \mathrm{~g} / \mathrm{kg}$ of milk produced) according to methods described by Hatew et al. (2015a). Average milk composition for each cow was calculated from the weighted average of all samples taken during the 72-h measurement period in the CRC. Fat- and protein-corrected milk yield (FPCM) was calculated according to the formula FPCM $(\mathrm{kg} / \mathrm{d})=(0.337+0.116 \times$ fat $\%+0.06 \times$ protein $\%) \times$ milk yield $(\mathrm{kg} / \mathrm{d})$ (CVB, 2008). For each cow, an additional milk sample was collected $(5 \mathrm{~g} / \mathrm{kg}$ of milk at each 
milking in the chambers) and analyzed for milk FA composition through gas chromatography as described by van Gastelen et al. (2015). Milk FA were expressed in grams per $100 \mathrm{~g}$ of total FA.

\section{Blood Samples}

During the $21 \mathrm{~d}$ of pre-experimental period of adaptation to the final inclusion level of dietary nitrate, a blood sample was collected from all 16 cows fed nitrate after each incremental dose of nitrate in the diet (i.e., d 1, 7, 14, and 21 of this pre-experimental period). Blood was collected from the tail vein in heparinized collection tubes at $3 \mathrm{~h}$ post feeding. Blood samples were analyzed for hemoglobin ( $\mathbf{H b})$ and methemoglobin (MetHb) content within $1.5 \mathrm{~h}$ after sampling in the laboratory of Hospital Gelderse Vallei (Ede, the Netherlands) using a blood gas analyzer ABL-825 (Radiometer, Copenhagen, Denmark).

\section{Statistical analysis}

Data on DMI, milk production, milk composition, and $\mathrm{CH}_{4}$ production are based on measurements during the last $72 \mathrm{~h}$ of the measurement period when cows were in the CRC. For one cow (DHA treatment) only the last $48 \mathrm{~h}$ of the measurement period were used, because this cow had an extremely low DMI and water intake during the first $24 \mathrm{~h}$ of the measurement period. Two cows ( $\mathrm{CON}$ and $\mathrm{NO}_{3}$ treatment) were excluded from the analyses because of a feeding error in the CRC. Energy and $\mathrm{N}$ retention and digestibility values were calculated based on the entire period in the CRC and averaged per day. For milk FA composition, values below the detection limit $(<0.02 \mathrm{~g} / 100 \mathrm{~g}$ of FA) were considered missing values.

All data were analyzed using PROC MIXED (SAS 9.2, SAS Inst. Inc., Cary, NC). The model contained main and interaction effects of dietary treatment factors (nitrate and DHA) as fixed effects and the effect of period (which is equal to block) as a random factor using a variance components (VC) covariance structure. The effect of chamber was initially included as fixed effect in the model, but was removed because it was not significant. Denominator degrees of freedom were estimated using the Kenward-Roger option. Multiple comparisons between treatments were made using the Tukey-Kramer method. 
Results are reported as least squares means, and significance of effects was declared at $P$ $\leq 0.05$ and trends at $0.05<\mathrm{P} \leq 0.10$.

\section{RESULTS AND DISCUSSION}

\section{Methane production and cow performance}

The main objective of this study was to examine if the effects of dietary nitrate and DHA on enteric $\mathrm{CH}_{4}$ production of lactating dairy cows are additive. For $\mathrm{CH}_{4}$ production in grams per day, a tendency for a nitrate $\times$ DHA interaction was found (Table 2.3), showing that the effect of nitrate and DHA is different when combined. This was most likely a result of the lower DMI of cows receiving the $\mathrm{NO}_{3}$ treatment, despite the restricted feeding regimen. Nevertheless, if DMI would have been equal across all treatments, the $\mathrm{CH}_{4}$ production per kilogram of DMI might have been slightly higher for cows on the $\mathrm{NO}_{3}$ treatment, but not to such an extent that it would have altered the overall conclusions of this experiment because the feed intake of the $\mathrm{NO}_{3}$ treatment is still $95 \%$ of the intake of the other treatments. Decreased feed intake after feeding dietary nitrate to ruminant animals has been reported previously (Newbold et al., 2014; Lee et al., 2015b).

With $\mathrm{CH}_{4}$ production expressed in grams per kilogram of DMI or grams per kilogram of FPCM, the nitrate $\times$ DHA interaction term was not significant, showing an additive effect between nitrate and DHA. Nitrate decreased $\mathrm{CH}_{4}$ irrespective of the unit in which it was expressed, whereas DHA had no effect on $\mathrm{CH}_{4}$ per kilogram of DMI or $\mathrm{CH}_{4}$ per kilogram of digestible OM intake, but resulted in a higher $\mathrm{CH}_{4}$ production per kilogram of FPCM (Table 2.3). Moate et al. (2013) reported increased $\mathrm{CH}_{4}$ emissions per kilogram of $\mathrm{DMI}$ and per kilogram of ECM in response to increasing levels of DHA in the diet. Cows in the study of Moate et al. (2013) had unrestricted access to roughage, whereas in the present experiment a restricted feeding regimen was applied. The latter may explain the absence of an effect of DHA on DMI in the present study, whereas in the study of Moate et al. (2013), DMI was significantly reduced at higher doses of DHA (22.1, 22.4, 21.3, and $20.5 \mathrm{~kg}$ of $\mathrm{DMI} / \mathrm{d}$ for the treatments receiving $0,25,50$, or $75 \mathrm{~g}$ of $\mathrm{DHA} / \mathrm{d}$, respectively). Previously, DHA has been found to reduce $\mathrm{CH}_{4}$ production in vitro (Fievez et al., 2007), but this 
reduction could not be confirmed in vivo by Moate et al. (2013) and in the present trial. Hatew et al. (2015b) showed that effects of starch source and level on in vitro $\mathrm{CH}_{4}$ production were not observed in vivo in animals adapted to the various starch sources and levels when $\mathrm{CH}_{4}$ production was expressed per unit of $\mathrm{OM}$ intake. We hypothesize that in the present trial the rumen microbial ecosystem adapted to DHA supply resulting in unchanged $\mathrm{CH}_{4}$ production compared with the control. If $21 \mathrm{~g}$ of nitrate/ $\mathrm{kg}$ of $\mathrm{DMI}$ is completely reduced to ammonia, $\mathrm{CH}_{4}$ emission should be lowered by $5.4 \mathrm{~g} / \mathrm{kg}$ of DMI based on stoichiometry. With an average $\mathrm{CH}_{4}$ production of 17.6 and $22.2 \mathrm{~g} / \mathrm{kg}$ of DMI for cows receiving a diet with and without nitrate, respectively, the average decline in $\mathrm{CH}_{4}$ reduction corresponds to $85 \%$ of the stoichiometric potential to decrease $\mathrm{CH}_{4}$. This agrees with findings from previous studies in which similar dietary inclusion levels of nitrate were fed to lactating dairy cows (Lund et al., 2014) or beef cattle (Hulshof et al., 2012) and where $\mathrm{CH}_{4}$ production was lowered by $86 \%$ and $87 \%$ of the stoichiometric potential, respectively. The present decrease in $\mathrm{CH}_{4}$ production is higher compared with the study of Van Zijderveld et al. (2011), who found a decrease of 59\% of the theoretical potential. The feed intake of cows in the study of Van Zijderveld et al. (2011) was higher ( $\pm 19 \mathrm{~kg}$ of $\mathrm{DMI} / \mathrm{d}$ ) than the DMI of cows in the current experiment ( $\pm 16 \mathrm{~kg}$ of $\mathrm{DMI} / \mathrm{d}$ ). The lower DMI in the present study may have resulted in a longer retention time of feed or fluid, and of nitrate, in the rumen and thus more time for nitrate to be completely reduced to ammonia. Although this argument seems to be in contrast with findings of Lund et al. (2014), who reported a similar decline in $\mathrm{CH}_{4}$ yield at DMI values above $19 \mathrm{~kg} / \mathrm{d}$ when nitrate was fed, this contrast may be partly explained by the differences in experimental setup. In the study of Van Zijderveld et al. (2011) methods of adaptation and feed restriction were similar to the present study, whereas in the study of Lund et al. (2014) no feed restriction was imposed and cows were also not gradually adapted to the experimental level of nitrate in their diet. Such differences in experimental setup may have affected rumen metabolism differently. Moreover, based on visual observations in the tie-stalls, cows receiving any of the additive treatments in the present study also seemed to have a more gradual feed intake pattern than cows on the CON treatment. Based on visual observations of the diurnal patterns of the respiration quotient (RQ; data not included), we noticed that the RQ value showed a sharp increase for the CON 
Table 2.3. Dry matter intake, milk production, milk composition, and $\mathrm{CH} 4$ production of dairy cattle fed the control (CON) diet or diets with nitrate $\left(\mathrm{NO}_{3}\right)$, docosahexaenoic acid (DHA), or $\mathrm{NO}_{3}+\mathrm{DHA}$ as feed additives

\begin{tabular}{|c|c|c|c|c|c|c|c|c|}
\hline \multirow[b]{2}{*}{ Item } & \multicolumn{4}{|c|}{ Treatment $^{1}$} & \multirow[b]{2}{*}{ SEM } & \multicolumn{3}{|c|}{$P$-value } \\
\hline & $\mathrm{CON}$ & $\mathrm{NO}_{3}$ & DHA & $\mathrm{NO}_{3}+\mathrm{DHA}$ & & $\mathrm{NO}_{3}$ & DHA & $\mathrm{NO}_{3} \times \mathrm{DHA}$ \\
\hline $\mathrm{DMI}(\mathrm{kg} / \mathrm{d})$ & 16.5 & 15.7 & 16.5 & 16.4 & 0.81 & 0.020 & 0.044 & 0.060 \\
\hline Milk production $(\mathrm{kg} / \mathrm{d})$ & 27.8 & 25.1 & 28.0 & 28.0 & 1.64 & 0.201 & 0.180 & 0.228 \\
\hline $\operatorname{FPCM}(\mathrm{kg} / \mathrm{d})^{2}$ & 27.9 & 24.7 & 24.2 & 23.8 & 1.58 & 0.128 & 0.062 & 0.233 \\
\hline Fat (g/kg) & 40.9 & 39.5 & 29.8 & 29.4 & 2.12 & 0.602 & $<0.001$ & 0.744 \\
\hline Fat $(g / d)$ & 1147 & 1008 & 824 & 814 & 76.4 & 0.231 & $<0.001$ & 0.296 \\
\hline Protein (g/kg) & 31.2 & 30.4 & 31.0 & 29.5 & 0.68 & 0.047 & 0.369 & 0.561 \\
\hline Protein $(\mathrm{g} / \mathrm{d})$ & 869 & 765 & 869 & 826 & 53.0 & 0.030 & 0.354 & 0.338 \\
\hline Lactose (g/kg) & 44.8 & 45.6 & 46.6 & 46.2 & 0.69 & 0.728 & 0.043 & 0.281 \\
\hline MUN (mg/dL) & 11.4 & 11.4 & 13.1 & 11.2 & 0.88 & 0.288 & 0.393 & 0.311 \\
\hline $\mathrm{CH}_{4}(\mathrm{~g} / \mathrm{d})$ & 363 & 263 & 369 & 298 & 14.5 & $<0.001$ & 0.016 & 0.069 \\
\hline $\mathrm{CH}_{4}(\mathrm{~g} / \mathrm{kg} \mathrm{DMI})$ & 22.0 & 16.9 & 22.4 & 18.2 & 0.52 & $<0.001$ & 0.086 & 0.305 \\
\hline $\mathrm{CH}_{4}\left(\mathrm{~g} / \mathrm{kg} \mathrm{DOMI}{ }^{3}\right)$ & 31.4 & 24.7 & 31.9 & 25.5 & 0.69 & $<0.001$ & 0.352 & 0.759 \\
\hline $\mathrm{CH}_{4}(\mathrm{~g} / \mathrm{kg} \mathrm{FPCM})$ & 13.1 & 10.8 & 15.4 & 12.6 & 0.57 & $<0.001$ & 0.001 & 0.629 \\
\hline $\mathrm{CH}_{4}\left(\%\right.$ of $\left.\mathrm{GEI}^{4}\right)$ & 6.8 & 5.3 & 7.0 & 5.7 & 0.35 & $<0.001$ & 0.090 & 0.487 \\
\hline
\end{tabular}

${ }^{1} \mathrm{CON}$ (urea as nonprotein $\mathrm{N}$ source), $\mathrm{NO}_{3}(21 \mathrm{~g}$ of nitrate/ $\mathrm{kg}$ of DM), DHA (3 $\mathrm{g}$ of DHA/kg of DM and urea as nonprotein $\mathrm{N}$ source), $\mathrm{NO}_{3}+\mathrm{DHA}$ (21 $\mathrm{g}$ of nitrate/kg of DM and $3 \mathrm{~g}$ of DHA/kg of DM). For $\mathrm{CON}$ and $\mathrm{NO}_{3}$ treatments $\mathrm{n}=6$, for DHA and $\mathrm{NO}_{3}+$ DHA treatments $\mathrm{n}=7$.

${ }^{2}$ Fat- and protein-corrected milk $(F P C M)=(0.337+0.116 \times$ fat $\%+0.06 \times$ protein $\%) \times$ milk yield $(\mathrm{kg} / \mathrm{d})(\mathrm{CVB}, 2008)$. ${ }^{3} \mathrm{DOMI}=$ digestible organic matter intake.

${ }^{4} \mathrm{GEI}=$ gross energy intake.

treatment shortly after feeding, whereas the other treatments had lower RQ peak values after feeding. This numerical difference supports the visual observations in tie-stalls and CRC that the feed intake pattern was different across treatments. Alteration of feeding behavior as a result of dietary nitrate supplementation has been reported previously for beef calves (Lichtenwalner et al., 1973). Such a difference in feed intake pattern could not be quantified in the present study, but a more gradual feed intake, with smaller portions per meal, may have contributed as well to a longer retention time of nitrate in the rumen. Guyader et al. (2015) fed nitrate (22.5 g/ kg of DMI) to nonlactating cows with an average DMI of $12.3 \mathrm{~kg} / \mathrm{d}$ and found a decrease in $\mathrm{CH}_{4}$ production of $5.6 \mathrm{~g} / \mathrm{kg}$ of DM compared with the control diet. This corresponds to $96 \%$ of the stoichiometric potential of $5.8 \mathrm{~g} / \mathrm{kg}$ of DM. The difference in physiological state (nonlactating), as well as an increased rumen retention time of nitrate as a result of the lower feed intake in the former study, may explain the larger decrease in $\mathrm{CH}_{4}$ as compared with the present experiment. 
Milk production was not affected by dietary treatment, but FPCM production tended to be decreased by DHA as a result of a significantly lower milk fat production (Table 2.3). Several rumen biohydrogenation intermediates, including trans-10 FA, increase upon feeding DHA, and after absorption such intermediates may decrease de novo FA synthesis in the mammary gland (Boeckaert et al., 2008b). Feeding DHA decreased SFA concentrations (expressed as $\mathrm{g} / 100 \mathrm{~g}$ of total FA) in milk and increased concentrations of PUFA (Table 2.4). The latter is comparable to findings of Boeckaert et al. (2008b) and Moate et al. (2013). To our knowledge, the effect of dietary nitrate on milk FA composition has not yet been reported. Nitrate had no effect on SFA proportion and proportion of MUFA, but increased the proportion of PUFA in milk FA. The proportion of C4:0 in milk FA was increased by feeding nitrate. Unlike other saturated short-chain FA, C4:0 in milk fat does not require acetate for its production as it can be produced directly from $\beta$-hydroxybutyrate derived from the blood. Nitrate also increased the proportion of C18:0 in milk fat (Table 2.4), which is indicative for more biohydrogenation in the rumen. This may be a consequence of the aforementioned longer retention time of feed in the rumen as compared with cows on the CON treatment. The proportions of C14:0 iso and C15:0 iso were also increased by nitrate, whereas $\mathrm{CH}_{4}$ was decreased. This is in contrast with findings of Castro-Montoya et al. (2011), who reported a positive relationship between iso-FA and $\mathrm{CH}_{4}$ yield. This relationship was associated with the higher abundance of iso-FA in fibrolytic microbes (Vlaeminck et al. 2006), which in turn are associated with a higher $\mathrm{CH}_{4}$ yield. However, feeding nitrate only was observed to decrease total-tract apparent fiber digestion, and the increased levels of C14:0 iso and C15:0 iso in milk fat, indicative of increased abundance of fibrolytic bacteria, are not in line with the reduced fiber digestion observed when feeding nitrate without DHA. The increase in trans-11 FA together with a decline in $\mathrm{CH}_{4}$ production in cows receiving nitrate is in line with van Lingen et al. (2014). In contrast to feeding nitrate, feeding DHA decreased the proportion of C18:0 in milk fat. This agrees qualitatively with in vitro studies with DHA added to rumen fluid of cows adapted to DHA, where biohydrogenation of C18:2 trans-11,cis-15 was hindered and no biohydrogenation of C18:1 trans-11 to C18:0 occurred (Vlaeminck et al., 2008). Feeding DHA increased proportions of several MUFA, including C18:1 trans-10 


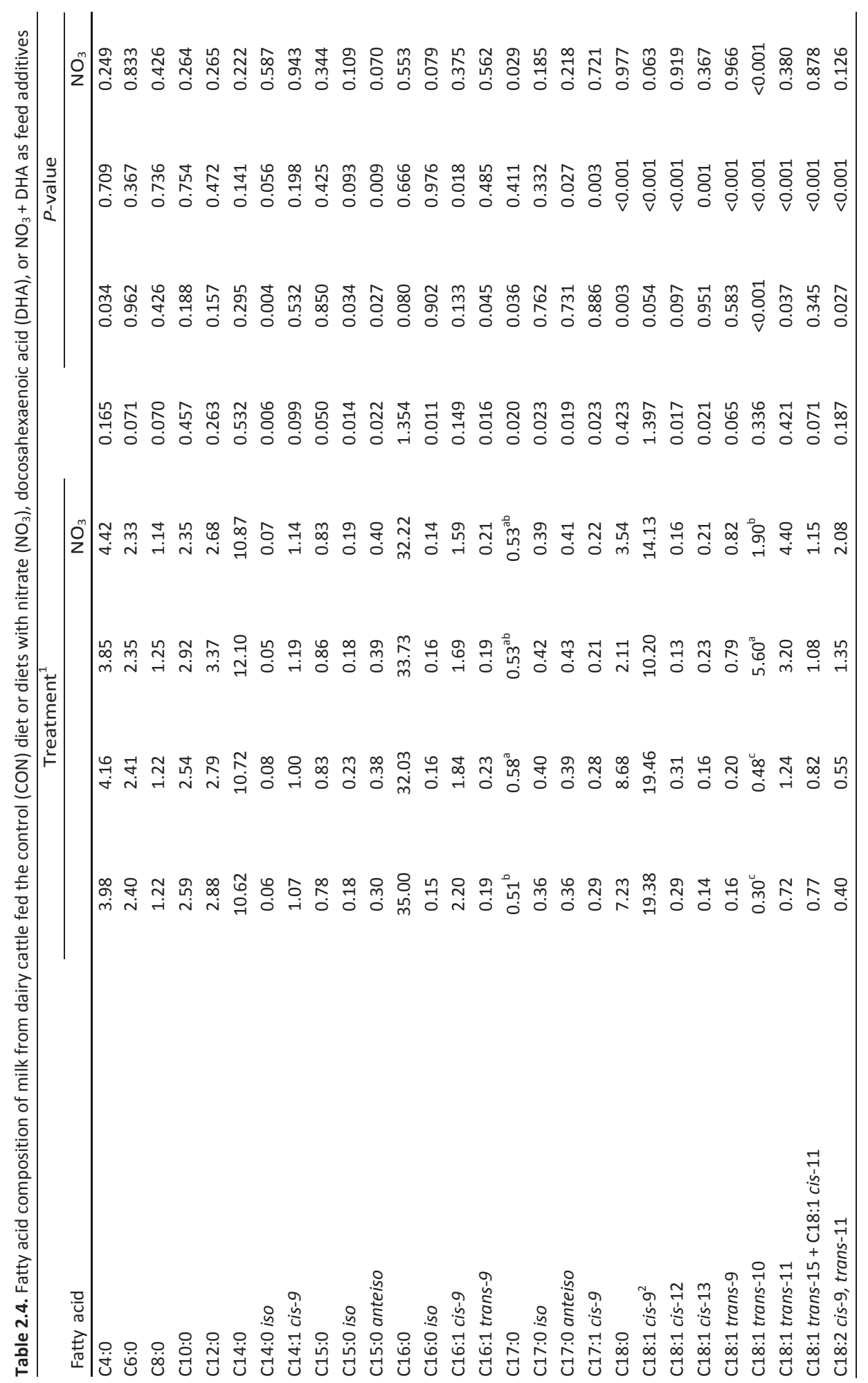




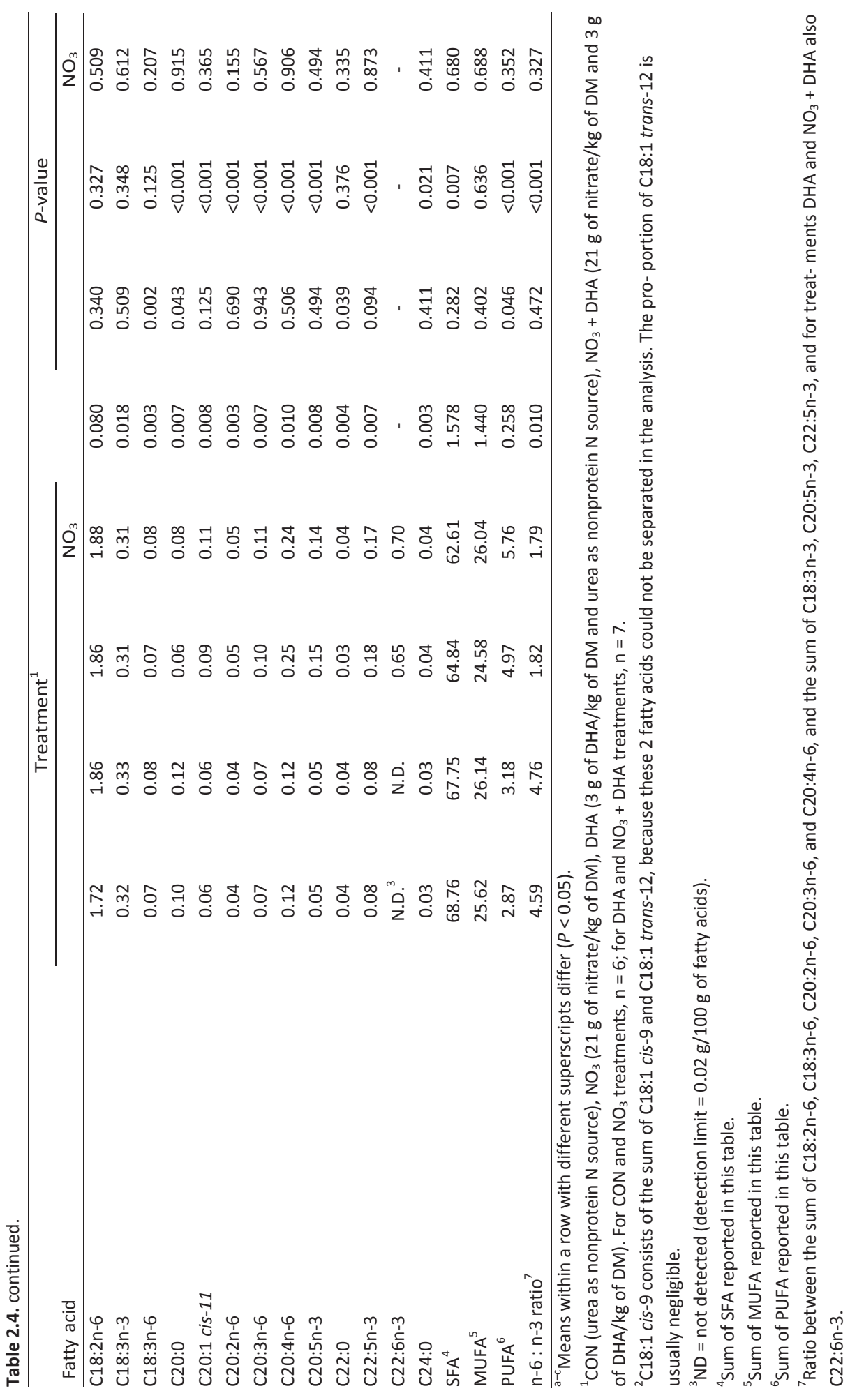


and C18:1 trans-11. The alteration in milk FA profile is in line with findings of Boeckaert et al. (2008b). However, contrary to the present study, these FA are often associated with a decrease in $\mathrm{CH}_{4}$ per unit of feed and per unit of FPCM (van Lingen et al. 2014). If the best performing equations (viz. equations 3 and 4) of van Lingen et al. (2014) are used to predict $\mathrm{CH}_{4} / \mathrm{kg}$ of DMI and $\mathrm{CH}_{4} / \mathrm{kg}$ of FPCM, respectively, from the present milk FA data, a considerable deviation is present between observed and predicted values. Predicted $\mathrm{CH}_{4}$ production is $20.8,19.9,12.4$, and $14.8 \mathrm{~g} / \mathrm{kg}$ of $\mathrm{DMI}$ and $12.1,11.5,9.7$, and $9.4 \mathrm{~g} / \mathrm{kg}$ of FPCM for the CON, $\mathrm{NO}_{3}, \mathrm{DHA}$, and $\mathrm{NO}_{3}+\mathrm{DHA}$ treatments, respectively. Based on the prediction equations, $\mathrm{CH}_{4}$ production should be decreased by $\mathrm{DHA}$ and nitrate would have almost no effect, which is in contrast with the present observations. These comparisons indicate that relationships between $\mathrm{CH}_{4}$ production and milk FA profile, obtained on a wide variety of diets (van Lingen et al. 2014), differ from relationships between $\mathrm{CH}_{4}$ production and milk FA profile when $\mathrm{CH}_{4}$-mitigating supplements such as nitrate and DHA are included in the diet, and thus also limit the general potential of milk FA to predict $\mathrm{CH}_{4}$ production. No DHA was detected in milk from cows receiving the $\mathrm{CON}$ or $\mathrm{NO}_{3}$ treatment. The absence of DHA levels above the detection limit of $0.02 \mathrm{~g} / 100 \mathrm{~g}$ of FA in milk of cows that were not supplemented with DHA corresponds to the findings of van Valenberg et al. (2013), who investigated milk FA composition of representative Dutch bovine milk samples that were collected weekly for a period of $1 \mathrm{yr}$. On average $0.67 \mathrm{~g}$ of DHA/100 g of FA was detected in milk from cows receiving DHA. The DHA content of the TMR $(3 \mathrm{~g} / \mathrm{kg}$ of $\mathrm{DM}$ ) resulted in a daily intake of almost $50 \mathrm{~g}$ of $\mathrm{DHA} / \mathrm{cow}$. This intake is comparable to the $50 \mathrm{~g}$ of DHA/cow (D50) dose fed by Moate et al. (2013) who found a similar amount of $0.60 \mathrm{~g}$ of $\mathrm{DHA} / 100 \mathrm{~g}$ of FA in milk.

Milk protein content was not affected by DHA, but feeding nitrate resulted in a small, but significant reduction in milk protein content and yield (Table 2.3). Dietary nitrate also resulted in a lower protein concentration in the study of Van Zijderveld et al. (2011). However, protein yield was not affected by nitrate in their study in contrast to the present study where protein yield was 796 and $869 \mathrm{~g} / \mathrm{d}$ for diets with or without nitrate, respectively $(P=0.030)$. In the Dutch protein evaluation system (DVE/OEB system), DVE indicates digestible feed and microbial true protein digested in the small intestine 
(Tamminga et al., 1994). In the current experiment, the calculated DVE supply based on diet composition exceeded $100 \%$ of the calculated DVE requirements, indicating that supply of protein did not limit milk protein synthesis. Incomplete reduction of dietary nitrate may decrease the amount of rumen-available $\mathrm{N}$ and consequently impair microbial protein synthesis and result in a lower DVE supply than expected based on standard feed values. The resulting lower DVE supply would then negatively affect milk protein yield. However, the actual decline in $\mathrm{CH}_{4}$ production in the current study was rather close to stoichiometric potential of nitrate, which implies that most of the nitrate must have been reduced to ammonia and has contributed to rumen available N. Alternatively, the negative effect of nitrate on milk protein yield may be related to a decreased supply of gluconeogenic precursors. Nitrate has been shown to increase the acetate:propionate ratio in the rumen (Guyader et al., 2015), which could also affect milk protein content. Rigout et al. (2003) reported an experiment and bibliographical study showing a positive linear relationship between the supply of glucogenic precursors and milk protein content. Glucose is an important factor in signaling pathways thought to regulate milk protein synthesis (Rius et al., 2010). No treatment effects were found for MUN content of milk (Table 2.3), and values were comparable to those found by Van Zijderveld et al. (2011), who fed a similar diet as in the present study.

\section{Blood methemoglobin}

The average $\mathrm{Hb}$ content $(\mathrm{mmol} / \mathrm{L})$ of blood of the 16 cows that were gradually adapted to increasing levels of dietary nitrate was 5.9 on d 1 and 7, and 5.6 on d 14 and 21 of the adaptation period before the experimental period. Blood MetHb (\% of total $\mathrm{Hb}$ ) was on average $1.3 \%$ on both $d 1$ and $d 7,2.5 \%$ on $d 14$, and $3.4 \%$ on $d 21$. The highest MetHb value measured for an individual animal was $11.8 \%$ on $d 21$. This level is substantially below the level of $30 \%$ that is considered to cause subclinical methemoglobinemia (Bruning-Fann and Kaneene, 1993). 


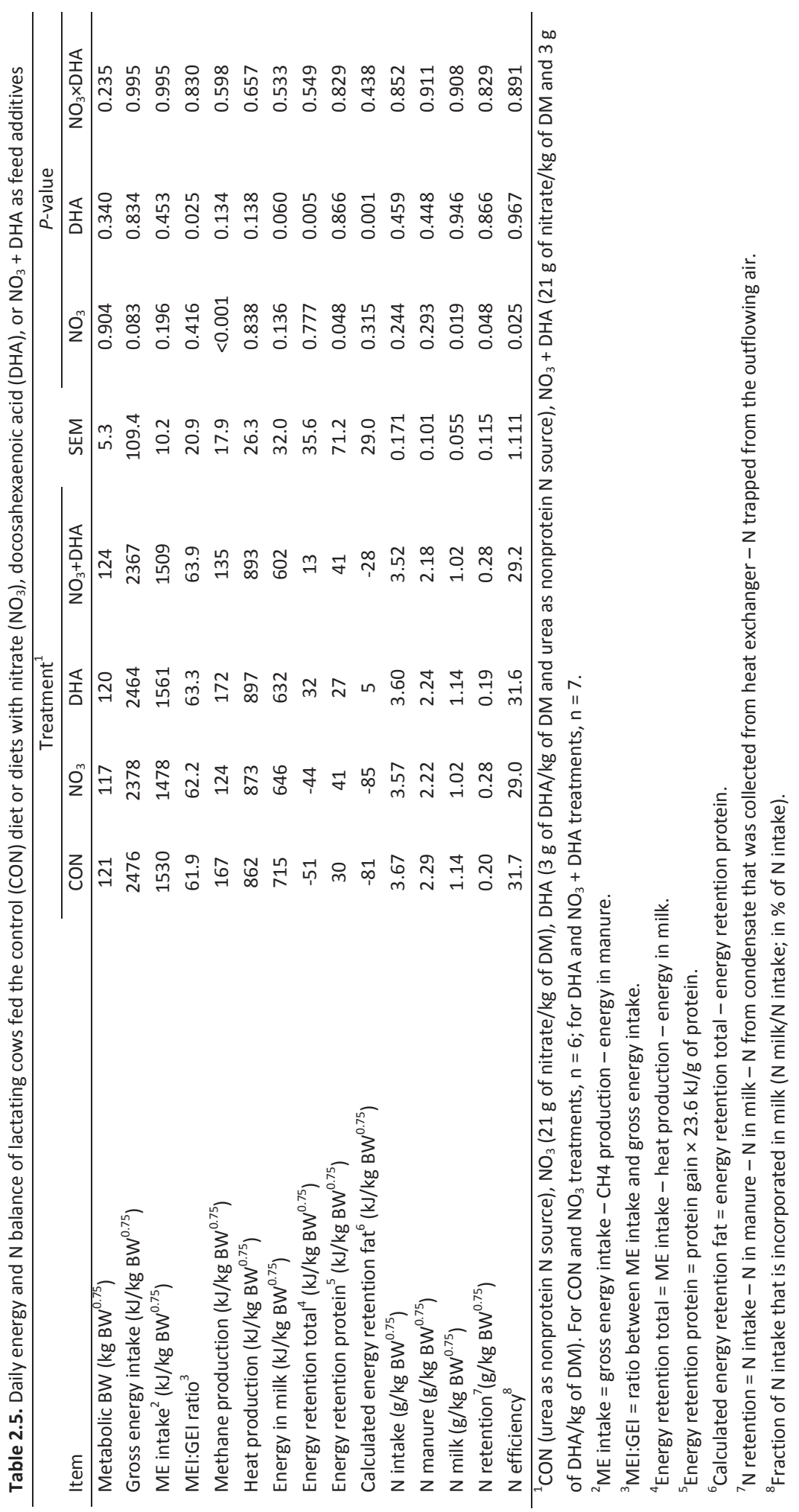




\section{Energy and nitrogen retention}

No $\mathrm{NO}_{3} \times$ DHA interaction effects on energy and $\mathrm{N}$ retention were found (Table 2.5). The MEI:GEI ratio was higher for the diets containing DHA (Table 2.5). The calculated energy retention was positive for cows receiving DHA and negative for cows on the CON or $\mathrm{NO}_{3}$ treatment. The tendency for decreased energy output in milk may explain the positive energy retention of the cows receiving DHA. The absence of a significant effect of nitrate on FPCM production or milk energy output is in line with results from a recent review by Lee and Beauchemin (2014), who also reported that the consistent decline in $\mathrm{CH}_{4}$ yield by dietary nitrate appears to be without directing additional energy toward animal production.

Nitrogen retention was positive for all treatments (Table 2.5). The average $\mathrm{N}$ retention was $28 \mathrm{~g} / \mathrm{d}$, which is in line with the generally small positive $\mathrm{N}$ retention reported for dairy cattle $\mathrm{N}$ balance trials as reviewed by Spanghero and Kowalski (1997). Intake and excretion of $\mathrm{N}$ was similar among treatments. As expected based on results for milk protein, the $\mathrm{N}$ output in milk and $\mathrm{N}$ efficiency of milk production were lower for cows receiving nitrate (Table 2.5). Nitrogen retention was significantly higher for cows receiving nitrate, whereas $\mathrm{N}$ in manure was not affected.

\section{Digestibility of nutrients}

Supplementation of DHA generally resulted in higher total-tract digestibility of various nutrients (Table 2.6). The higher fat digestibility on treatments with DHA is probably caused by the slight difference in fat content of the TMR with and without DHA (Table 2.2). If fat supplementation is higher, the calculated digestibility values are less affected by fecal excretion of endogenous fat sources (Kil et al., 2010). This difference in dietary fat content could not be prevented in the experimental set-up as exchanging DHA against another fat source would not allow to distinguish between the effect of fat or a specific FA on $\mathrm{CH}_{4}$ emissions.

Unlike the results for $\mathrm{CH}_{4}$ production, effects of nitrate and DHA on apparent total-tract digestibility of nutrients were often not additive (Table 2.6). Digestibility of CP was not 
Table 2.6. Apparent total-tract digestibility of nutrients in lactating dairy cows fed the control (CON) diet or diets with nitrate $\left(\mathrm{NO}_{3}\right)$, docosahexaenoic acid $(\mathrm{DHA})$, or $\mathrm{NO}_{3}+\mathrm{DHA}$ as feed additives

\begin{tabular}{|c|c|c|c|c|c|c|c|c|}
\hline \multirow[b]{2}{*}{ Digestibility (\%) } & \multicolumn{4}{|c|}{ Treatment $^{1}$} & \multirow[b]{2}{*}{ SEM } & \multicolumn{3}{|c|}{$P$-value } \\
\hline & CON & $\mathrm{NO}_{3}$ & $\mathrm{DHA}$ & $\mathrm{NO}_{3}+\mathrm{DHA}$ & & $\mathrm{NO}_{3}$ & $\mathrm{DHA}$ & $\mathrm{NO}_{3} \times \mathrm{DHA}$ \\
\hline $\mathrm{DM}$ & 73.9 & 71.2 & 75.2 & 75.6 & 0.72 & 0.133 & 0.001 & 0.051 \\
\hline OM & $75.6^{\mathrm{ab}}$ & $73.2^{b}$ & $76.9^{\mathrm{a}}$ & $77.3^{\mathrm{a}}$ & 0.67 & 0.143 & $<0.001$ & 0.048 \\
\hline $\mathrm{CP}$ & 70.8 & 69.7 & 68.6 & 69.8 & 1.10 & 0.989 & 0.313 & 0.265 \\
\hline NDF & $61.0^{\mathrm{a}}$ & $55.3^{b}$ & $63.6^{\mathrm{a}}$ & $65.1^{a}$ & 1.31 & 0.132 & $<0.001$ & 0.011 \\
\hline Crude fat & 70.2 & 71.3 & 74.4 & 76.0 & 1.37 & 0.330 & 0.004 & 0.884 \\
\hline Starch & 99.0 & 99.3 & 99.7 & 99.6 & 0.18 & 0.597 & 0.014 & 0.193 \\
\hline Gross energy & $73.4^{\mathrm{a}}$ & $70.3^{b}$ & $74.6^{a}$ & $75.1^{\mathrm{a}}$ & 0.75 & 0.099 & $<0.001$ & 0.027 \\
\hline
\end{tabular}

${ }^{a, b}$ Means within a row with different superscripts differ $(P<0.05)$.

${ }^{1} \mathrm{CON}$ (urea as nonprotein $\mathrm{N}$ source), $\mathrm{NO}_{3}$ (21 g of nitrate/kg of DM), DHA (3 g of DHA/kg of DM and urea as nonprotein $\mathrm{N}$ source), $\mathrm{NO}_{3}+\mathrm{DHA}$ (21 g of nitrate/kg of DM and $3 \mathrm{~g}$ of $\mathrm{DHA} / \mathrm{kg}$ of DM). For $\mathrm{CON}$ and $\mathrm{NO}_{3}$ treatments, $\mathrm{n}=6$; for $\mathrm{DHA}$ and $\mathrm{NO}_{3}+$ DHA treatments, $\mathrm{n}=7$.

different between treatments and does therefore not provide an explanation for the difference in milk protein yield and $\mathrm{N}$ utilization for milk production that was observed between treatments with and without nitrate. Moreover, a reduction in DMI and nutrient digestibility was only found for the $\mathrm{NO}_{3}$ treatment and not for the $\mathrm{NO}_{3}+\mathrm{DHA}$ treatment (Table 2.6). The effect of DHA on NDF digestibility and significance of the interaction term seems mainly to be the result of the low NDF digestibility value obtained for the $\mathrm{NO}_{3}$ treatment (Table 2.6). The significantly lower NDF digestion may be related to a decreased functioning of cell wall degrading microorganisms as a result of a temporarily increased ruminal concentrations of $\mathrm{H}_{2}$. Such increases in $\mathrm{H}_{2}$ concentration after nitrate supplementation have been reported previously (Van Zijderveld et al., 2011; Lund et al., 2014). Accumulation of $\mathrm{H}_{2}$ in the rumen may impair regeneration of $\mathrm{NAD}+$ from NADH (McAllister and Newbold, 2008), and this may negatively affect cell wall degradation by rumen microbes. Nitrite, as intermediate in the reduction of nitrate to ammonia, decreased in vitro cell wall digestion and inhibited growth of cellulolytic bacteria (Marais et al., 1988) and may also have negatively affected NDF digestibility. However, the MetHb concentrations in blood of cows receiving nitrate were relatively low in the present study, and it is thus less likely that nitrite accumulated to substantial amounts in the rumen. Nevertheless, a possible negative effect of nitrite on fiber digestion cannot be excluded. The findings of Lee et al. (2015b) suggest that a restricted feeding regimen influences the potential adverse effects of nitrate on animal health and performance. Despite the poor 
palatability of nitrate, cows may consume relatively large amounts of nitrate in one meal under restricted feeding, which may exert negative effects in the rumen. Lee et al. (2015a) observed no effect of nitrate on NDF digestibility in beef cattle that had free access to feed. However, ADF digestibility was significantly decreased by nitrate, which indicated that also in their study, fiber degradability did not remain completely unaffected. Better NDF degradation in the rumen and thus more fermentation, probably explains the numerically smaller decrease in $\mathrm{CH}_{4}$ per kilogram of DMI for cows on the $\mathrm{NO}_{3}+\mathrm{DHA}$ treatment as compared with cows on the $\mathrm{NO}_{3}$ treatment (Table 2.3).

\section{CONCLUSIONS}

Additive $\mathrm{CH}_{4}$-mitigating effects, or a positive interaction, of nitrate and DHA fed together would have allowed for a significant decrease in $\mathrm{CH}_{4}$ at lower doses of individual additives. Feeding DHA strongly affected milk FA composition, but did not decrease $\mathrm{CH}_{4}$ production per kilogram of DMI and increased $\mathrm{CH}_{4}$ production per kilogram of FPCM, whereas nitrate showed a large and consistent decrease in $\mathrm{CH}_{4}$ production irrespective of the unit in which it was expressed. No interaction effect was found for the effects of nitrate and DHA on $\mathrm{CH}_{4}$ in grams per kilogram of $\mathrm{DMI}$ and $\mathrm{CH}_{4}$ in grams per kilogram of $\mathrm{FPCM}$. A significant interaction effect between nitrate and DHA on NDF digestibility indicated that negative effects of nitrate on apparent total-tract digestibility of nutrients were alleviated by DHA. Such an interaction effect between nitrate and DHA could be of interest if nitrate is fed to decrease $\mathrm{CH}_{4}$ production, because a decrease in $\mathrm{CH}_{4}$ production should not be accompanied by reduced animal performance. Given the significant reductions in milk fat and protein yield by DHA and nitrate, respectively, the current doses of the additives are not recommended for application in practice.

\section{ACKNOWLEDGMENTS}

Abdulai Guinguina and Kitty Elsinghorst (Students of Wageningen University, the Netherlands) and the staff of the experimental facilities "Carus" (Wageningen, the Netherlands) are gratefully acknowledged for their assistance during the implementation 
of the experiment. This study is part of the Low Emission Animal Feed project. The authors acknowledge financial support of the Dutch Ministry of Economic Affairs (The Hague, the Netherlands), Product Board Animal Feed (Zoetermeer, the Netherlands), and the Dutch Dairy Board (Zoetermeer, the Netherlands), and acknowledge the TI Food and Nutrition project "Reduced methane emission of dairy cows" for providing milk fatty acid data.

\section{REFERENCES}

Boeckaert, C., V. Fievez, D. Van Hecke, W. Verstraete, and N. Boon. 2007. Changes in rumen biohydrogenation intermediates and ciliate protozoa diversity after algae supplementation to dairy cattle. Eur. J. Lipid Sci. Technol. 109:767-777.

Boeckaert, C., B. Vlaeminck, V. Fievez, L. Maignien, J. Dijkstra, and N. Boon. 2008a. Accumulation of trans C18:1 fatty acids in the rumen after dietary algae supplementation is associated with changes in the Butyrivibrio community. Appl. Environ. Microbiol. 74:6923-6930.

Boeckaert, C., B. Vlaeminck, J. Dijkstra, A. Issa-Zacharia, T. Van Nespen, W. Van Straalen, and V. Fievez. 2008b. Effect of dietary starch or micro algae supplementation on rumen fermentation and milk fatty acid composition of dairy cows. J. Dairy Sci. 91:4714-4727.

Brouwer, E. 1965. Report of sub-committee on constants and factors. Pages 441-443 in Energy Metabolism: Proc. 3rd Symp. K. L. Blaxter, ed. EAAP Publ. No. 11. Academic Press, London, UK.

Bruning-Fann, C. S., and J. B. Kaneene. 1993. The effects of nitrate, nitrite and N-nitroso compounds on human health: A review. Vet. Hum. Toxicol. 35:521-538.

Castro Montoya, J., A. M. Bhagwat, N. Peiren, S. De Campeneere, B. De Baets, and V. Fievez. 2011. Relationships between odd- and branched-chain fatty acid profiles in milk and calculated enteric methane proportion for lactating dairy cattle. Anim. Feed Sci. Technol. 166:596-602.

CVB. 2008. CVB Table booklet feeding of ruminants. CVB series no. 43. Centraal Veevoederbureau, Lelystad, the Netherlands.

Fievez, V., C. Boeckaert, B. Vlaeminck, J. Mestdagh, and D. Demeyer. 2007. In vitro examination of DHA-edible micro-algae 2. Effect on rumen methane production and apparent degradability of hay. Anim. Feed Sci. Technol. 136:80-95.

Grainger, C., and K. A. Beauchemin. 2011. Can enteric methane emissions from ruminants be lowered without lowering their production? Anim. Feed Sci. Technol. 166-167:308-320. 
Guo, W. S., L. P. Ren, Z. M. Zhou, and Q. X. Meng. 2007. Difference of nitrogen contents determined by the combustion and Kjeldahl method in response to nitrate nitrogen in some feedstuffs. J. Anim. Feed Sci. 16:178-183.

Guyader, J., M. Eugène, B. Meunier, M. Doreau, D. P. Morgavi, M. Silberberg, Y. Rochette, C. Gerard, C. Loncke, and C. Martin. 2015. Additive methane-mitigating effect between linseed oil and nitrate fed to cattle. J. Anim. Sci. 93:3564-3577.

Hatew, B., S. C. Podesta, H. Van Laar, W. F. Pellikaan, J. L. Ellis, J. Dijkstra, and A. Bannink. 2015a. Effects of dietary starch content and rate of fermentation on methane production in lactating dairy cows. J. Dairy Sci. 98:486-499.

Hatew, B., J. W. Cone, W. F. Pellikaan, S. C. Podesta, A. Bannink, W. H. Hendriks, and J. Dijkstra. 2015b. Relationship between in vitro and in vivo methane production measured simultaneously with different dietary starch sources and starch levels in dairy cattle. Anim. Feed Sci. Technol. 202:20-31.

Hristov, A. N., J. Oh, J. Firkins, J. Dijkstra, E. Kebreab, G. Waghorn, A. Adesogan, W. Yang, J. Tricarico, C. Lee, P. J. Gerber, B. Henderson, and H. P. S. Makkar. 2013. Mitigation of methane and nitrous oxide emissions from animal operations: I. A review of enteric methane mitigation options. J. Anim. Sci. 91:5045-5069.

Hulshof, R. B. A., A. Berndt, W. J. J. Gerrits, J. Dijkstra, S. M. Van Zijderveld, J. R. Newbold, and H. B. Perdok. 2012. Dietary nitrate supplementation reduces methane emission in beef cattle fed sugarcane based diets. J. Anim. Sci. 90:2317-2323.

ISO. 1998. Animal feeding stuffs, animal products, and feces or urine. Determination of gross calorific value - Bomb calorimeter method. International Standards Organization, Geneva, Switzerland.

ISO. 1999a. Animal feeding stuffs. Determination of fat content. International Standards Organization, Geneva, Switzerland.

ISO. 1999b. Animal feeding stuffs. Determination of moisture and other volatile matter content. International Standards Organization, Geneva, Switzerland.

ISO. 2002. Animal feeding stuffs. Determination of crude ash. International Standards Organisation, Geneva, Switzerland.

ISO. 2004. Animal feeding stuffs. Enzymatic determination of total starch content. International Standards Organization, Geneva, Switzerland.

ISO. 2005. Animal feeding stuffs. Determination of nitrogen content and calculation of crude protein content-Part1: Kjeldahl method. International Standards Organization, Geneva, Switzerland. 
Kil, D. Y., T. E. Sauber, D. B. Jones, and H. H. Stein. 2010. Effect of the form of dietary fat and the concentration of dietary neutral detergent fiber on ileal and total tract endogenous losses and apparent and true digestibility of fat by growing pigs. J. Anim. Sci. 88:2959-2967.

Lee, C., and K. A. Beauchemin. 2014. A review of feeding supplementary nitrate to ruminant animals: Nitrate toxicity, methane emissions, and production performance. Can. J. Anim. Sci. 94:557570.

Lee, C., R. C. Araujo, K. M. Koenig, and K. A. Beauchemin. 2015a. Effects of encapsulated nitrate on enteric methane production, and nitrogen and energy utilization in beef heifers. J. Anim. Sci. 93:2391-2404.

Lee, C., R. C. Araujo, K. M. Koenig, and K. A. Beauchemin. 2015b. Effects of encapsulated nitrate on eating behavior, rumen fermentation, and blood profile of beef heifers fed restrictively or ad libitum. J. Anim. Sci. 93:2405-2418.

Lichtenwalner, R. E., J. P. Fontenot, and R. E. Tucker. 1973. Effect of source of supplemental nitrogen and level of nitrate on feedlot performance and vitamin A metabolism of fattening beef calves. J.Anim. Sci. 37:837-847.

Lund, P., R. Dahl, H. J. Yang, A. L. F. Hellwing, B. B. Cao, and M.R. Weisbjerg. 2014. The acute effect of addition of nitrate on in vitro and in vivo methane emission in dairy cows. Anim. Prod. Sci. 54:1432-1435.

Marais, J. P., J. J. Therion, R. I. Mackie, A. Kistner, and C. Dennison. 1988. Effect of nitrate and its reduction products on the growth and activity of the rumen microbial population. Br. J. Nutr. 59:301-313.

McAllister, T. A., and C. J. Newbold. 2008. Redirecting rumen fermentation to reduce methanogenesis. Aust. J. Exp. Agric. 48:7-13.

Moate, P. J., S. R. O. Williams, M. C. Hannah, R. J. Eckard, M. J. Auldist, B. E. Ribaux, J. L. Jacobs, and W. J. Wales. 2013. Effects of feeding algal meal high in docosahexaenoic acid on feed intake, milk production, and methane emissions in dairy cows. J. Dairy Sci. 96:3177-3188.

Newbold, J. R., S. M. Van Zijderveld, R. B. A. Hulshof, W. B. Fokkink, R. A. Leng, P. Terencio, W. J. Powers, P. S. J. Van Adrichem, N. D. Paton, and H. B. Perdok. 2014. The effect of incremental levels of dietary nitrate on methane emissions in Holstein steers and performance in Nelore bulls. J. Anim. Sci. 92:5032-5040.

Rigout, S., C. Hurtaud, S. Lemosquet, A. Bach, and H. Rulquin. 2003. Lactational effect of propionic acid and duodenal glucose in cows. J. Dairy Sci. 86:243-253.

Rius, A. G., J. A. D. R. N. Appuhamy, J. Cyriac, D. Kirovski, O. Becvar, J. Escobar, M. L. McGilliard, B. J. Bequette, R. M. Arkers, and M. D. Hanigan. 2010. Regulation of protein synthesis in 
mammary glands of lactating dairy cows by starch and amino acids. J. Dairy Sci. 93:31143127.

Robertson, J. B., and P. J. Van Soest. 1981. The detergent system of analysis. Chapter 9, pages 123158 in The Analysis of Dietary Fibre in Food. W. P. T. James, and O. Theander, ed. Marcel Dekker, New York, NY.

Shingfield, K. J., M. Bonnet, and N. D. Scollan. 2013. Recent developments in altering the fatty acid composition of ruminant-derived foods. Animal 7(Suppl. 1):132-162.

Spanghero, M., and Z. M. Kowalski. 1997. Critical analysis of N balance experiments with lactating cows. Livest. Prod. Sci. 52:113-122.

Tamminga, S., W. M. Van Straalen, A. P. J. Subnel, R. G. M. Meijer, A. Steg, C. J. G. Wever, and M. C. Blok. 1994. The Dutch protein evaluation system-The DVE/OEB-system. Livest. Prod. Sci. 40:139-155.

Van Gastelen, S., E. C. Antunes-Fernandes, K. A. Hettinga, G. Klop, S. J. J. Alferink, W. H. Hendriks, and J. Dijkstra. 2015. Enteric methane production, rumen volatile fatty acid concentrations, and milk fatty acid composition in lactating Holstein-Friesian cows fed grass silage or corn silage-based diets. J. Dairy Sci. 98:1915-1927.

Van Lingen, H. J., L. A. Crompton, W. H. Hendriks, C. K. Reynolds, and J. Dijkstra. 2014. Meta-analysis of relationships between enteric methane yield and milk fatty acid profile in dairy cattle. J. Dairy Sci. 97:7115-7132.

Van Soest, P. J., J. B. Robertson, and B. A. Lewis. 1991. Methods for dietary fiber, neutral detergent fiber, and non-starch polysaccharides in relation to animal nutrition. J. Dairy Sci. 74:35833597.

Van Valenberg, H. J., K. A. Hettinga, J. Dijkstra, H. Bovenhuis, and E. J. M. Feskens. 2013. Concentrations of $n-3$ and $n-6$ fatty acids in Dutch bovine milk fat and their contribution to human dietary intake. J. Dairy Sci. 96:4173-4181.

Van Zijderveld, S. M., W. J. J. Gerrits, J. A. Apajalahti, J. R. Newbold, J. Dijkstra, R. A. Leng, and H. B. Perdok. 2010. Nitrate and sulfate: Effective alternative hydrogen sinks for mitigation of ruminal methane production in sheep. J. Dairy Sci. 93:5856-5866.

Van Zijderveld, S. M., W. J. J. Gerrits, J. Dijkstra, J. R. Newbold, R. B. A. Hulshof, and H. B. Perdok. 2011. Persistency of methane mitigation by dietary nitrate supplementation in dairy cows. J. Dairy Sci. 94:4028-4038.

Vlaeminck, B., V. Fievez, A. R. J. Cabrita, A. J. M. Fonseca, and R. J. Dewhurst. 2006. Factors affecting odd- and branched-chain fatty acids in milk: A review. Anim. Feed Sci. Technol. 131:389-417. 
Vlaeminck, B., G. Mengistu, V. Fievez, L. de Jonge, and J. Dijkstra. 2008. Effect of in vitro docosahexaenoic acid supplementation to marine algae-adapted and unadapted rumen inoculum on the biohydrogenation of unsaturated fatty acids in freeze dried grass. J. Dairy Sci. 91:1122-1132.

Williams, C. H., O. lismaa, and D. J. David. 1962. Determination of chromic oxide in feces samples by atomic absorption spectrophotometry. J. Agric. Sci. 59:381-385. 


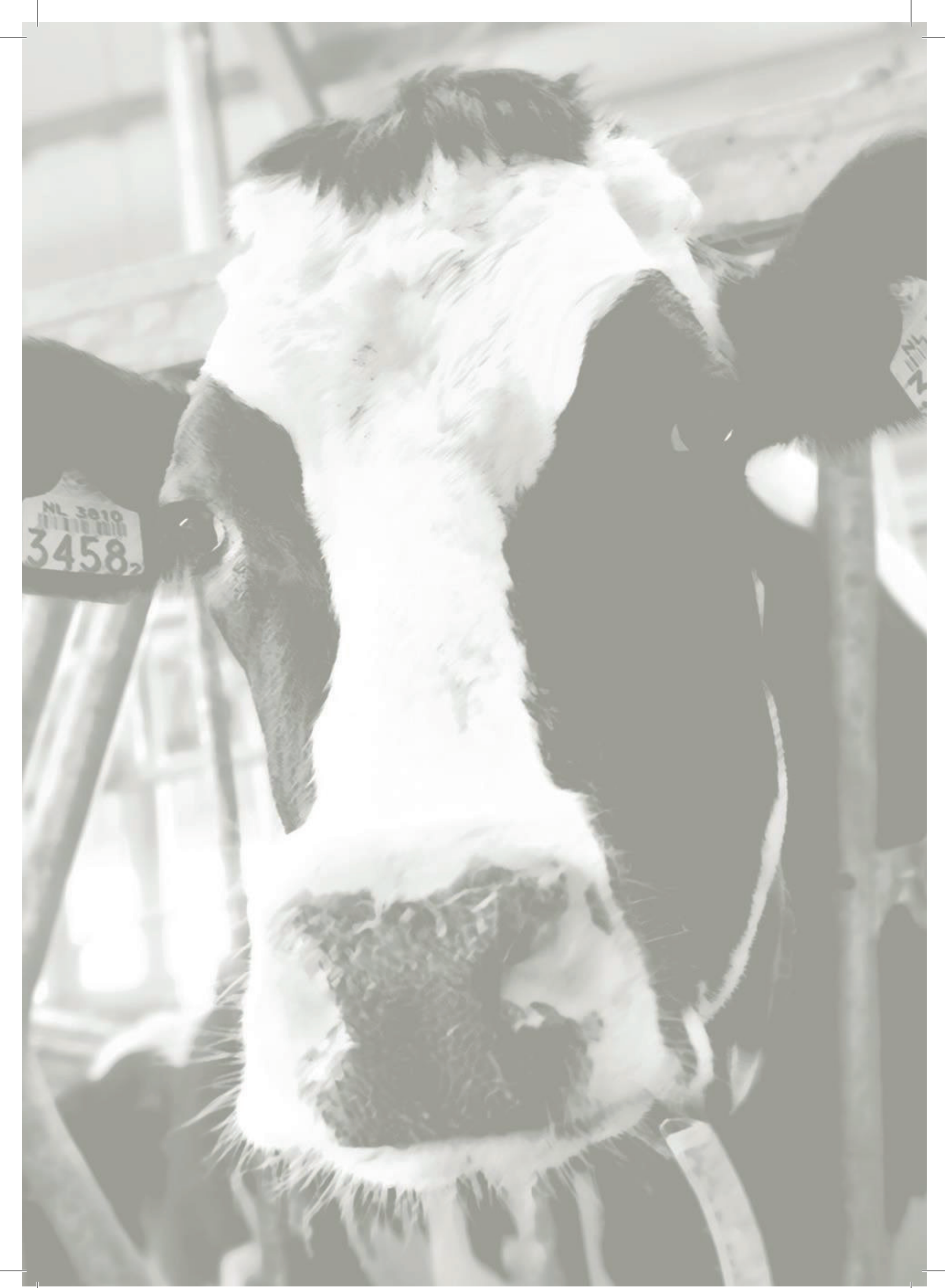




\title{
Chapter 3
}

Using diurnal patterns of ${ }^{13} \mathrm{C}$ enrichment of $\mathrm{CO}_{2}$ to evaluate the effects of nitrate and docosahexaenoic acid on fiber degradation in the rumen of lactating dairy cows

\author{
G. Klop*, A. Bannink ${ }^{\dagger}$, K. Dieho*, W.J.J. Gerrits*, J. Dijkstra* \\ * Animal Nutrition Group, Wageningen University, PO Box 338, $6700 \mathrm{AH}$ Wageningen, The \\ Netherlands \\ ${ }^{\dagger}$ Wageningen UR Livestock Research, PO Box 338, 6700 AH Wageningen, The Netherlands
}




\begin{abstract}
Nitrate decreases enteric methane $\left(\mathrm{CH}_{4}\right)$ production in ruminants, but may also negatively affect fiber degradation. In this experiment, twenty-eight lactating Holstein dairy cows were grouped into seven blocks. Within blocks, cows were randomly assigned to 1 of 4 isonitrogenous treatments in a $2 \times 2$ factorial arrangement: Control (CON); $\mathrm{NO}_{3}$ [21 g of nitrate/kg dry matter (DM)]; DHA [3 g of docosahexaenoic acid (DHA)/kg of DM]; or $\mathrm{NO}_{3}+\mathrm{DHA}(21 \mathrm{~g}$ of nitrate/kg of DM and $3 \mathrm{~g}$ of DHA/kg of DM). Cows were fed a total mixed ration consisting of $21 \%$ grass silage, $49 \%$ corn silage and $30 \%$ concentrates on a DM basis. Based on the difference in natural ${ }^{13} \mathrm{C}$ enrichment and neutral detergent fiber and starch content between grass silage and corn silage, we investigated whether a negative effect on rumen fiber degradation could be detected by evaluating diurnal patterns of ${ }^{13} \mathrm{C}$ enrichment of exhaled carbon dioxide. A significant nitrate $\times$ DHA interaction was found for neutral detergent fiber digestibility, which was reduced on the $\mathrm{NO}_{3}$ treatment to an average of $55 \%$, as compared with 61,64 , and $65 \%$ on treatments $\mathrm{CON}, \mathrm{DHA}$ and $\mathrm{NO}_{3}+\mathrm{DHA}$, respectively. Feeding nitrate, but not DHA, resulted in a pronounced increase in ${ }^{13} \mathrm{C}$ enrichment of $\mathrm{CO}_{2}$ in the first 3 to $4 \mathrm{~h}$ after feeding only. Results support the hypothesis that effects of a feed additive on the rate of fiber degradation in the rumen can be detected by evaluating diurnal patterns of ${ }^{13} \mathrm{C}$ enrichment of $\mathrm{CO}_{2}$. To be able to detect this, the main ration components have to differ considerably in fiber and nonfiber carbohydrate content as well as in natural ${ }^{13} \mathrm{C}$ enrichment.
\end{abstract}

Key words: feed additives, methane, fiber degradation, ${ }^{13} \mathrm{C}$ enrichment 


\section{SHORT COMMUNICATION}

Nitrate is among the relatively few feed additives that have been shown to effectively mitigate enteric $\mathrm{CH}_{4}$ production in ruminants (reviewed by Hristov et al., 2013). However, $\mathrm{CH}_{4}$ mitigating additives should not adversely affect animal health and performance or quality of animal products to be applicable in practice. Methemoglobinemia is a health risk of feeding nitrate to ruminants, but a gradual introduction of nitrate in the diet alleviates this risk (Van Zijderveld et al., 2011). A growing body of literature also documents the effects of nitrate feeding on animal performance. As discussed by Newbold et al. (2014), nitrate might reduce feed intake and the magnitude of the decrease seems larger on diets that contain more NDF. At least two factors may be associated with this decrease in feed intake. First, nitrite, as an intermediate in the reduction of nitrate to ammonia, is toxic for fibrolytic bacteria in vitro (Marais et al. 1988). Second, nitrate feeding increases hydrogen production in the rumen (Van Zijderveld et al. 2011; Lund et al. 2014; Guyader et al., 2015), which may indicate increased aqueous hydrogen concentrations (Guyader et al. 2015). Increased hydrogen concentration inhibits the regeneration of $\mathrm{NAD}^{+}$from NADH (Hegarty and Gerdes, 1999), which may impair metabolism of fibrolytic bacteria. An increased ratio of $\mathrm{NADH}$ to $\mathrm{NAD}^{+}$will cause a shift from acetate towards propionate formation, partly via the lactic acid pathway. The latter pathway yields less ATP for the fibrolytic microbes. Impaired fibrolytic activity increases retention time of fiber in the rumen and therefore may reduce feed intake.

The effects of nitrate and docosahexaenoic acid (C22:6n-3; DHA) on total enteric $\mathrm{CH}_{4}$ production and milk fatty acid composition in lactating dairy cows in climate respiration chambers (CRC) were recently reported by Klop et al. (2016). A negative effect of nitrate on DMI was observed as well as reduced total tract digestibility of fiber on the $\mathrm{NO}_{3}$ treatment. However, no adverse effect of DHA on total tract fiber digestion was observed. Digestibility of NDF was not reported in other studies in which DHA was supplemented to dairy cows (Boeckaert et al., 2008; Moate et al., 2013). It was hypothesized that the between-treatment differences in fiber digestion would cause variation in diurnal pattern

of ${ }^{13} \mathrm{C}$ enrichment of $\mathrm{CO}_{2}$. When nitrate is supplemented to a diet of which the main 
components differ considerably in starch (or another non-NDF carbohydrate source) and NDF content as well as in natural ${ }^{13} \mathrm{C}$ enrichment, an adverse effect on fiber degradation may be detectable from an increased ${ }^{13} \mathrm{C}$ enrichment of exhaled $\mathrm{CO}_{2}$. In comparison with corn, grass has a lower natural ${ }^{13} \mathrm{C}$ enrichment (Knobbe et al. 2006) and it does not contain starch. When fed as a TMR, changes in the ${ }^{13} \mathrm{C}$ enrichment of $\mathrm{CO}_{2}$ after a meal hence likely reflect changes in the degradation rate of starch or fiber by the rumen bacteria. The aim of this study was to investigate if a negative effect on ruminal fiber degradation upon feeding nitrate to dairy cattle can be detected by evaluating diurnal patterns of ${ }^{13} \mathrm{C}$ enrichment of exhaled $\mathrm{CO}_{2}$.

The experimental procedures were approved by the Animal Care and Use Committee of Wageningen University (Wageningen, The Netherlands). Detailed information regarding experimental design, diets, feeding, and measurements was reported by Klop et al. (2016). Briefly, 8 primiparous and 20 multiparous (125 \pm 16 DIM at the start of the experimental period; mean \pm SD) lactating Holstein dairy cows were divided over 7 blocks based on parity, lactation stage, milk production, and presence or absence of a rumen cannula. Within blocks, cows were randomly assigned to 1 of 4 experimental diets: control (CON; no nitrate or DHA added and urea as NPN source), nitrate $\left(\mathrm{NO}_{3} ; 21 \mathrm{~g}\right.$ of nitrate/kg of DM), DHA (DHA; $3 \mathrm{~g}$ of DHA/kg of DM and urea as NPN source), or nitrate and DHA $\left(\mathrm{NO}_{3}+\mathrm{DHA}\right.$; $21 \mathrm{~g}$ of nitrate/kg of DM and $3 \mathrm{~g}$ of DHA/kg of DM). The sources of nitrate and DHA were Bolifor CNF (Yara, Norway) containing 75\% nitrate, and DHAgold (DSM Nutritional Products, Columbia, MD), a whole cell algae product containing $25.4 \% \mathrm{DHA}$, respectively. Feed additives were included in the concentrates and chromium oxide $\left(\mathrm{Cr}_{2} \mathrm{O}_{3} ; 1.7 \mathrm{~g} / \mathrm{kg}\right.$ of DM) was used as external marker to determine apparent total-tract digestibility of nutrients.

Diets were isonitrogenous, offered as TMR, and consisted of $49 \%$ corn silage, $21 \%$ grass silage, and $30 \%$ concentrate on a DM basis. Dietary DM, CP, NDF and starch contents were on average 454, 165, 355 and $240 \mathrm{~g} / \mathrm{kg}$ of DM, respectively. Due to lameness, 1 of 8 rumen cannulated cows was replaced by a non-cannulated cow already adapted to the same experimental diet $\left(\mathrm{NO}_{3}\right)$. 
The experimental period lasted $17 \mathrm{~d}$. During the experimental periods, cows were fed individually with equal portions offered twice daily (at 0600 and 1600h). Until d 9, each block of cows had free access to feed. Thereafter, DMI within a block was restricted to $95 \%$ of that of the animal with the lowest voluntary DMI between $\mathrm{d} 5$ and 8 , while ensuring that none of the animals in the block was restricted to less than $80 \%$ of its voluntary DMI. Cows were housed in tie stalls until the afternoon of day 13 and in CRC for the remainder of the experimental period. In the $\mathrm{CRC}$, gaseous exchange $\left(\mathrm{CH}_{4}, \mathrm{O}_{2}\right.$, and $\left.\mathrm{CO}_{2}\right)$ was measured as described by van Gastelen et al. (2015) and ${ }^{13} \mathrm{CO}_{2}$ production was determined as described by Gerrits et al. (2012). Data relate to the last $72 \mathrm{~h}$ in the CRC, except for digestibility values calculated over the complete period the cows were in the CRC. Natural ${ }^{13} \mathrm{C}$ enrichment of the TMR components was determined by means of combustion isotope ratio MS (Gerrits et al., 2012).

Data were analyzed using PROC MIXED (SAS Inst. Inc., Cary, NC). Two cows (receiving the $\mathrm{CON}$ or $\mathrm{NO}_{3}$ treatment) were excluded from analysis because of a feeding error in the CRC. Gaseous exchange data, heat production (HP), respiration quotient (RQ), and ${ }^{13} \mathrm{C}$ enrichment of $\mathrm{CO}_{2}$ were averaged per hour and analyzed using repeated measures ANOVA. Main and interaction effects of nitrate, DHA, and time were included as fixed effects in the model. Period (which equals block) was included as random factor in the model and average values for each hour of the day were treated as repeated measures per cow $\times$ treatment combination using a first order autoregressive covariance structure. Multiple comparisons between treatment least squares means for each hour were made using a SLICE statement in the model. Effects were considered significant if $P \leq 0.05$, and trends if $0.05<P<0.10$.

Cows receiving nitrate consumed less $\mathrm{DM}$ and a tendency for a $\mathrm{NO}_{3} \times \mathrm{DHA}$ interaction was observed, because the $\mathrm{NO}_{3}$ cows consumed less DM than the $\mathrm{NO}_{3}+\mathrm{DHA}$ cows. Daily fatand protein-corrected milk production was not affected by nitrate, and tended to be reduced by DHA (Klop et al., 2016). Distinct responses to meals were observed for HP, RQ, and $\mathrm{CH}_{4}$, and for ${ }^{13} \mathrm{C}$ enrichment of the $\mathrm{CO}_{2}$ produced (Figure 3.1). Both $\mathrm{HP}$ and $\mathrm{RQ}$ 
changed over time within day, but no interactions between treatment factors and time were found. The numerically higher RQ and HP peak values for cows on the CON treatment shortly after feeding (Figure 3.1B) can be explained by our visual observations that cows on the CON treatment consumed their meals faster than cows on the other treatments. In line with Van Zijderveld et al. (2011), the $\mathrm{CH}_{4}$-mitigating effect of nitrate was largest during the first hours postfeeding (Figure 3.1C). The restricted feeding regimen imposed during the measurement period and the more rapid degradation of starch compared with fiber may explain the overall increase in ${ }^{13} \mathrm{C}$ enrichment shortly after feeding. The shorter interval between morning and afternoon feeding (10 h) as compared with the interval between afternoon and morning feeding (14 h) may explain the numerically lower ${ }^{13} \mathrm{C}$ enrichment of $\mathrm{CO}_{2}$ in the morning (Figure 3.1D). Feeding nitrate, but not $\mathrm{DHA}$, resulted in a pronounced increase in ${ }^{13} \mathrm{C}$ enrichment of $\mathrm{CO}_{2}$ in the first 3 to $4 \mathrm{~h}$ after feeding only, which resulted in a significant nitrate $\times$ time interaction.

For cows receiving nitrate, the timing of the increased ${ }^{13} \mathrm{C}$ enrichment of $\mathrm{CO}_{2}$ coincided with that of a marked decrease in $\mathrm{CH}_{4}$ emission. Based on previous findings (Van Zijderveld et al. 2011; Lund et al. 2014; Guyader et al., 2015), it is likely that the period of decreased $\mathrm{CH}_{4}$ production coincided with an increased concentration of aqueous $\mathrm{H}_{2}$ in the rumen, which may have impaired the functioning of fibrolytic bacteria. However, only Guyader et al. (2015) measured aqueous $\mathrm{H}_{2}$ in the rumen, whereas Lund et al. (2014) and Van Zijderveld et al. 2011, measured in vivo $\mathrm{H}_{2}$ emissions. An increase in aqueous $\mathrm{H}_{2}$ is likely associated with increased $\mathrm{H}_{2}$ emissions (Hegarty and Gerdes, 1999), but it can also be speculated that supersaturation in the liquid phase may occur, which may give rise to poor relationships between concentrations of dissolved $\mathrm{H}_{2}$ and gaseous $\mathrm{H}_{2}$.

Neither aqueous $\mathrm{H}_{2}$ concentrations, nor $\mathrm{H}_{2}$ emissions were measured in the present experiment. Therefore, it cannot be excluded that other mechanisms were involved in the adverse effect of nitrate on ruminal fiber digestion and $\mathrm{CH}_{4}$ production. As reviewed by Latham et al. (2016), the reduction intermediate nitrite can be particularly toxic to certain fibrolytic microbes, as well as to methanogens. Also, a changed intraruminal reduction 
potential may disturb reactions involved in electron transfer by microorganisms (Latham et al., 2016).

A nitrate $\times$ DHA interaction was found for apparent total-tract digestibility of NDF $(P=$ 0.011; Klop et al., 2016), with NDF digestibility only being reduced on the $\mathrm{NO}_{3}$ treatment where it averaged 55\%, compared with 61,64 , and $65 \%$ on treatments CON, DHA and $\mathrm{NO}_{3}+\mathrm{DHA}$, respectively. In line with reduced feed intake resulting from nitrate feeding (Newbold et al., 2014), based on visual observations, cows on the $\mathrm{NO}_{3}+\mathrm{DHA}$ treatment appeared to have a more gradual intake pattern than cows on the $\mathrm{NO}_{3}$ treatment. This may explain why values for ${ }^{13} \mathrm{C}$ enrichment of $\mathrm{CO}_{2}$ of these cows returned to baseline values at a later time point than for the $\mathrm{NO}_{3}$ treatment (Figure 3.1D). The more gradual feed intake pattern may also have resulted in a higher overall NDF degradation in the rumen of $\mathrm{NO}_{3}+\mathrm{DHA}$ cows as compared with $\mathrm{NO}_{3}$ cows, because of a longer retention time of feed. It would also provide an explanation for the numerically smaller decrease in $\mathrm{CH}_{4}$ per $\mathrm{kg}$ of DMI observed for cows on the $\mathrm{NO}_{3}+\mathrm{DHA}$ treatment compared with the $\mathrm{NO}_{3}$ treatment $\left(\mathrm{CH}_{4}\right.$ production was $1.37,1.05,1.40$, and $1.13 \mathrm{~mol} / \mathrm{kg}$ of DMI on treatments $\mathrm{CON}, \mathrm{NO}_{3}, \mathrm{DHA}$, and $\mathrm{NO}_{3}+\mathrm{DHA}$, respectively; Klop et al., 2016). Total-tract starch digestibility (>99\%) was not affected by feeding nitrate (Klop et al., 2016).

The significantly lower NDF digestibility, absence of changes in starch digestibility, and the significantly higher ${ }^{13} \mathrm{C}$ enrichment of $\mathrm{CO}_{2}$ for cows on the $\mathrm{NO}_{3}$ treatment provides a strong lead that effects of feed additives on fiber degradation in the rumen can be detected by evaluating diurnal patterns of ${ }^{13} \mathrm{C}$ enrichment of $\mathrm{CO}_{2}$. The difference required to detect effects depends on accuracy of the measurements, number of measurements and repeats, frequency of feeding and meal size, and the expected size of the effect. The concept of evaluating ${ }^{13} \mathrm{C}$ enrichment of $\mathrm{CO}_{2}$ to evaluate dietary effects on fiber degradation in the rumen might have a broader application potential than the study of effects of feed 


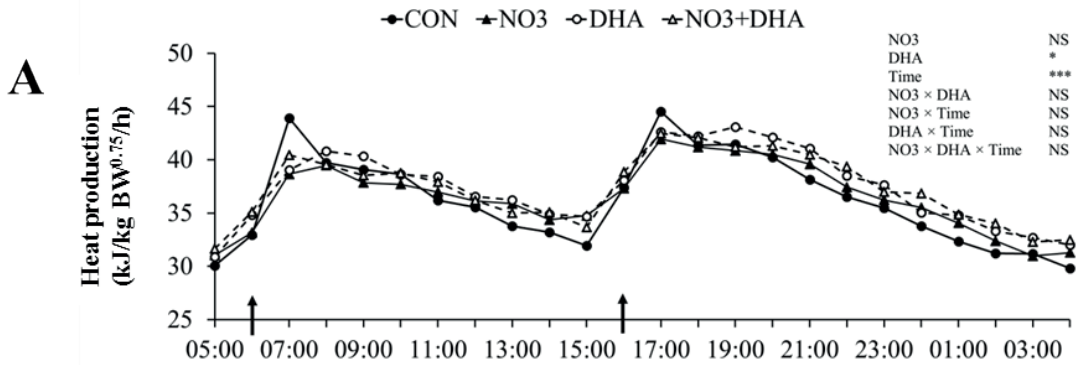

B

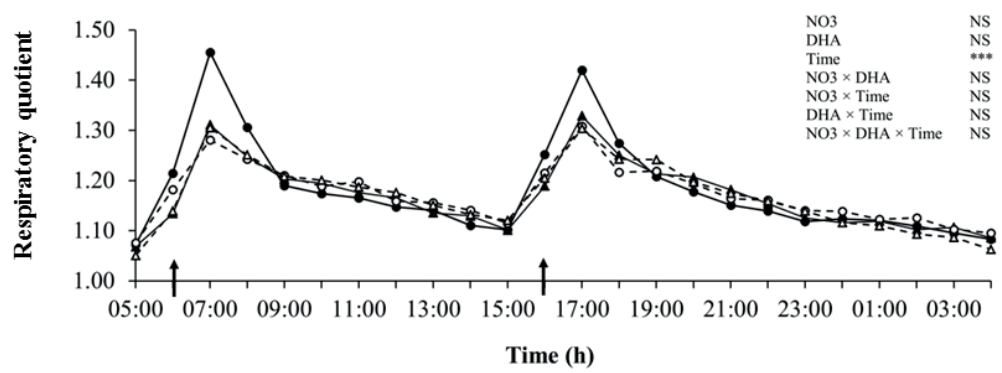

C

NO3 NS $\quad * * * * * * * * * * * * * * * * *+$ NS $* * * * * * * * * * * * * * * * * * *$ NS NS NS NS NS

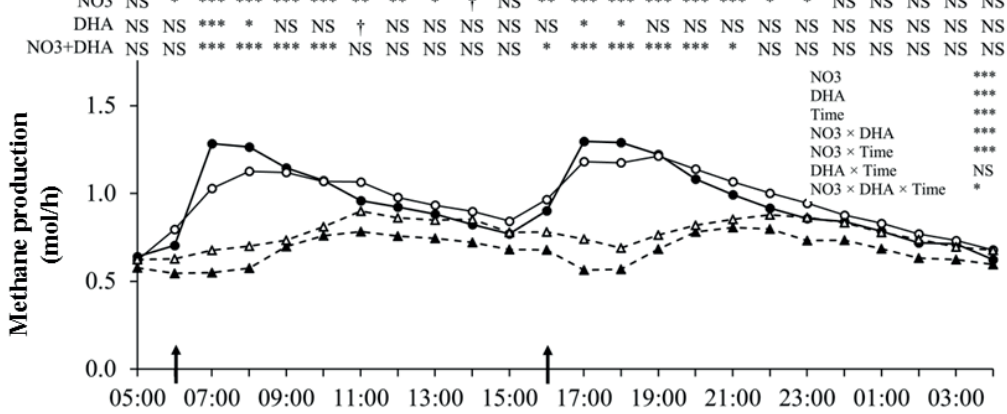

D

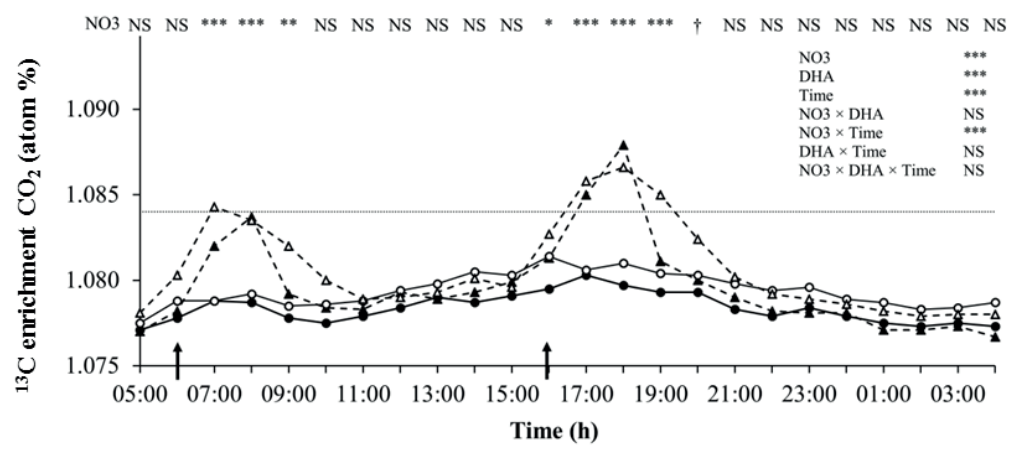


《 Figure 3.1. Diurnal patterns of heat production (A), respiration quotient (B), methane production (C) and ${ }^{13} \mathrm{C}$ enrichment of $\mathrm{CO}_{2}$ (D) of cows receiving different dietary treatments: control (CON); $\mathrm{NO}_{3}$ (21 g of nitrate/kg of dry matter (DM)); DHA [3 g of docosahexaenoic acid (DHA)/kg of DM]; or $\mathrm{NO}_{3}+\mathrm{DHA}\left(21 \mathrm{~g}\right.$ of nitrate/kg of DM and $3 \mathrm{~g}$ of $\mathrm{DHA} / \mathrm{kg}$ of DM). For CON and $\mathrm{NO}_{3}$ treatments $\mathrm{n}=6$, for $\mathrm{DHA}$ and $\mathrm{NO}_{3}+\mathrm{DHA}$ treatments $\mathrm{n}=7$. Arrows indicate feeding times. Significance of main effects and interaction effects is indicated in the figure. Symbols (NS not significant; $+0.05<P<0.10$; $P<0.05$; ** $P<0.01$; ** $P<0.001)$ in $(C)$ indicate hourly comparison of each of the additive treatments with the CON treatment. Symbols in (D) indicate effect of nitrate at different time points. The dashed line indicates the overall average background ${ }^{13} \mathrm{C}$ enrichment of the TMR (1.0844). Values for atom\% ${ }^{13} \mathrm{C}$ were 1.0924 and 1.0722 for corn silage and grass silage, respectively, and 1.0794, 1.0791, 1.0808 and 1.0806 for concentrates of the $\mathrm{CON}, \mathrm{NO}_{3}, \mathrm{DHA}$, and $\mathrm{NO}_{3}+\mathrm{DHA}$ treatment, respectively. The pooled SEM values were $1.4,0.024,0.05$, and 0.0007 for $A, B, C$, and $D$ respectively.

additives only. For example, fiber degradation may also be impaired in cows with a low rumen $\mathrm{pH}$, and measuring ${ }^{13} \mathrm{C}$ enrichment of $\mathrm{CO}_{2}$ in repeated spot samples of breath could then be a tool to detect individuals with suboptimal conditions for fiber fermentation.

Results presented here indicate that effects of a $\mathrm{CH}_{4}$-mitigating feed additive on fiber degradation in the rumen can be detected by evaluating the change in the diurnal pattern of ${ }^{13} \mathrm{C}$ enrichment of $\mathrm{CO}_{2}$. A prerequisite is that the main ration components differ in natural ${ }^{13} \mathrm{C}$ enrichment (e.g., C3 and C4 plants; Sudekum et al. 1995), and in content of the nutrients that are expected to be involved in a shift in fermentation (e.g., starch and fiber) or in degradability of a nutrient.

\section{ACKNOWLEDGMENTS}

This study is part of the 'Low Emission Animal Feed' project. Authors acknowledge financial support of the Dutch Ministry of Economic Affairs (The Hague, the Netherlands), Product Board Animal Feed (Zoetermeer, the Netherlands) and the Dutch Dairy Board (Zoetermeer, the Netherlands). 


\section{REFERENCES}

Boeckaert, C., V. Fievez, D. Van Hecke, W. Verstraete, and N. Boon. 2007. Changes in rumen biohydrogenation intermediates and ciliate protozoa diversity after algae supplementation to dairy cattle. Eur. J. Lipid Sci. Technol. 109:767-777.

Boeckaert, C., B. Vlaeminck, J. Dijkstra, A. Issa-Zacharia, T. Van Nespen, W. Van Straalen, and V. Fievez. 2008. Effect of dietary starch or micro algae supplementation on rumen fermentation and milk fatty acid composition of dairy cows. J. Dairy Sci. 91:4714-4727.

Gerrits, W.J.J., M.W. Bosch, and J.J.G.C. van den Borne. 2012. Quantifying resistant starch using novel, in vivo methodology and the energetic utilization of fermented starch in pigs. J. Nutr. 142: $238-244$.

Guyader, J., M. Eugène, B. Meunier, M. Doreau, D. P. Morgavi, M. Silberberg, Y. Rochette, C. Gerard, C. Loncke, and C. Martin. 2015. Additive methane-mitigating effect between linseed oil and nitrate fed to cattle. J. Anim. Sci. 93: 3564-3577.

Hegarty, R.S., and R. Gerdes. 1999. Hydrogen production and transfer in the rumen. Recent Adv. Anim. Nutr. Austr. 12:37-44.

Hristov, A. N., J. Oh, J. Firkins, J. Dijkstra, E. Kebreab, G. Waghorn, A. Adesogan, W. Yang, J. Tricarico, C. Lee, P. J. Gerber, B. Henderson, and H. P. S. Makkar. 2013. Mitigation of methane and nitrous oxide emissions from animal operations: I. A review of enteric methane mitigation options. J. Anim. Sci. 91:5045-5069.

Klop, G., B. Hatew, A. Bannink, and J. Dijkstra. 2016. Feeding nitrate and docosahexaenoic acid affects enteric methane production and milk fatty acid composition in lactating dairy cows. J. Dairy Sci. 99: 1161-1172.

Knobbe, K., J. Vogl, W. Pritzkow, U. Panne, H. Fry, H. M. Lochotzke, and A. Preiss-Weigert. 2006. C and $\mathrm{N}$ stable isotope variation in urine and milk of cattle depending on the diet. Anal. Bioanal. Chem. 386:104-108.

Latham, E.A., R.C. Anderson, W.E. Pinchak, and D.J. Nisbet. 2016. Insight on alterations to the rumen ecosystem by nitrate and nitrocompounds. Front. Microbiol. 7:228.

Lund, P., R. Dahl, H. J. Yang, A. L. F. Hellwing, B. B. Cao, and M. R. Weisbjerg. 2014. The acute effect of addition of nitrate on in vitro and in vivo methane emission in dairy cows. Anim. Prod. Sci. 54:1432-1435.

Marais, J. P., J. J. Therion, R. I. Mackie, A. Kistner, and C. Dennison. 1988. Effect of nitrate and its reduction products on the growth and activity of the rumen microbial population. Br. J. Nutr. 59:301-313. 
Moate P. J., S. R. O. Williams, M. C. Hannah, R. J. Eckard, M. J. Auldist, B. E. Ribaux, J. L. Jacobs, and W. J. Wales. 2013. Effects of feeding algal meal high in docosahexaenoic acid on feed intake, milk production, and methane emissions in dairy cows. J. Dairy Sci. 96:3177-3188.

Newbold, J. R., S. M. Van Zijderveld, R. B. A. Hulshof, W. B. Fokkink, R. A. Leng, P. Terencio, W. J. Powers, P. S. J. van Adrichem, N. D. Paton, and H. B. Perdok. 2014. The effect of incremental levels of dietary nitrate on methane emissions in Holstein steers and performance in Nelore bulls. J. Anim. Sci. 92:5032-5040.

Sudekum, K-H., W. Ziggers, N. Roos, H. Sick, S. Tamminga, and M. Stangassinger. 1995. Estimating 


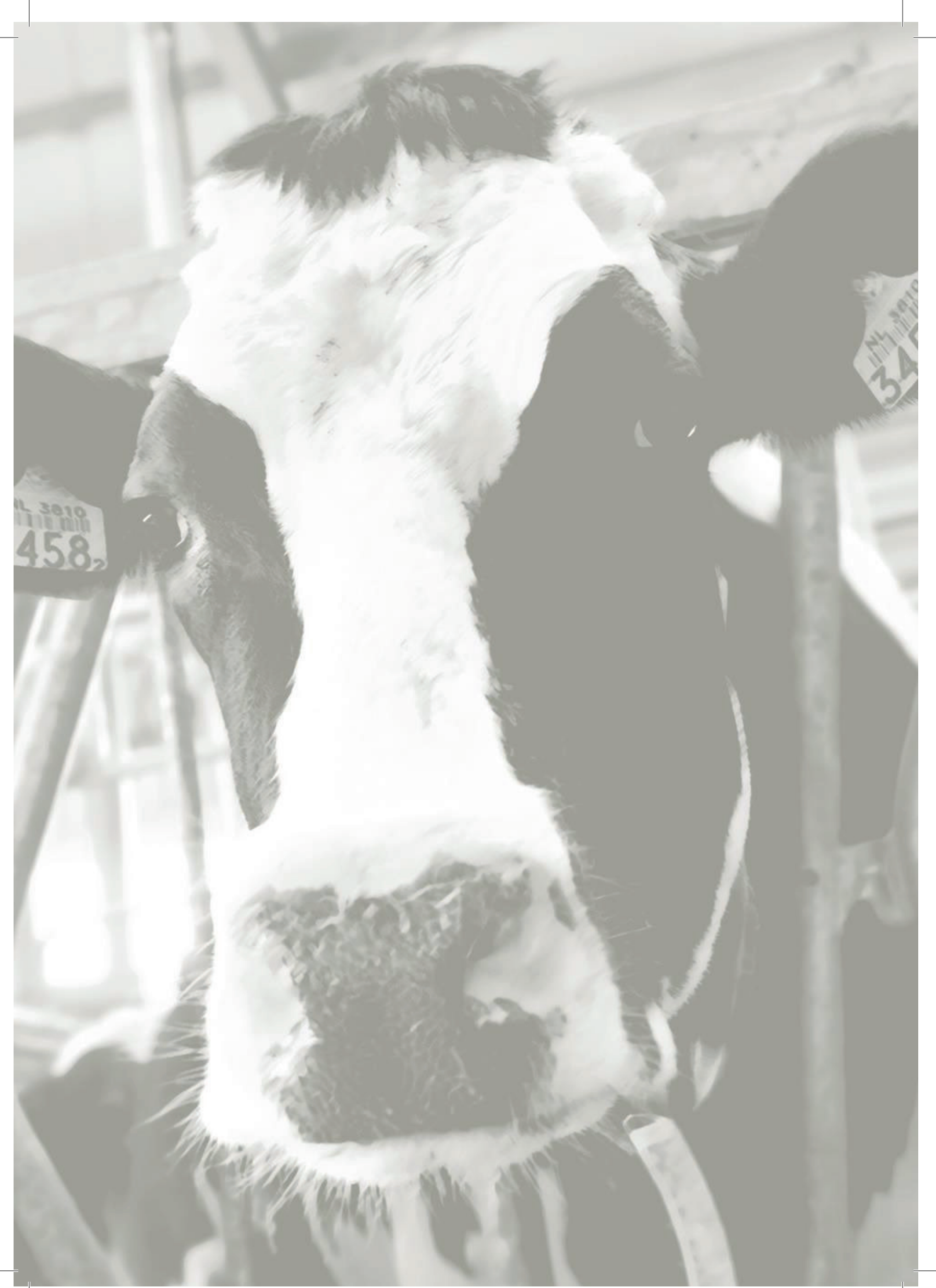




\section{Chapter 4}

\section{Changes in in vitro gas and methane production from rumen}

fluid from dairy cows during adaptation to feed additives in vivo

G. Klop*, S. van Laar-van Schuppen*, W.F. Pellikaan*, W.H. Hendriks*, A. Bannink ${ }^{\dagger}$ and J. Dijkstra* * Animal Nutrition Group, Wageningen University, PO Box 338, 6700 AH Wageningen, The Netherlands

${ }^{\dagger}$ Wageningen UR Livestock Research, PO Box 338, 6700 AH Wageningen, The Netherlands (A revised version is accepted for publication in ANIMAL) 


\begin{abstract}
The adaptation of dairy cows to methane $\left(\mathrm{CH}_{4}\right)$ mitigating feed additives was evaluated using the in vitro gas production (GP) technique. Nine rumen-fistulated lactating Holstein cows were grouped into three blocks and within blocks randomly assigned to one of three experimental diets: Control (CON; no feed additive), Agolin Ruminant (AR; 0.05 g/kg DM) or lauric acid (LA; $30 \mathrm{~g} / \mathrm{kg} \mathrm{DM})$. Total mixed rations composed of maize silage, grass silage and concentrate were fed in a 40:30:30 ratio on DM basis. Rumen fluid was collected from each cow at days $-4,1,4,8,15$ and 22 relative to the introduction of the additives in the diets. On each of these days, a $48 \mathrm{~h}$ GP experiment was performed in which rumen fluid from each donor cow was incubated with each of the three substrates that reflected the treatment diets offered to the cows. Dry matter intake was on average 19.8, 20.1, and $16.2 \mathrm{~kg} / \mathrm{d}$ with an average fat- and protein-corrected milk production of 30.7, 31.7, and $26.2 \mathrm{~kg} / \mathrm{d}$ with diet CON, AR, and LA, respectively. In general, feed additives in the donor cow diet had a larger effect on gas and $\mathrm{CH}_{4}$ production than the same additives in the incubation substrate. Incubation substrate affected asymptotic GP, half-time of asymptotic $\mathrm{CH}_{4}$ production, total volatile fatty acid (VFA) concentration, molar proportions of propionate and butyrate, and degradation of organic matter (OMD), but did not affect $\mathrm{CH}_{4}$ production. No substrate $x$ day interactions were observed. A significant diet $x$ day interaction was observed for in vitro gas and $\mathrm{CH}_{4}$ production, total volatile fatty acid (VFA) concentration, molar proportions of VFA and OMD. From day 4 onwards, the LA diet persistently reduced gas and $\mathrm{CH}_{4}$ production, total VFA concentration, acetate molar proportion and $\mathrm{OMD}$, and increased propionate molar proportion. In vitro $\mathrm{CH}_{4}$ production was reduced by the AR diet on day 8 , but not on days 15 and 22. In line with these findings, the molar proportion of propionate in fermentation fluid was higher, and that of acetate smaller, for the AR diet than for the CON diet on day 8, but not on days 15 and 22 . Overall, the data indicate a transient effect of $\mathrm{AR}$ on $\mathrm{CH}_{4}$ production, which may indicate microbial adaptation, whereas the $\mathrm{CH}_{4}$ mitigating effect of LA persisted.
\end{abstract}

Keywords: rumen fermentation, adaptation, essential oils, lauric acid, methane 


\section{IMPLICATIONS}

In vitro fermentation characteristics and methane production depend on the composition of the diet fed to donor animal, giving rise to inconsistent effects of additives in vitro. Feed additives in the donor cow diet had stronger effects on in vitro gas and methane production than the same additives in the incubation substrate. Over time, the extent of this effect was affected by the adaptation to a diet with essential oils, but not with lauric acid. These findings help to better understand adaptation to methane mitigating feeding strategies.

\section{INTRODUCTION}

Several feed additives may mitigate methane $\left(\mathrm{CH}_{4}\right)$ emissions from ruminants (Hristov et al. 2013). However, the rumen microbial ecosystem can adapt to feed additives, which results mostly in a transient decrease of $\mathrm{CH}_{4}$ production only. For example, promising results on $\mathrm{CH}_{4}$ reduction using essential oils or their active ingredients have been obtained using in vitro batch cultures, whereas no or only a temporary effect on fermentation characteristics was found in continuous cultures or in vivo (Benchaar and Greathead, 2011; Van Zijderveld et al., 2011). Cardozo et al. (2004) reported a transient effect of plant extracts on fermentation characteristics that disappeared after six days. The latter indicates that microbial adaptation can occur after short term exposure. The response in $\mathrm{CH}_{4}$ production to plant extracts evaluated in vitro may also vary with composition of the diet consumed by the donor animals (O'Brien et al., 2014), as diet composition affects the microbial activity in rumen inoculum.

In broilers, shuttle programmes with two or more anticoccidial compounds, usually with different modes of action, are widely used to reduce resistance of protozoan parasites (Chapman 2001). Similarly, the alternating use of two or more $\mathrm{CH}_{4}$ reducing feed additives with a different mode of action may alleviate the problem of microbial adaptation in the rumen. If successful, a persistently lower $\mathrm{CH}_{4}$ production could be achieved without the requisite for a persistent $\mathrm{CH}_{4}$ reduction by a single feed additive. Before testing this concept in vivo, more information is needed on the duration and persistency of the $\mathrm{CH}_{4}$ 
reducing effect of the selected additives. The present study, therefore, examined the adaptation of dairy cows to $\mathrm{CH}_{4}$ reducing feed additives that have different modes of action in vivo, using the in vitro gas production (GP) technique.

\section{MATERIALS AND METHODS}

\section{Animals, diets and feeding}

All experimental procedures were approved by the Animal Care and Use Committee of Wageningen University (Wageningen, The Netherlands). Nine rumen cannulated, second parity cows (105 $\pm 6.5 \mathrm{DIM}$; mean \pm S.D. at the start of the experiment) were assigned to three blocks based on milk yield. Within blocks, cows were randomly assigned to one of three diets: Control (CON; no feed additive), Agolin Ruminant (Agolin SA, Bière, Switzerland; AR; $0.05 \mathrm{~g} / \mathrm{kg}$ DM) or lauric acid (C12:0) (Sigma Aldrich, Zwijndrecht, the Netherlands; LA; $30 \mathrm{~g} / \mathrm{kg}$ DM). Agolin Ruminant contains $0.2 \mathrm{~g}$ essential oils/g product (Castro-Montoya et al., 2015) with eugenol, geranyl acetate and coriander oil being the main components.

Additives were included in the concentrate meals (Table 4.1). The CON concentrate was composed of maize $(310 \mathrm{~g} / \mathrm{kg})$, maize gluten feed $(140 \mathrm{~g} / \mathrm{kg})$, rapeseed meal $(94 \mathrm{~g} / \mathrm{kg})$, soybean meal ( $90 \mathrm{~g} / \mathrm{kg}$ ), rumen-protected soybean meal (formaldehyde-treated; $86 \mathrm{~g} / \mathrm{kg}$ ), beet pulp $(75 \mathrm{~g} / \mathrm{kg})$, palm kernel expeller $(70 \mathrm{~g} / \mathrm{kg})$, rumen-protected rapeseed meal (formaldehyde-treated; $57 \mathrm{~g} / \mathrm{kg}$ ), cane molasses (40 g/kg), limestone (13 g/ $\mathrm{kg}$ ), soybean hulls $(10 \mathrm{~g} / \mathrm{kg})$, vitamin and mineral premix $(8 \mathrm{~g} / \mathrm{kg})$, salt $(3.6 \mathrm{~g} / \mathrm{kg})$, sodium bicarbonate $(2.5 \mathrm{~g} / \mathrm{kg})$, and magnesium oxide $(1.5 \mathrm{~g} / \mathrm{kg})$. Given the low inclusion level of Agolin Ruminant the ingredient composition of AR concentrate was the same as of the CON concentrate. Agolin Ruminant was first homogenously mixed with other ingredients, before it was included in the large concentrate mixture. In the LA concentrate, ingredients were proportionally exchanged against C12:0, except for the minerals and the vitamin and mineral premix, which were kept at the same level as in the other two concentrates. Before introduction of the additives in the diets, cows were adapted for a period of $19 \mathrm{~d}$ to a total mixed ration (TMR) that consisted of grass silage, maize silage and CON concentrate in a 30:40:30 ratio on a DM basis. During the first seven days of this period, 
animals were housed in a freestall barn. Thereafter, cows were individually housed in tiestalls to determine dry matter intake (DMI) of each cow. Feed was supplied in equal portions at 0600 and $1600 \mathrm{~h}$. A mixture of grass silage and maize silage was prepared twice weekly and stored in a cooled room $\left( \pm 7^{\circ} \mathrm{C}\right)$. The concentrate was weighed separately into buckets and manually mixed into the roughage mixture at the moment of feeding. After five days in the tie-stalls, feed supply to each cow was restricted to $95 \%$ of voluntary to minimize the risk of feed refusals during the experiment. For cows assigned to either the AR or LA diet, the CON concentrate in the TMR was replaced by the respective treatment concentrate from day 12 in the tie-stalls onwards.

\section{Sampling and analyses of TMR, substrate components and milk}

Representative samples of all individual TMR components were collected at the moments of feed preparation prior to one of the six rumen fluid collection days. The average DMI per time point was calculated based on the two days prior to rumen fluid collection. Milk samples of four milkings prior to each rumen fluid collection day were collected from all cows and analysed for fat, protein and lactose according to Hatew et al. (2015a). Fat and protein corrected milk yield (FPCM; $\mathrm{kg} / \mathrm{d})$ was calculated as $(0.337+0.116 \times$ fat $\%+0.06 \times$ protein\%) × milk yield (kg/d) $(\mathrm{CVB}, 2008)$.

Samples of TMR components, incubation substrate components, and orts were analysed for chemical composition as described by Klop et al. (2016) except for crude fat analysis, which was based on NEN-ISO 1735 (ISO, 2004). A modification to the standard procedure was that samples were hydrolysed with hydrochloric acid at $75^{\circ} \mathrm{C}$ and subsequently, the solution containing hydrochloric acid and ethanol was extracted with diethyl ether and petroleum ether. Solvents were removed by distillation before the mass of the extracted material was determined. 


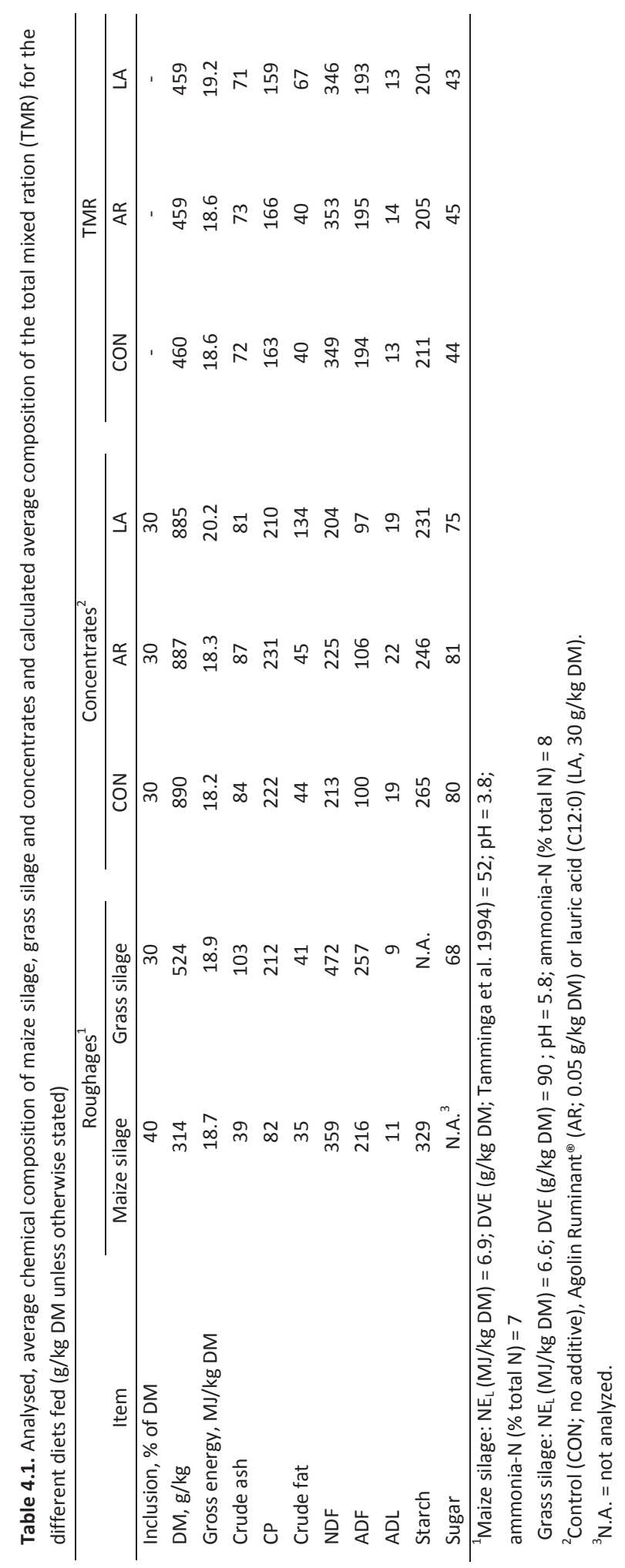




\section{Rumen fluid, in vitro gas production equipment and methods of incubation}

Rumen fluid from each cow was collected just before morning feeding in pre-warmed thermos flasks filled with $\mathrm{CO}_{2}$ as described by Hatew et al. (2015a) on days $-4,1,4,8,15$ and 22 relative to the introduction of the additives in the diets. Volatile fatty acid (VFA) concentrations were determined in a subsample of strained rumen fluid from each cow. The equipment described by Pellikaan et al. (2011) was used to determine in vitro gas and $\mathrm{CH}_{4}$ production. Rumen fluid from individual cows was used as inoculum and after straining through cheesecloths, mixed with a pre-warmed, semi-defined incubation medium (medium B; Lowe et al., 1985 as modified by Williams et al., 2005). Each bottle contained $84 \mathrm{~mL}$ of incubation medium mixed with $5 \mathrm{~mL}$ of filtrated rumen fluid. Bottles were directly placed into a shaking water bath (Haake SWB25, Clausthal-Zellerfeld, Germany) at $39^{\circ} \mathrm{C}$, connected to the automated GP system.

The incubation substrates $(0.5 \mathrm{~g})$ were a TMR of grass silage, maize silage and one of the three concentrates at a 30:40:30 ratio on a DM basis. Silages were dried at $60^{\circ} \mathrm{C}$ and all components were ground to pass a 1-mm screen before incubation. The three different substrate components were weighed separately into each bottle and originated from the same batches that were fed to the animals (Table 4.1). In each of the six runs, 90 bottles were incubated for $48 \mathrm{~h}$. Total GP was continuously measured in triplicate and $\mathrm{CH}_{4}$ concentration was measured in duplicate at $2,4,6,8,10,12,14,16,24,36$, and $48 \mathrm{~h}$ of incubation for all inoculum $\times$ substrate combinations.

\section{Sampling and analyses of fermentation fluid and gas}

Methane was determined using gas chromatography (see Ellis et al., 2016 for details). At the end of each $48 \mathrm{~h}$ incubation, bottles were placed on ice and a subsample $(0.6 \mathrm{~mL})$ of fermentation fluid was mixed with an equal volume of ortho-phosphoric acid, containing isocaproic acid as internal standard, and stored at $-20^{\circ} \mathrm{C}$ pending VFA analysis. The VFA were separated by gas chromatography using a $30 \mathrm{~m} \times 0.53 \mathrm{~mm} \times 1.0 \mu \mathrm{m}$ Agilent J\&W HPFFAP (Santa Clara, USA) column, hydrogen as mobile phase and a flame ionization detector. The residual incubation substrates were analysed for DM and ash following Williams et al. (2005) to calculate organic matter degradation (OMD). 


\section{Calculations and curve fitting}

For all analyses, the experimental unit was the average of the replicate bottles for each inoculum $\times$ substrate combination. Triplicates for each inoculum $\times$ substrate combination were visually explored for outliers. In the second run (day 1 after introduction of additives in the diets), gas data from two out of eight units of the automated GP system had to be excluded because of a technical problem. For three diet $\times$ substrate combinations (CON $\times$ $L A, A R \times A R$, and $A R \times L A)$, the gas and $\mathrm{CH}_{4}$ results of the second run are therefore based on rumen fluid from two instead of three cows.

Cumulative gas and $\mathrm{CH}_{4}$ production data were fitted with the following monophasic Michaelis-Menten equation (Groot et al., 1996) using the NLIN procedure in SAS (SAS 9.2, SAS Inst. Inc., Cary, NC):

$$
G=A /\left[1+(C / t)^{B}\right]
$$

where $\mathrm{G}(\mathrm{mL} / \mathrm{g}$ organic matter $(\mathrm{OM}))$ is the cumulative amount of gas or $\mathrm{CH}_{4}$ produced, $\mathrm{A}$ is the asymptotic $G(\mathrm{~mL} / \mathrm{g} O M), B$ is the switching characteristic of the curve, $C$ is the time at which half of the asymptotic $G$ has been reached (half-time, $h$ ) and $t$ is the time during the in vitro incubation (h). Measured $\mathrm{CH}_{4}$ concentrations in individual bottles were expressed relative to the maximum concentration in each bottle and fitted with the monophasic Michaelis-Menten model, with further details presented by Pellikaan et al. (2011).

Unlike the model estimated kinetic parameters for gas- and $\mathrm{CH}_{4}$ production, VFA concentration and OMD are endpoint measurements only. As technical issues with the recording of gas and $\mathrm{CH}_{4}$ do not affect these parameters, no VFA and OMD data were excluded.

\section{Statistical analysis}

All data were analysed using PROC MIXED (SAS 9.2, SAS Inst. Inc., Cary, NC). Two-day averages of individual cow data for DMI, milk production and milk composition at each incubation day $(-4,1,4,8,15$ or 22 d relative to the introduction of the additives in the 
diets) were analysed using a model containing block, diet, day and diet $\times$ day interaction as fixed effects. Repeated measures for each cow $\times$ diet combination were accounted for. Data on gas and $\mathrm{CH}_{4}$ production parameter estimates, VFA and OMD for each cow $\times$ diet $\times$ substrate combination were averaged per incubation day and analysed using repeated measures ANOVA. Block and the main effects of diet, substrate and day and their interactions were included as fixed effects. In all statistical analyses, a spatial power (SP(POW)) covariance structure was fitted, because of unequal time intervals between incubation days. Denominator degrees of freedom were estimated using the KenwardRoger method. In case of significant interaction terms, between-treatment comparisons for each incubation day were made using a SLICE statement and $P$-values were corrected using the Tukey-Kramer method. Results are reported as least squares means. Significance of effects was declared at $P \leq 0.05$ and trends at $0.05<P \leq 0.10$.

\section{RESULTS AND DISCUSSION}

The objective of this study was to examine adaptation to $\mathrm{CH}_{4}$ mitigating feed additives with different modes of action in vivo using the in vitro GP technique. The selection of Agolin Ruminant and C12:0 as feed additives for the present study was based on a pilot study (data not shown) in which the following substrates were screened for their potential to reduce $\mathrm{CH}_{4}$ production in vitro: Agolin Ruminant ${ }^{\circ} \mathrm{C} 12: 0$, activated charcoal, L-ascorbic acid, coconut oil, krabok oil, and myristic acid (C14:0). The additive selection for the pilot study was based on recent literature (Benchaar and Greathead, 2011; Hansen et al. 2012; O’Brien et al. 2014; Panyakaew et al. 2013) and unpublished data from our research group.

\section{Dry matter intake and milk yield}

Dry matter intake was similar for all treatments on days -4 and 1 . From day 4 onwards, DMI of LA cows was significantly lower than for CON and AR, which resulted in a significant treatment $x$ day interaction for DMI (Table 4.2). A DMI depression after supplementation with medium-chain fatty acids (MCFA) is frequently reported in literature. As discussed by Faciola and Broderick (2014), dosage, delivery method and characteristics of the basal diet all affect the DMI response to C12:0, and comparison of 
effect of doses among experiments is, therefore, complicated. In their study, $13 \mathrm{~g}$ C12:0/kg DM did not affect DMI, but did reduce total tract digestibility of NDF. Dohme et al. (2001) found that MCFA, in particular C10:0 and C12:0, supplemented at $50 \mathrm{~g} / \mathrm{kg} \mathrm{DM}$, negatively affected NDF degradation using the rumen simulation technique (RUSITEC). A treatment $\times$ day interaction was also observed for FPCM yield, which declined from day 8 onwards in cows receiving the LA diet. Based on the extent of the observed milk fat depression, it is likely that not only the lower DMI, but also impaired fibre digestion contributed to the lower FPCM yield of LA cows.

\section{In vitro gas and $\mathrm{CH}_{4}$ production}

The asymptotic GP ( $\mathrm{mL} / \mathrm{g}$ OM incubated) was lower for the LA substrate, but did not differ between $A R$ and CON substrate (Table 4.3). No substrate $x$ day or substrate $\times$ diet interactions were found (except for a substrate $x$ diet interaction for GP halftime), indicating that the effect of the LA substrate on GP was largely constant throughout the experiment and independent of the effect of donor cow diets. The halftime of $\mathrm{CH}_{4}$

production ( $\mathrm{mL} / \mathrm{g} \mathrm{OM}$ incubated), but not the asymptotic $\mathrm{CH}_{4}$ production, was affected by substrate (Table 4.4). The effect of donor cow diet on gas and $\mathrm{CH}_{4}$ production varied after introduction of an additive in the diet, which resulted in a significant diet $\times$ day interaction. Using rumen fluid at day -4 from cows assigned to the AR diet resulted in a lower $(P=0.003)$ gas production compared to cows assigned to the LA diet. This difference on day -4 was unexpected, because all cows received the same basal diet. However, no between diet differences were observed on day 1 (less than $24 \mathrm{~h}$ after introduction of the additives in the diets).

From day 4 onwards, the LA diet always resulted in a lower $(P \leq 0.05)$ gas and $\mathrm{CH}_{4}$ production than the CON or AR diet. The findings of Zhou et al. (2013) using pure ruminal Methanobrevibacter ruminantium cell suspensions support such a delay in the effect of C12:0. A significant effect of C12:0 on survival was observed after $3 \mathrm{~h}$, and after $24 \mathrm{~h}$ almost all M. ruminantium cells were dead, which indicates a delay in the effect of C12:0 on cell death. Results of the present study indicate that similar effects may be present in a mixed culture environment. 
Table 4.2. Average dry matter intake (DMI), milk production and milk composition of dairy cattle fed the control $\operatorname{diet}(\mathrm{CON})$ or a diet with Agolin Ruminant ${ }^{\circ}$ (AR) or lauric acid (LA) as feed additives

\begin{tabular}{|c|c|c|c|c|c|c|c|}
\hline \multirow[t]{2}{*}{ Item } & \multicolumn{3}{|c|}{$\operatorname{Diet}^{1}$} & \multirow[b]{2}{*}{ SEM } & \multicolumn{3}{|c|}{$P$-value } \\
\hline & CON & AR & LA & & Treatment & Day $^{2}$ & Treatment×Day \\
\hline $\mathrm{DMI}, \mathrm{kg} / \mathrm{d}$ & 19.8 & 20.1 & 16.2 & 0.45 & 0.003 & $<0.001$ & $<0.001$ \\
\hline Milk, kg/d & 30.0 & 30.8 & 28.9 & 0.94 & 0.426 & $<0.001$ & $<0.001$ \\
\hline $\mathrm{FPCM}, \mathrm{kg} / \mathrm{d}$ & 30.7 & 31.7 & 26.2 & 1.00 & 0.019 & $<0.001$ & $<0.001$ \\
\hline Fat, $\mathrm{g} / \mathrm{kg}$ & 41.8 & 42.6 & 32.5 & 2.09 & 0.025 & 0.716 & 0.032 \\
\hline Protein, g/kg & 34.5 & 33.0 & 31.1 & 1.38 & 0.333 & 0.065 & 0.079 \\
\hline Lactose, $\mathrm{g} / \mathrm{kg}$ & 46.7 & 45.6 & 44.2 & 0.95 & 0.292 & 0.013 & 0.024 \\
\hline
\end{tabular}

FPCM = fat- and protein-corrected milk; SEM = standard error of the mean.

${ }^{1} \mathrm{CON}$ (no additive), Agolin Ruminant ${ }^{\circledast}$ (AR; $0.05 \mathrm{~g} / \mathrm{kg} \mathrm{DM}$ ) or lauric acid (C12:0) (LA; $30 \mathrm{~g} / \mathrm{kg} \mathrm{DM).}$

${ }^{2}$ Relates to each day an in vitro run was conducted $(-4,1,8,15$ and 22 days relative to the introduction of the additives in the diets).

Asymptotic gas and $\mathrm{CH}_{4}$ production from rumen fluid of cows on the AR diet differed $(P \leq$ 0.05 ) from that of cows on the CON diet on day 8 but not on days 15 and 22. The latter observation may indicate adaptation to effects of AR in the diet. A tendency for a reduced $\mathrm{CH}_{4}$ production in $\mathrm{g} / \mathrm{d}$ and $\mathrm{g} / \mathrm{kg} \mathrm{DMI}$ in dairy cows, but not in beef cattle, fed $1.0 \mathrm{~g}$ Agolin Ruminant per day was reported by Castro Montoya et al. (2015). One of the components of Agolin Ruminant is eugenol, a phenolic compound that has antimicrobial effects on gram-positive and gram-negative bacteria (Calsamiglia et al., 2007). In a dose response experiment, eugenol did not affect in vivo $\mathrm{CH}_{4}$ production of dairy cattle (Benchaar et al., 2015). In the latter study, the $\mathrm{CH}_{4}$ measurement period was preceded by an 18-day adaptation period to the experimental diets. Based on the observations in the present study, the absence of an effect of eugenol in the experiment of Benchaar et al. (2015) may be a result of adaptation to the additive. In an in vitro study of Durmic et al. (2013), Agolin Ruminant significantly reduced $\mathrm{CH}_{4}$ production $(\mathrm{mL} / \mathrm{g} \mathrm{DM}$ ) by almost $30 \%$ when added to rumen fluid from non-adapted sheep at a 10 -fold higher dose $(0.1 \mathrm{mg} / \mathrm{g}$ substrate) than used in the present experiment. In contrast to such observations, Pirondini et al. (2015) found no effect of Agolin Ruminant on in vitro $\mathrm{CH}_{4}$ production using rumen fluid from non-adapted cows. The dose of Agolin Ruminant was similar to the dose used in the present study, but it was dissolved in ethanol before incubation. This was not done in the present experiment, as this would not mimic in vivo conditions. 
Effects of additives on gas and $\mathrm{CH}_{4}$ production may appear at initial stages of in vitro fermentation only, and be absent at the end of the incubation (48-h) (Ellis et al., 2016). Endpoint in vitro measurements may not reflect substrate degradation and gas and $\mathrm{CH}_{4}$ production in vivo because retention time of feed in the rumen may differ from the endpoint retention time in vitro. Therefore, we examined the in vitro $\mathrm{CH}_{4}$ to total gas ratio after $12 \mathrm{~h}$ incubation for all diet $\times$ substrate combinations on all six measurement days (Figure 4.1). The numerical difference between the CON and AR diet was larger on day 8 than on days 15 and 22, but variation was also large and therefore the difference was not significant $(P=0.112)$. Compared to days -4 and 1 , the $\mathrm{CH}_{4}$ to total gas ratio with the $\mathrm{LA}$ diet was significantly reduced from day 4 onwards, to almost zero at day 8 , and to increase again on days 15 and 22. The difference in $\mathrm{CH}_{4}$ to total gas ratio between day 8 on the one hand and day 15 or day 22 on the other hand is not significant, indicating that for the duration of the present trial (22 days) the $\mathrm{CH}_{4}$ reducing effect of $\mathrm{C} 12: 0$ in the diet persisted. The higher half-time for $\mathrm{CH}_{4}$ production from the LA diet at day 8 compared with day 15 , but not when compared with day 22 , may indicate that the $\mathrm{CH}_{4}$ depressing effect is not fully persistent.

Results on $\mathrm{CH}_{4}$ production in vitro should be interpreted with care and may not reflect the in vivo situation (Flachowsky and Lebzien, 2012). The relationship between in vitro and in vivo $\mathrm{CH}_{4}$ production may also depend on the units of expression of $\mathrm{CH}_{4}$ production. In an experiment in which rumen inocula was obtained from dairy cattle adapted to the same experimental diet as incubated in vitro, Hatew et al. (2015b) reported $\mathrm{CH}_{4}$ production in vitro ( $\mathrm{mL}$ per g OM incubated) to be moderately related $\left(\mathrm{R}^{2}=0.54\right)$ with in vivo $\mathrm{CH}_{4}$ production ( $\mathrm{mL}$ per $\mathrm{g}$ of estimated rumen-fermentable OM). However, no association was found when in vivo $\mathrm{CH}_{4}$ production was expressed per unit of ingested $\mathrm{OM}\left(\mathrm{R}^{2}=0.05\right)$. Thus, even inoculum obtained from specifically adapted animals may still lead to large differences between $\mathrm{CH}_{4}$ production observed in vitro and in vivo. 


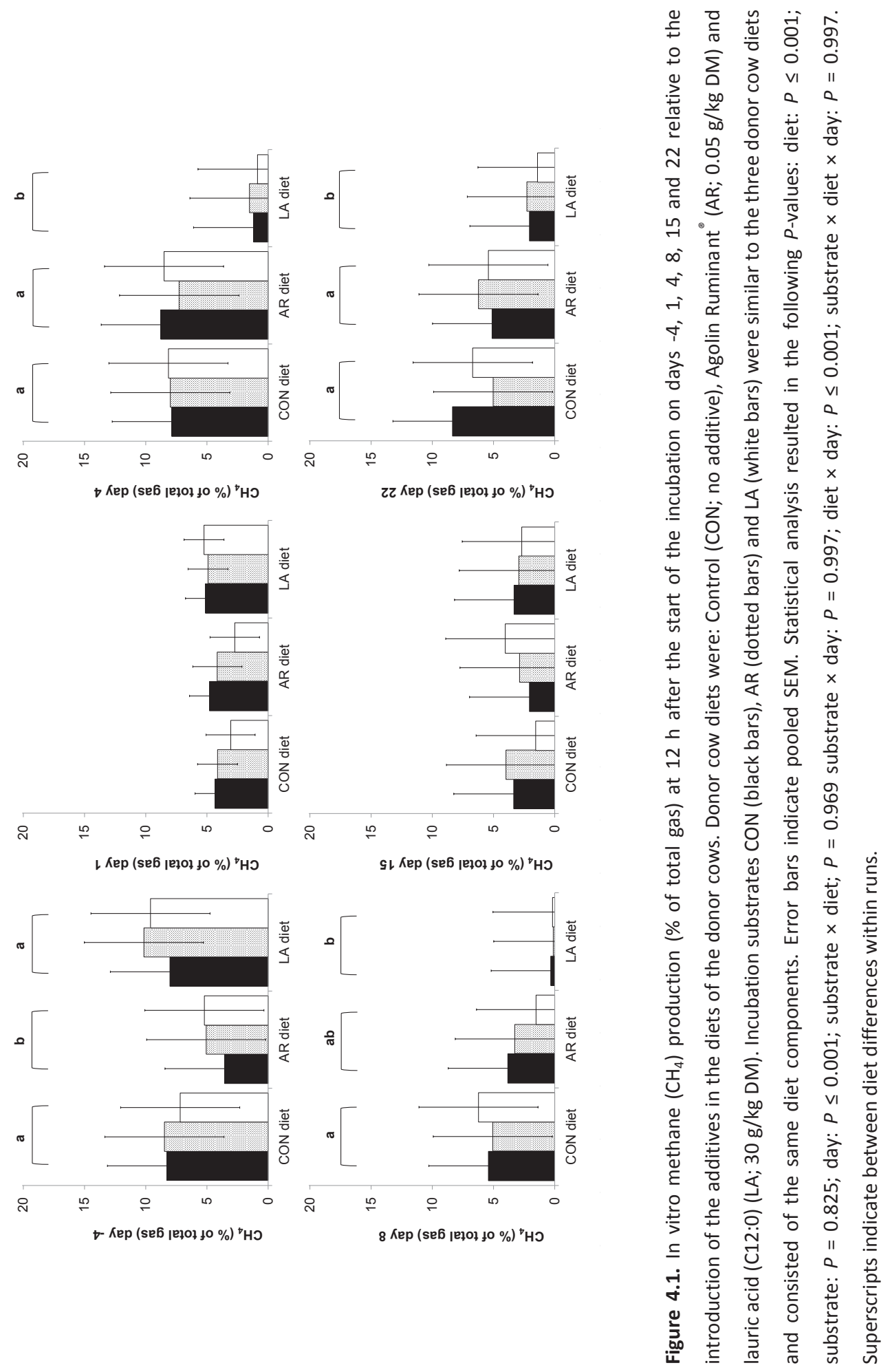


Table 4.3. Average gas production curve fit parameters for each combination of donor cow diet (top row) and incubation substrate (second row) during $48 \mathrm{~h}$ incubations at $-4,1,4,8,15$, and 22 days relative to the introduction of the additives in the diets of the donor cows. Composition of the incubation substrates (g/kg DM) was similar to the experimental diets: Control (CON), Agolin Ruminant (AR; $0.05 \mathrm{~g} / \mathrm{kg} \mathrm{DM}$ ) or lauric acid (LA, 30 $\mathrm{g} / \mathrm{kg} \mathrm{DM})$

\begin{tabular}{|c|c|c|c|c|c|c|c|c|c|}
\hline \multirow[b]{2}{*}{ Substrate } & \multicolumn{3}{|c|}{ Donor cow diet CON } & \multicolumn{3}{|c|}{ Donor cow diet AR } & \multicolumn{3}{|c|}{ Donor cow diet LA } \\
\hline & CON & $A R$ & LA & CON & AR & LA & $\mathrm{CON}$ & AR & LA \\
\hline \multicolumn{10}{|c|}{$\mathrm{A}^{1}, \mathrm{~mL} / \mathrm{g}$ organic matter } \\
\hline Day -4 & $329.1^{a b}$ & $335.7^{\mathrm{ab}}$ & $292.1^{\mathrm{ab}}$ & $291.1^{\mathrm{a}}$ & $296.2^{\mathrm{a}}$ & $281.7^{\mathrm{a}}$ & $342.2^{b}$ & $327.0^{\mathrm{b}}$ & $330.2^{b}$ \\
\hline Day 1 & 310.3 & 285.4 & 279.7 & 327.5 & 315.6 & 302.9 & 334.2 & 331.4 & 305.7 \\
\hline Day 4 & $338.6^{b}$ & $324.3^{b}$ & $311.7^{b}$ & $316.0^{b}$ & $316.7^{b}$ & $312.0^{\mathrm{b}}$ & $280.5^{\mathrm{a}}$ & $267.2^{\mathrm{a}}$ & $252.1^{\mathrm{a}}$ \\
\hline Day 8 & $314.3^{c}$ & $308.4^{c}$ & $285.0^{c}$ & $275.5^{\mathrm{b}}$ & $277.2^{\mathrm{b}}$ & $221.5^{\mathrm{b}}$ & $221.2^{\mathrm{a}}$ & $206.9^{a}$ & $195.7^{\mathrm{a}}$ \\
\hline Day 15 & $296.7^{b}$ & $296.5^{b}$ & $255.3^{\mathrm{b}}$ & $292.8^{\mathrm{b}}$ & $299.5^{\mathrm{b}}$ & $292.2^{\mathrm{b}}$ & $249.2^{\mathrm{a}}$ & $251.7^{\mathrm{a}}$ & $227.2^{\mathrm{a}}$ \\
\hline Day 22 & $303.9^{b}$ & $303.0^{\mathrm{b}}$ & $273.2^{\mathrm{b}}$ & $303.6^{\mathrm{b}}$ & $308.7^{b}$ & $252.5^{\mathrm{b}}$ & $248.9^{\mathrm{a}}$ & $246.4^{\mathrm{a}}$ & $246.5^{\mathrm{a}}$ \\
\hline \multicolumn{10}{|l|}{$B^{2}$} \\
\hline Day -4 & 1.92 & 1.94 & 1.76 & 2.13 & 2.02 & 1.93 & 1.77 & 1.88 & 1.79 \\
\hline Day 1 & $1.93^{b}$ & $1.98^{\mathrm{b}}$ & $1.88^{\mathrm{b}}$ & $1.84^{b}$ & $1.85^{b}$ & $1.51^{b}$ & $1.28^{\mathrm{a}}$ & $1.28^{\mathrm{a}}$ & $1.33^{\mathrm{a}}$ \\
\hline Day 4 & 1.78 & 1.78 & 1.62 & 1.91 & 1.87 & 1.79 & 1.63 & 1.66 & 1.70 \\
\hline Day 8 & $1.77^{\mathrm{a}}$ & $1.81^{\mathrm{a}}$ & $1.73^{\mathrm{a}}$ & $2.15^{\mathrm{b}}$ & $2.12^{b}$ & $2.23^{b}$ & $1.96^{b}$ & $2.18^{b}$ & $2.25^{b}$ \\
\hline Day 15 & 1.84 & 1.67 & 1.94 & 1.97 & 1.98 & 1.76 & 1.96 & 1.86 & 1.92 \\
\hline Day 22 & 1.70 & 1.69 & 1.56 & 1.76 & 1.74 & 1.70 & 1.57 & 1.60 & 1.42 \\
\hline \multicolumn{10}{|l|}{$\mathrm{C}^{3}, \mathrm{~h}$} \\
\hline Day -4 & 11.6 & 11.5 & 11.4 & 11.4 & 11.5 & 11.6 & 12.3 & 11.0 & 12.1 \\
\hline Day 1 & $11.9^{\mathrm{ab}}$ & $11.7^{\mathrm{ab}}$ & $11.5^{\mathrm{ab}}$ & $12.2^{\mathrm{b}}$ & $12.4^{\mathrm{b}}$ & $13.6^{b}$ & $12.1^{\mathrm{a}}$ & $11.8^{\mathrm{a}}$ & $10.4^{a}$ \\
\hline Day 4 & $10.4^{b}$ & $10.3^{b}$ & $10.9^{b}$ & $10.3^{b}$ & $10.7^{\mathrm{b}}$ & $10.8^{b}$ & $9.8^{\mathrm{a}}$ & $9.6^{a}$ & $8.6^{a}$ \\
\hline Day 8 & $11.2^{\mathrm{b}}$ & $11.1^{b}$ & $10.9^{b}$ & $11.5^{\mathrm{b}}$ & $12.1^{b}$ & $12.0^{b}$ & $9.8^{\mathrm{a}}$ & $9.6^{\mathrm{a}}$ & $9.1^{a}$ \\
\hline Day 15 & 11.3 & 11.7 & 10.3 & 11.1 & 11.1 & 11.3 & 12.0 & 11.8 & 10.3 \\
\hline \multirow[t]{2}{*}{ Day 22} & 10.9 & 11.3 & 11.3 & 10.9 & 11.3 & 11.6 & 10.5 & 10.3 & 10.8 \\
\hline & \multicolumn{9}{|c|}{$P$-Value ${ }^{4}$} \\
\hline Paramet & Substrate & Donor & & & $b^{5} \times$ Diet & Sub×Day & Diet> & Day & oled SEM \\
\hline$A$ & $<0.001$ & $<0.001$ & & 001 & 0.815 & 0.980 & & 001 & 15.99 \\
\hline B & 0.382 & 0.003 & & 001 & 0.671 & 0.923 & & 001 & 0.136 \\
\hline C & 0.559 & $<0.001$ & & 001 & 0.009 & 0.696 & & 001 & 0.52 \\
\hline
\end{tabular}

${ }^{1} \mathrm{~A}=$ Asymptotic gas production, $\mathrm{mL} / \mathrm{g}$ organic matter incubated.

${ }^{2} \mathrm{~B}=$ Switching characteristic of the curve.

${ }^{3} \mathrm{C}=$ Time at which half of the asymptotic gas production has been reached (half-time).

${ }^{4} P$-value for Substrate $\times$ Diet $\times$ Day interaction non-significant $(P>0.05)$ and not presented.

${ }^{5} \mathrm{Sub}=$ substrate.

${ }^{\mathrm{ab}}$ Superscripts indicate significance of diet $x$ day interaction term. Diets within rows with different superscripts are significantly $(P \leq 0.05)$ different from each other. 
Table 4.4. Average gas production curve fit parameters of methane $\left(\mathrm{CH}_{4}\right)$ production for each combination of donor cow diet (top row) and incubation substrate (second row) during $48 \mathrm{~h}$ incubations at -4, 1, 4, 8, 15, and 22 days relative to the introduction of the additives in the diets of the donor cows. Composition of the incubation substrates (g/kg DM) was similar to the experimental diets: Control (CON), Agolin Ruminant (AR; $0.05 \mathrm{~g} / \mathrm{kg} \mathrm{DM}$ ) or lauric acid (LA, $30 \mathrm{~g} / \mathrm{kg}$ DM)

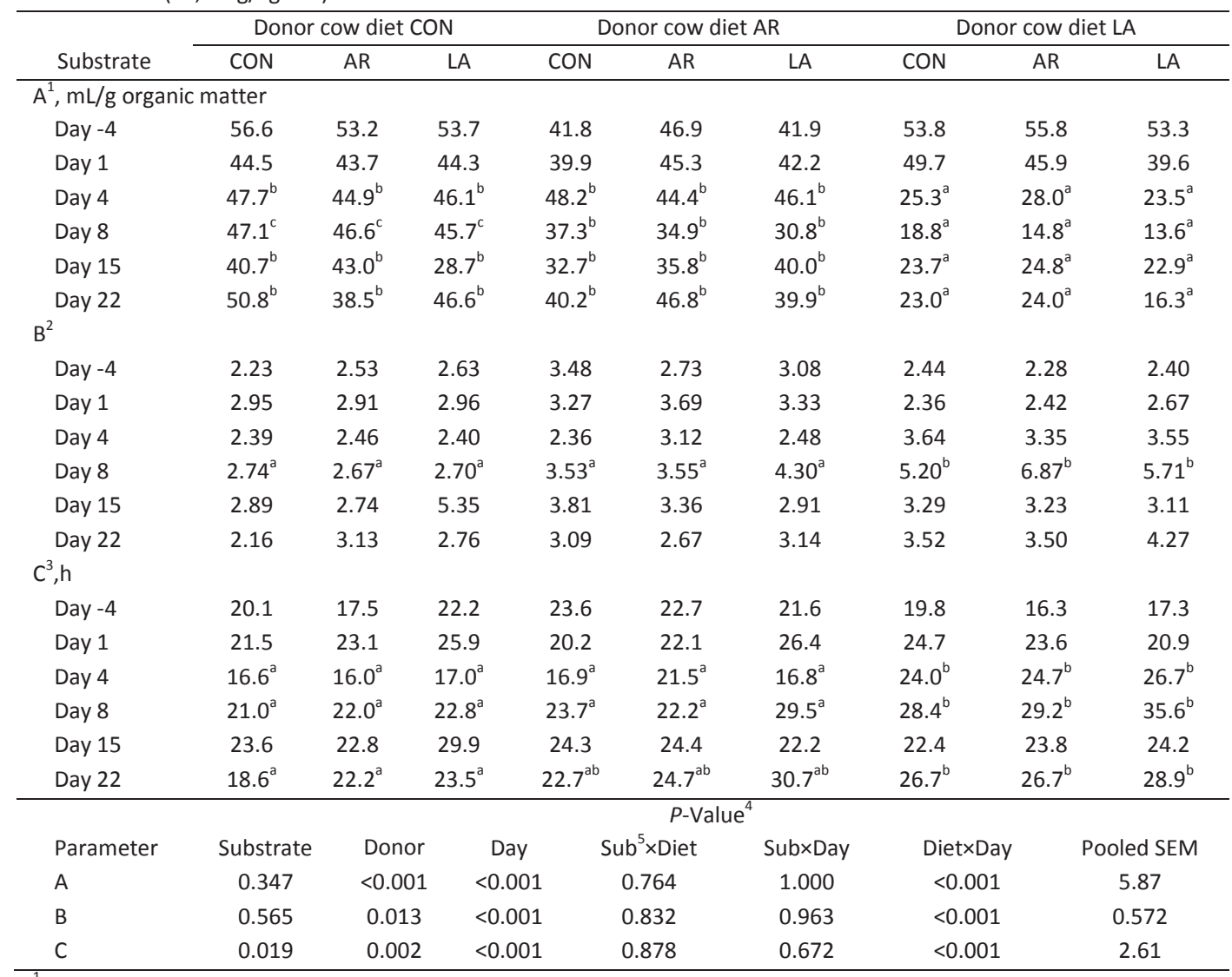

${ }^{1} \mathrm{~A}=$ Asymptotic gas production.

${ }^{2} \mathrm{~B}=$ Switching characteristic of the curve.

${ }^{3} \mathrm{C}=$ Time at which half of the asymptotic gas production has been reached (half-time).

${ }^{4} P$-value for Substrate $\times$ Diet $\times$ Day interaction non-significant $(P>0.05)$ and not presented.

${ }^{5} \mathrm{Sub}=$ substrate.

${ }^{\mathrm{ab}}$ Superscripts indicate significance of diet $\times$ day interaction term. Diets within rows, with different superscripts are significantly $(P \leq 0.05)$ different from each other. 
Table 4.5. Average concentrations and molar proportions of volatile fatty acids (VFA) in fermentation fluid for each combination of donor cow diet (top row) and incubation substrate (second row) at the end of $48 \mathrm{~h}$ incubations at $-4,1,4,8,15$, and 22 days relative to the introduction of the additives in the diets of the donor cows. Composition of the incubation substrates $(\mathrm{g} / \mathrm{kg}$ dry $\mathrm{DM})$ was similar to the experimental diets: Control (CON), Agolin Ruminant (AR; $0.05 \mathrm{~g} / \mathrm{kg}$ DM) or lauric acid (LA, $30 \mathrm{~g} / \mathrm{kg} \mathrm{DM)}$

\begin{tabular}{|c|c|c|c|c|c|c|c|c|c|}
\hline \multirow[b]{2}{*}{ Substrate } & \multicolumn{3}{|c|}{ Donor cow diet CON } & \multicolumn{3}{|c|}{ Donor cow diet AR } & \multicolumn{3}{|c|}{ Donor cow diet LA } \\
\hline & CON & AR & LA & CON & AR & LA & CON & $A R$ & LA \\
\hline \multicolumn{10}{|c|}{ Total VFA, mmol/L } \\
\hline Day -4 & 55 & 55 & 49 & 53 & 48 & 49 & 54 & 56 & 50 \\
\hline Day 1 & 53 & 51 & 46 & 54 & 48 & 46 & 49 & 50 & 42 \\
\hline Day 4 & $50^{b}$ & $50^{b}$ & $46^{b}$ & $51^{\mathrm{ab}}$ & $47^{\mathrm{ab}}$ & $45^{\mathrm{ab}}$ & $45^{\mathrm{a}}$ & $45^{\mathrm{a}}$ & $43^{a}$ \\
\hline Day 8 & $53^{b}$ & $50^{\mathrm{b}}$ & $48^{b}$ & $49^{b}$ & $51^{\mathrm{b}}$ & $43^{b}$ & $43^{a}$ & $41^{a}$ & $37^{\mathrm{a}}$ \\
\hline Day 15 & $49^{\mathrm{ab}}$ & $47^{\mathrm{ab}}$ & $40^{\mathrm{ab}}$ & $48^{\mathrm{b}}$ & $50^{b}$ & $46^{\mathrm{b}}$ & $44^{\mathrm{a}}$ & $44^{\mathrm{a}}$ & $42^{\mathrm{a}}$ \\
\hline Day 22 & $50^{b}$ & $46^{\mathrm{b}}$ & $45^{b}$ & $50^{\mathrm{b}}$ & $48^{\mathrm{b}}$ & $44^{b}$ & $44^{\mathrm{a}}$ & $45^{\mathrm{a}}$ & $41^{\mathrm{a}}$ \\
\hline \multicolumn{10}{|c|}{ Acetic acid, $\%$ of total VFA } \\
\hline Day -4 & 62.3 & 62.7 & 61.2 & 60.4 & 62.6 & 61.7 & 61.7 & 62.2 & 62.9 \\
\hline Day 1 & 60.6 & 59.0 & 59.8 & 61.0 & 61.8 & 59.3 & 61.9 & 61.1 & 63.6 \\
\hline Day 4 & $61.6^{b}$ & $61.1^{b}$ & $63.6^{b}$ & $61.3^{b}$ & $59.4^{b}$ & $63.5^{\mathrm{b}}$ & $58.3^{\mathrm{a}}$ & $57.6^{\mathrm{a}}$ & $57.8^{a}$ \\
\hline Day 8 & $61.7^{c}$ & $60.7^{c}$ & $63.0^{c}$ & $58.6^{b}$ & $57.9^{b}$ & $57.2^{\mathrm{b}}$ & $54.6^{\mathrm{a}}$ & $53.8^{\mathrm{a}}$ & $55.4^{a}$ \\
\hline Day 15 & $59.7^{b}$ & $57.8^{\mathrm{b}}$ & $58.2^{\mathrm{b}}$ & $57.2^{\mathrm{b}}$ & $59.7^{b}$ & $60.9^{b}$ & $55.9^{\mathrm{a}}$ & $55.3^{\mathrm{a}}$ & $56.0^{\mathrm{a}}$ \\
\hline Day 22 & $60.1^{b}$ & $58.6^{b}$ & $61.8^{\mathrm{b}}$ & $59.7^{b}$ & $58.7^{b}$ & $59.7^{b}$ & $56.3^{\mathrm{a}}$ & $56.3^{\mathrm{a}}$ & $57.2^{\mathrm{a}}$ \\
\hline \multicolumn{10}{|c|}{ Propionic acid, $\%$ of total VFA } \\
\hline Day -4 & 21.1 & 21.2 & 20.9 & 24.1 & 22.8 & 21.3 & 21.6 & 20.8 & 19.1 \\
\hline Day 1 & 22.3 & 22.8 & 19.8 & 23.1 & 23.2 & 21.9 & 23.0 & 22.9 & 20.6 \\
\hline Day 4 & $21.9^{\mathrm{a}}$ & $22.0^{\mathrm{a}}$ & $18.9^{\mathrm{a}}$ & $21.3^{\mathrm{a}}$ & $22.3^{\mathrm{a}}$ & $19.0^{\mathrm{a}}$ & $25.1^{b}$ & $25.4^{\mathrm{b}}$ & $23.8^{b}$ \\
\hline Day 8 & $20.2^{\mathrm{a}}$ & $20.1^{\mathrm{a}}$ & $16.7^{\mathrm{a}}$ & $23.0^{\mathrm{b}}$ & $23.7^{\mathrm{b}}$ & $20.3^{\mathrm{b}}$ & $25.3^{b}$ & $24.8^{b}$ & $22.8^{\mathrm{b}}$ \\
\hline Day 15 & $22.1^{\mathrm{a}}$ & $23.3^{\mathrm{a}}$ & $20.4^{\mathrm{a}}$ & $22.8^{a}$ & $21.9^{\mathrm{a}}$ & $18.6^{\mathrm{a}}$ & $25.9^{b}$ & $26.0^{\mathrm{b}}$ & $25.6^{b}$ \\
\hline Day 22 & $20.8^{a}$ & $21.7^{\mathrm{a}}$ & $18.1^{\mathrm{a}}$ & $19.8^{\mathrm{a}}$ & $19.8^{\mathrm{a}}$ & $16.9^{\mathrm{a}}$ & $23.9^{b}$ & $24.0^{b}$ & $22.2^{\mathrm{b}}$ \\
\hline \multicolumn{10}{|c|}{ Butyric acid, $\%$ of total VFA } \\
\hline Day -4 & 9.0 & 9.0 & 10.2 & 8.3 & 7.0 & 9.3 & 10.0 & 9.7 & 10.6 \\
\hline Day 1 & $10.6^{b}$ & $11.2^{\mathrm{b}}$ & $12.8^{\mathrm{b}}$ & $8.7^{\mathrm{a}}$ & $7.6^{\mathrm{a}}$ & $9.6^{a}$ & $8.4^{\mathrm{a}}$ & $9.1^{\mathrm{a}}$ & $8.2^{\mathrm{a}}$ \\
\hline Day 4 & 8.0 & 8.1 & 9.1 & 8.6 & 8.5 & 8.9 & 7.6 & 8.0 & 8.1 \\
\hline Day 8 & 11.0 & 11.8 & 12.3 & 9.8 & 10.0 & 12.1 & 10.2 & 11.3 & 11.4 \\
\hline Day 15 & $10.8^{b}$ & $10.9^{b}$ & $12.3^{\mathrm{b}}$ & $10.9^{b}$ & $10.2^{b}$ & $11.3^{\mathrm{b}}$ & $8.7^{\mathrm{a}}$ & $8.8^{\mathrm{a}}$ & $9.0^{\mathrm{a}}$ \\
\hline \multirow[t]{2}{*}{ Day 22} & $10.7^{b}$ & $11.1^{\mathrm{b}}$ & $11.7^{b}$ & $11.4^{b}$ & $11.6^{\mathrm{b}}$ & $12.8^{\mathrm{b}}$ & $8.8^{\mathrm{a}}$ & $8.9^{\mathrm{a}}$ & $9.2^{\mathrm{a}}$ \\
\hline & \multicolumn{9}{|c|}{$P$-Value ${ }^{1}$} \\
\hline Parameter & Substrate & \multicolumn{2}{|c|}{ Donor } & Day & Sub ${ }^{2} \times$ Diet & SubxDay & \multicolumn{2}{|c|}{ Diet×Day } & Pooled SEM \\
\hline Total VFA & $<0.001$ & \multicolumn{2}{|c|}{$<0.001$} & $<0.001$ & 0.412 & 0.948 & \multicolumn{2}{|c|}{$<0.001$} & 1.9 \\
\hline Acetic acid & 0.253 & \multicolumn{2}{|c|}{$<0.001$} & $<0.001$ & 0.900 & 0.837 & \multicolumn{2}{|c|}{$<0.001$} & 1.38 \\
\hline Propionic & $<0.001$ & \multicolumn{2}{|c|}{$<0.001$} & 0.025 & 0.896 & 0.997 & \multicolumn{2}{|c|}{$<0.001$} & 1.38 \\
\hline Butyric acid & 0.026 & \multicolumn{2}{|c|}{0.005} & $<0.001$ & 0.579 & 0.992 & \multicolumn{2}{|c|}{$<0.001$} & 0.97 \\
\hline
\end{tabular}

\footnotetext{
${ }^{1} P$-value for Substrate $\times$ Diet $\times$ Day interaction non-significant $(P>0.05)$ and not presented.

${ }^{2} \mathrm{Sub}=$ substrate.

${ }^{\mathrm{ab}}$ Superscripts indicate significance of diet $\times$ day interaction term. Diets within rows, with different superscripts are significantly $(P \leq 0.05)$ different from each other.
} 


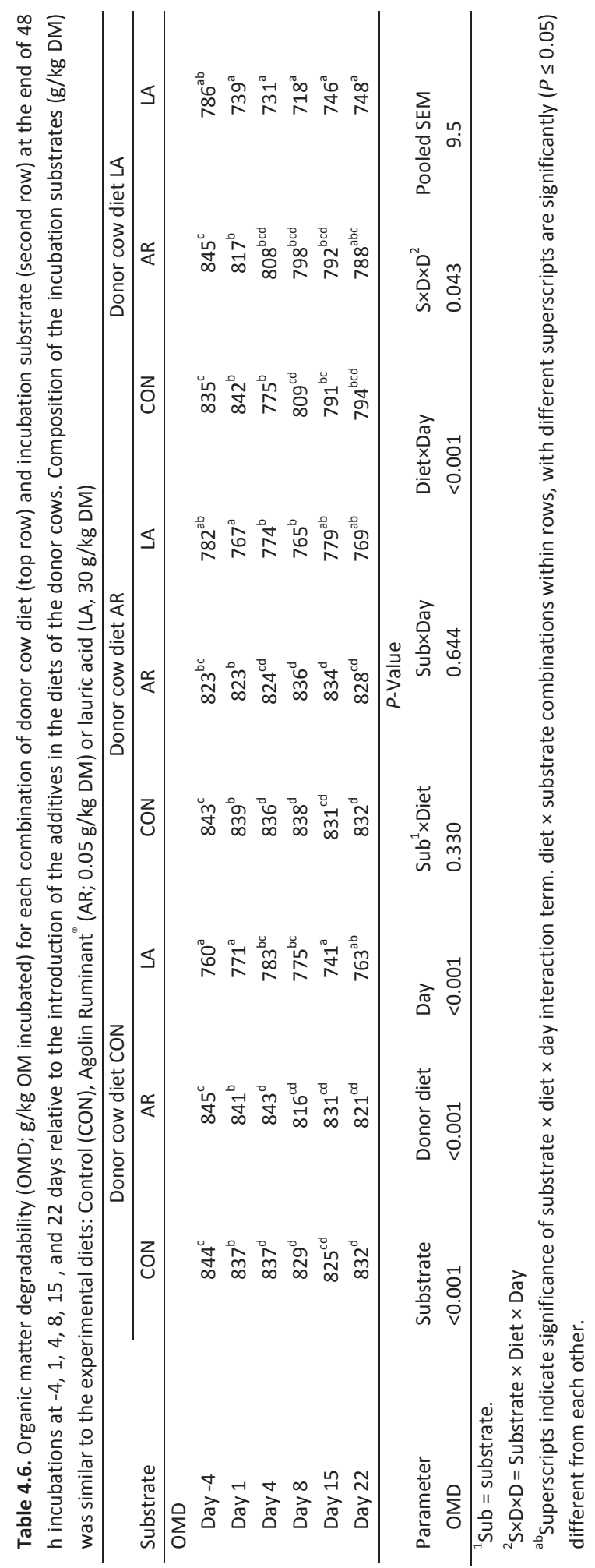




\section{Volatile fatty acids}

Overall, significant diet $x$ day interactions indicate that the LA diet reduced VFA concentrations and relative molar proportions of acetate and butyrate in fermentation fluid, and increased molar proportions of propionate, for all three substrates from day 4 onwards (Table 4.5). Such changes in VFA molar proportions correspond to an observed reduction in $\mathrm{CH}_{4}$ production. Reductions in VFA concentration and acetate molar proportion following C12:0 supplementation have been reported previously (Faciola and Broderick, 2014; Hristov et al. 2011). Similar effects were observed for filtrated rumen fluid before incubation after introduction of $\mathrm{C} 12: 0$ into the diet of the cows (data not shown). Only $5 \mathrm{~mL}$ of rumen fluid was added to $84 \mathrm{~mL}$ buffer solution, and thus this similarity in results may indicate that the microbial composition of the rumen fluid was affected by the donor cow diets.

Compared with the CON diet, the acetate and propionate molar proportions for the AR diet were significantly lower and higher, respectively, on day 8 only, whereas total VFA concentration in fermentation fluid was not different. This shift in relative proportions of VFA is in line with the results for $\mathrm{CH}_{4}$ production on this day. Similar to the absence of differences in $\mathrm{CH}_{4}$ production between the $\mathrm{CON}$ diet and the AR diet at days 15 and 22, the relative proportions of acetate and propionate also did not differ between AR and CON at days 15 and 22. Benchaar et al. (2015) and Pirondini et al. (2015) found no treatment effect of eugenol or Agolin Ruminant on total VFA concentrations or acetate:propionate ratio, which is in line with the absence of a $\mathrm{CH}_{4}$ reduction in their studies.

\section{In vitro organic matter degradability}

The OMD results (Table 4.6) generally support the data of the in vitro gas and $\mathrm{CH}_{4}$ production and VFA concentration for the various diet $\times$ substrate combinations. A significant substrate $\times$ diet $\times$ day interaction was observed. The OMD results for the CON and $A R$ diet were not different and consistent over time, whereas OMD was reduced by both the LA diet (from day 4 onwards) and the LA substrate (all days). The latter is in line with earlier findings in vitro (Dohme et al., 2001) and in vivo (Faciola et al., 2014). 


\section{CONCLUSIONS}

Feed additives in the donor cow diet have a stronger effect on in vitro gas and $\mathrm{CH}_{4}$ production than the same additives in the incubation substrate. The LA diet persistently reduced in vitro gas and $\mathrm{CH}_{4}$ production from day 4 onwards, but also decreased $\mathrm{DMI}$ and FPCM production of the donor cows. No negative effects on DMI and FPCM production were observed in cows receiving the AR diet. In vitro gas and $\mathrm{CH}_{4}$ production was reduced by the AR diet on day 8 , but not on days 15 and 22, which may indicate a transient effect of $\mathrm{AR}$ on $\mathrm{CH}_{4}$ production and adaptation of the rumen microbial ecosystem to AR.

\section{ACKNOWLEDGEMENTS}

Staff of the experimental facilities "Carus" (Wageningen, The Netherlands) and laboratory staff of Wageningen UR Animal Nutrition Group are gratefully acknowledged for their assistance during the implementation of the experiment. This study is part of the Low Emission Animal Feed project. Authors acknowledge financial support of the Dutch Ministry of Economic Affairs (The Hague, the Netherlands), the Product Board Animal Feed (Zoetermeer, the Netherlands) and the Dutch Dairy Board (Zoetermeer, the Netherlands).

\section{REFERENCES}

Benchaar, C., and H. Greathead. 2011. Essential oils and opportunities to mitigate enteric methane emissions from ruminants. Anim. Feed Sci. Technol. 166-167:338-355.

Benchaar, C., F. Hassanat, and H. V. Petit. 2015. Dose-response to eugenol supplementation to dairy cow diets: Methane production, $\mathrm{N}$ excretion, ruminal fermentation, nutrient digestibility, milk production, and milk fatty acid profile. Anim. Feed Sci. Technol. 209:51-59.

Calsamiglia, S., M. Busquet, P. W. Cardozo, L. Castillejos, and A. Ferret. 2007. Invited Review: Essential oils as modifiers of rumen microbial fermentation. J. Dairy Sci. 90:2580-2595.

Castro-Montoya, J., N. Peiren, J. W. Cone, B. Zweifel, V. Fievez, and S. De Campeneere. 2015. In vivo and in vitro effects of a blend of essential oils on rumen methane mitigation. Livest. Sci. 180:134-142. 
Cardozo, P. W., S. Calsamiglia, A. Ferret, and C. Kamel. 2004. Effects of natural plant extracts on ruminal protein degradation and fermentation profiles in continuous culture. J. Anim. Sci. 82:3230-3236.

Chapman, H. D. 2001. Use of anticoccidial drugs in broiler chickens in the USA: Analysis for the years 1995 to 1999. Poultry Sci. 80:572-580.

CVB, 2008. CVB Table booklet feeding of ruminants. CVB series no. 43. Centraal Veevoederbureau, Lelystad, the Netherlands.

Dohme, F., A. Machmüller, A. Wasserfallen, and M. Kreuzer. 2001. Ruminal methanogenesis as influenced by individual fatty acids supplemented to complete ruminant diets. Lett. Appl. Microbiol. 32:47-51.

Durmic, Z., P. J. Moate, R. Eckard, D. K. Revell, R. Williams, and P. E. Vercoe. 2013. In vitro screening of selected feed additives, plant essential oils and plant extracts for rumen methane mitigation. J. Sci. Food Agric. 94: 1191-1196.

Ellis, J. L., A. Bannink, I. K. Hindrichsen, R. D. Kinley, W. F. Pellikaan, N. Milora, and J. Dijkstra. 2016. The effect of lactic acid bacteria included as a probiotic or silage inoculant on in vitro rumen digestibility, total gas and methane production. Anim. Feed Sci. Technol. 211:61-74

Faciola, A. P., and G.A. Broderick. 2014. Effects of feeding lauric acid or coconut oil on ruminal protozoa numbers, fermentation pattern, digestion, omasal nutrient flow, and milk production in dairy cows. J. Dairy Sci. 97:5088-5100.

Flachowsky, G., and P. Lebzien. 2012. Effects of phytogenic substances on rumen fermentation and methane emissions: A proposal for a research process. Anim. Feed Sci. Technol. 176:70-77.

Groot, J. C. J., J. W. Cone, B. A. Williams, F. M. A. Debersaques, and E. A. Lantinga. 1996. Multiphasic analysis of gas production kinetics for in vitro fermentation of ruminant feeds. Anim. Feed Sci. Technol. 64:77-89.

Hatew, B., S. C. Podesta, H. van Laar, W. F. Pellikaan, J. L. Ellis, J. Dijkstra, and A. Bannink. $2015 a$. Effects of dietary starch content and rate of fermentation on methane production in lactating dairy cows. J. Dairy Sci. 98:486-499.

Hatew, B., J. W. Cone, W. F. Pellikaan, S. C. Podesta, A. Bannink, W. H. Hendriks, and J. Dijkstra. 2015b. Relationship between in vitro and in vivo methane production measured simultaneously with different dietary starch sources and starch levels in dairy cattle. Anim. Feed Sci. Technol. 202:20-31.

Hansen, H. H., I. M. L. D. Storm, and A. M. Sell. 2012. Effect of biochar on in vitro rumen methane production. Act. Agric. Scan. A - Anim. Sci. 62:305-309. 
Hristov, A. N., J. Oh, J. Firkins, J. Dijkstra, E. Kebreab, G. Waghorn, A. Adesogan, W. Yang, J. Tricarico, C. Lee, P. J. Gerber, B. Henderson, and H. P. S. Makkar. 2013. Mitigation of methane and nitrous oxide emissions from animal operations: I. A review of enteric methane mitigation options. J. Anim. Sci. 91:5045-5069.

Hristov, A. N., C. Lee, T. Cassidy, M. Long, K. Heyler, B. Corl, and R. Forster. 2011. Effects of lauric and myristic acids on ruminal fermentation, production, and milk fatty acid composition in lactating dairy cows. J. Dairy Sci. 94:382-395.

ISO. 2004. NEN-EN-ISO 1735:2004 Cheese and processed cheese products - Determination of fat content - Gravimetric method (reference method). International Standards Organization. Geneva. Switzerland.

Klop, G., B. Hatew, A. Bannink, and J. Dijkstra. 2016. Feeding nitrate and docosahexaenoic acid affects enteric methane production and milk fatty acid composition in lactating dairy cows. J. Dairy Sci. 99: 1161-1172.

Lowe, S., M. K. Theodorou, A. P. J. Trinci, and R. B. Hespell. 1985. Growth of anaerobic rumen fungi on defined and semi-defined media lacking rumen fluid. J. Gen. Microbiol. 131:2225-2229.

O’Brien, M., A. Navarro-Villa, P. J. Purcell, T. M. Boland, and P. O'Kiely. 2014. Reducing in vitro rumen methanogenesis for two contrasting diets using a series of inclusion rates of different additives. Anim. Prod. Sci. 54:141-157.

Panyakaew, P., G. Goel, M. Lourenço, C. Yuangklang, and V. Fievez. 2013. Medium-chain fatty acids from coconut or krabok oil inhibit in vitro rumen methanogenesis and conversion of nonconjugated dienoic biohydrogenation intermediates. Anim. Feed Sci. Technol. 180:18-25.

Pellikaan, W. F., W. H. Hendriks, G. Uwimana, L. J. G. M. Bongers, P. M. Becker, and J. W. Cone. 2011. A novel method to determine simultaneously methane production during in vitro gas production using fully automated equipment. Anim. Feed Sci. Technol. 168:196-205.

Pirondini, M., S. Colombini, L. Malagutti, L. Rapetti, G. Galassi, R. Zanchi, and G. M. Crovetto. 2015. Effects of a selection of additives on in vitro ruminal methanogenesis and in situ and in vivo NDF digestibility. Anim. Sci. J. 86:59-68.

Tamminga, S., W. M. Van Straalen, A. P. J. Subnel, R. G. M. Meijer, A. Steg, C. J. G. Wever, and M. C. Blok. 1994. The Dutch protein evaluation system-The DVE/OEB-system. Livest. Prod. Sci. 40:139-155.

Van Zijderveld, S. M., J. Dijkstra, H. B. Perdok, J. R. Newbold, and W. J. J. Gerrits. 2011. Dietary inclusion of diallyl disulfide, yucca powder, calcium fumarate, an extruded linseed product, or medium-chain fatty acids does not affect methane production in lactating dairy cows. J. Dairy Sci. 94:3094-3104. 
Williams, B. A. , M. W. Bosch, H. Boer, M. W. A. Verstegen, and S. Tamminga. 2005. An in vitro batch culture method to assess potential fermentability of feed ingredients for monogastric diets. Anim. Feed Sci. Technol. 123-124:445-462.

Zhou, X., L. Meile, M. Kreuzer, and J. O. Zeitz. 2013. The effect of saturated fatty acids on methanogenesis and cell viability of Methanobrevibacter ruminantium. Archaea 2013:106916. 


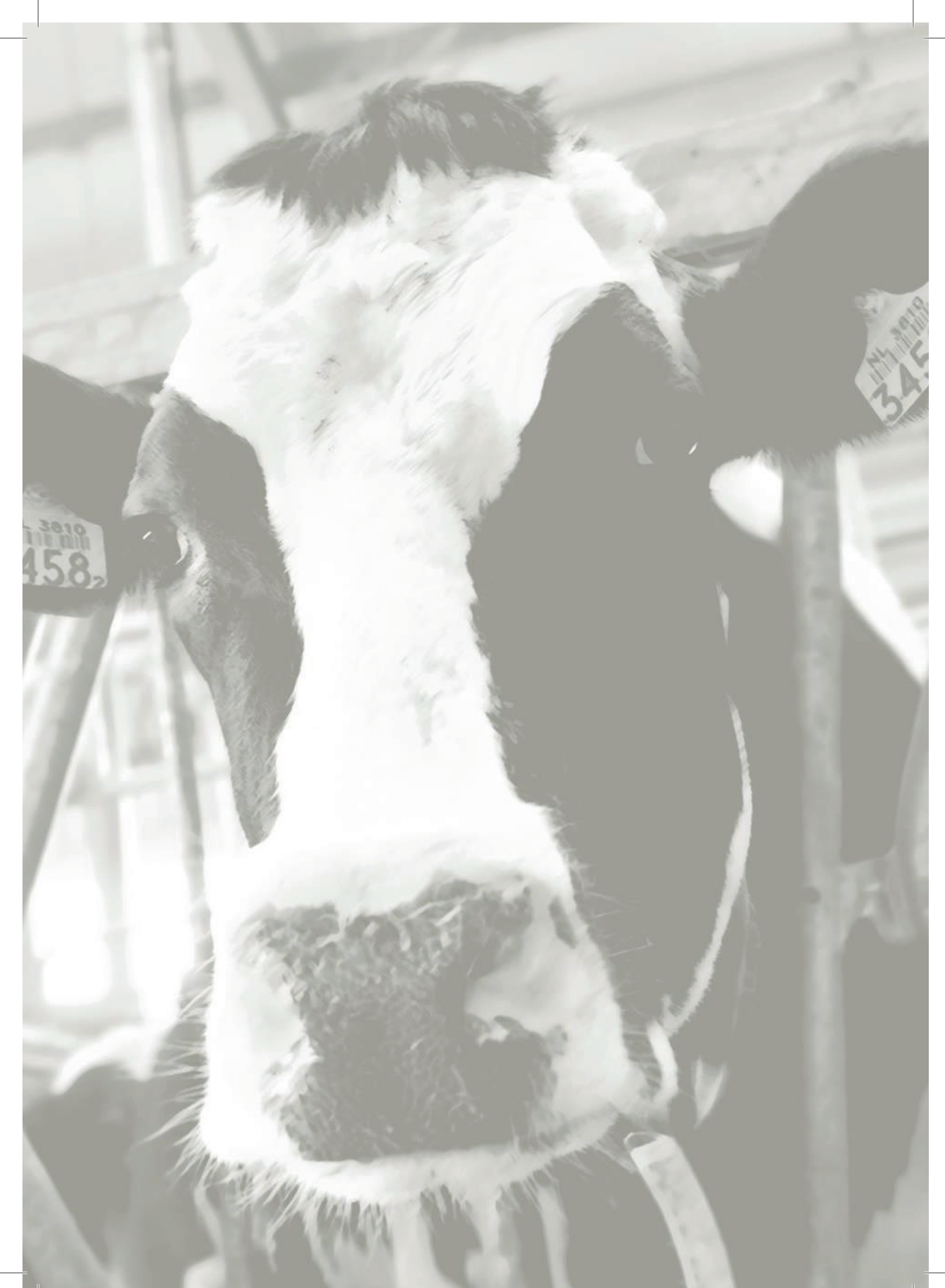




\title{
Chapter 5
}

\section{Effects of continuous feeding of essential oils or rotational feeding of essential oils and lauric acid on enteric methane production in lactating dairy cows}

\author{
G. Klop*, A. Bannink ${ }^{\dagger}$, K. Dieho*, W.H. Hendriks*, J. Dijkstra* \\ * Animal Nutrition Group, Wageningen University, PO Box 338, 6700 AH Wageningen, The \\ Netherlands \\ ${ }^{+}$Wageningen UR Livestock Research, PO Box 338, $6700 \mathrm{AH}$ Wageningen, The Netherlands
}

(to be submitted to Journal of Dairy Science) 


\begin{abstract}
The rumen microbes can adapt to feed additives, which may make the decrease in enteric $\mathrm{CH}_{4}$ production upon feeding an additive a transient response only. This study investigated alternate feeding of two $\mathrm{CH}_{4}$ mitigating feed additives with a different mode of action on persistency of lowering $\mathrm{CH}_{4}$ production compared to feeding a single additive over a period of 10 weeks. Four pairs of cows were selected, and within pairs, cows were randomly assigned to either the control (AR-AR) or the alternating (AR-LA) concentrate treatment. The AR concentrate contained a blend of essential oils (Agolin Ruminant ; 0.17 $\mathrm{g} / \mathrm{kg}$ of DM) and the LA concentrate contained lauric acid (C12:0; $20 \mathrm{~g} / \mathrm{kg}$ of DM). A basal concentrate without Agolin Ruminant and lauric acid was fed during the pre-treatment period ( 2 weeks). Thereafter, the cows assigned to AR-AR treatment received the AR concentrate during all 10 treatment weeks (5 periods of twee weeks each), whereas cows assigned to the AR-LA treatment received AR and LA concentrates rotated on a weekly basis. Methane emission was measured in climate respiration chambers during periods 1 , 3 and 5 . From period 3 onwards, DMI and milk protein concentration were reduced in the AR-LA treatment. Milk fat concentration was not affected, but the proportion of C12:0 in milk fat increased upon feeding C12:0. Molar proportions of acetate and propionate in rumen fluid were lower and higher, respectively, in the AR-LA than in the AR-AR treatment. Methane yield (g/kg of DMI) and intensity (g/kg FPCM) were not affected by treatment. Methane yield and intensity were significantly lower (12 and 11\%, respectively) in period 1 compared with the pre-treatment period, but no significant difference relative to pretreatment period was observed in period 3 (numerically 9 and $7 \%$ lower, respectively) and in period 5 (numerically 8 and $4 \%$ lower, respectively). Results indicate a transient decrease in $\mathrm{CH}_{4}$ yield and intensity in time, but no improvement in extent or persistency of $\mathrm{CH}_{4}$ reduction due to rotational feeding of essential oils and $\mathrm{C} 12: 0$ in lactating dairy cows.
\end{abstract}

Key words: methane, lauric acid, essential oils, dairy cow 


\section{INTRODUCTION}

The mitigating effect of feed additives supplemented to dairy cow diets on enteric $\mathrm{CH}_{4}$ emission may be a transient effect if rumen microbes adapt to these additives. Guan et al. (2006) compared the effect of feeding a single ionophore (monensin) with feeding a rotation of ionophores (monensin and lasalocid) on enteric $\mathrm{CH}_{4}$ production in Angus steers. Both the size and duration of the decrease in $\mathrm{CH}_{4}$ production were not different between the two ionophore treatments, and the mitigating effect disappeared after several weeks. The absence of an effect is probably a result of the similar mode of action of both ionophores, which may be overcome if several additives with different mode of action are rotated.

In agronomy, herbicide rotations are applied as tactic to prevent or delay herbicide resistance of weeds (Beckie, 2006). In broilers, shuttle programmes with two or more anticoccidial compounds, usually with different modes of action, are widely used to reduce resistance of these protozoa (Chapman, 2001). Yáñez-Ruiz et al. (2016) reviewed the use of in vitro batch culture technique to assess enteric $\mathrm{CH}_{4}$ production, and recommended use of inoculum from animals that have been adapted to treatment for at least 2 weeks. In Chapter 4, the adaptation of dairy cows to feed additives with different modes of action in vivo [viz. lauric acid (C12:0) and Agolin Ruminant ${ }^{\circledR}$ (commercial blend of essential oils, with eugenol, geranyl acetate and coriander oil being the main components)] was evaluated using the in vitro gas production technique. Results indicated a transient effect of the essential oil blend on in vitro $\mathrm{CH}_{4}$ production, with $\mathrm{CH}_{4}$ production being lowered after $8 \mathrm{~d}$ of feeding the additive to the donor cows, whereas after 15 and $22 \mathrm{~d}$, in vitro $\mathrm{CH}_{4}$ production did not differ anymore from the control treatment. In contrast, a persistent mitigating effect on in vitro $\mathrm{CH}_{4}$ production was observed when donor cows were fed lauric acid.

Based on these findings, it was hypothesized that continuous feeding of AR would result in a transient decrease of $\mathrm{CH}_{4}$ emission, whereas weekly rotation of $\mathrm{AR}$ and $\mathrm{C} 12: 0$ would result in a persistent $\mathrm{CH}_{4}$ decline. Therefore, the aim of the present study was to compare 
the extent and duration of changes in $\mathrm{CH}_{4}$ emission and in performance of dairy cows receiving either AR only or AR and C12:0 using a weekly rotation schedule.

\section{MATERIALS AND METHODS}

\section{Experimental design, animals and housing}

All experimental procedures were approved by the Animal Care and Use Committee of Wageningen University (Wageningen, The Netherlands). Four pairs of cows (4 primiparous and 4 multiparous; $139 \pm 38$ DIM at the start of the experimental period; mean \pm SD), of which 4 cows were fitted with a permanent rumen cannula $(10 \mathrm{~cm}$ i.d., Type 1C, Bar Diamond Inc., Parma, ID) were included in the experiment. Cows were paired based on parity, lactation stage, milk production and presence or absence of a rumen fistula. Within pairs, cows were randomly assigned to either the control (AR-AR) or the alternating (ARLA) concentrate treatment with a total treatment length of $10 \mathrm{wk}$ (5 periods of $2 \mathrm{wks}$ each). The treatments were preceded by an 11-d pre-treatment period. In the pretreatment period, cows were housed in tie-stalls and fed the basal diet without experimental feed additives. Thereafter, cows were individually housed in climate respiration chambers (CRC) for a period of $2.5 \mathrm{~d}$ to measure $\mathrm{CH}_{4}$ emissions on the basal diet. Four individual CRC were available at the same time and therefore a staggered approach was taken with the first 2 pairs of cows (block A) starting $3 d$ earlier with the pre-treatment period than the second 2 pairs of cows (block B). After the initial $\mathrm{CH}_{4}$ measurement in the $\mathrm{CRC}$, block A cows returned to the tie-stalls and were fed the basal ration without additives for another $17 \mathrm{~d}$. During these $17 \mathrm{~d}$, block $\mathrm{B}$ cows were housed in CRC for their initial 2.5- $\mathrm{d} \mathrm{CH}_{4}$ measurements, where after they started a treatment schedule of 2 wks in the CRC (period 1, period 3, period 5) with intermediate 2 wk tie-stall periods (period 2, period 4). In the 2 wk period that the block A cows were housed in the tie-stalls, the cows of block B were housed in the CRC with a similar treatment schedule. For each two-week CRC period, cows entered the CRC at $1500 \mathrm{~h}$ and left around $0900 \mathrm{~h}$ on d 15. Days 2-7 and 9-14 were used to collect $\mathrm{CH}_{4}$ data. The $\mathrm{CRC}$ were cleaned in the mornings of $d 1$ (before entrance of the cows) and $d$ 8. Rotation (AR to LA or vice versa) occurred in the mornings of $d 2$ and $d 9$. 
A detailed description of the CRC design and gas measurements was reported by van Gastelen et al. (2015). Briefly, in each CRC (volume $35 \mathrm{~m}^{3}$ ) relative humidity was maintained at $70 \%$ and temperature at $16^{\circ} \mathrm{C}$, and the ventilation rate in each compartment was $42 \mathrm{~m}^{3} / \mathrm{h}$. Inlet and exhaust air of each compartment was sampled at 10min intervals. Gas concentrations and ventilation rates were corrected for pressure, temperature and humidity to arrive at standard temperature pressure dew point volumes of inlet and exhaust air. Immediately prior to the experiment, compartments were checked by releasing known amounts of $\mathrm{CO}_{2}$ in each compartment and the recovery calculated. The recovered amounts of $\mathrm{CO}_{2}$ were between 98 and $100 \%$. Cows were exposed to $16 \mathrm{~h}$ of light per day.

Table 5.1. Ingredient composition ( $\mathrm{g} / \mathrm{kg}$ of $\mathrm{DM}$ ) of the pre-treatment concentrate (Basal) and the treatment concentrates that contained either Agolin Ruminant ${ }^{\circ}$ (AR) or lauric acid (LA) as feed additive.

\begin{tabular}{lccc}
\hline & & Concentrates & LA \\
\cline { 2 - 4 } Ingredient & Basal & 305 & 285 \\
\hline Corn & 305 & 143 & 133 \\
Corn gluten feed & 143 & 99 & 93 \\
Soybean meal & 99 & 93 & 87 \\
Rapeseed meal & 93 & 85 & 79 \\
Formaldehyde treated soybean meal & 85 & 78 & 73 \\
Sugar beet pulp & 78 & 68 \\
Palm kernel expeller & 73 & 73 & 53 \\
Formaldehyde treated rapeseed meal & 57 & 57 & 32 \\
Sugar cane molasses & 34 & 34 & 14 \\
$\mathrm{CaCO}_{3}$ & 14 & 14 & 9 \\
$\mathrm{Trace}$ mineral and vitamin premix & 9 & 9 & 4 \\
$\mathrm{NaCl}_{\mathrm{NaHCO}}$ & 4 & 4 & 2.8 \\
$\mathrm{MgO}_{\mathrm{Cr}} \mathrm{O}_{3}$ & 2.8 & 1.7 \\
$\mathrm{Agolin} \mathrm{Ruminant}$ & 1.7 & 2.8 & 1.7 \\
$\mathrm{Lauric}^{\circ}$ acid (C12:0) & 1.7 & 1.7 & - \\
\hline
\end{tabular}




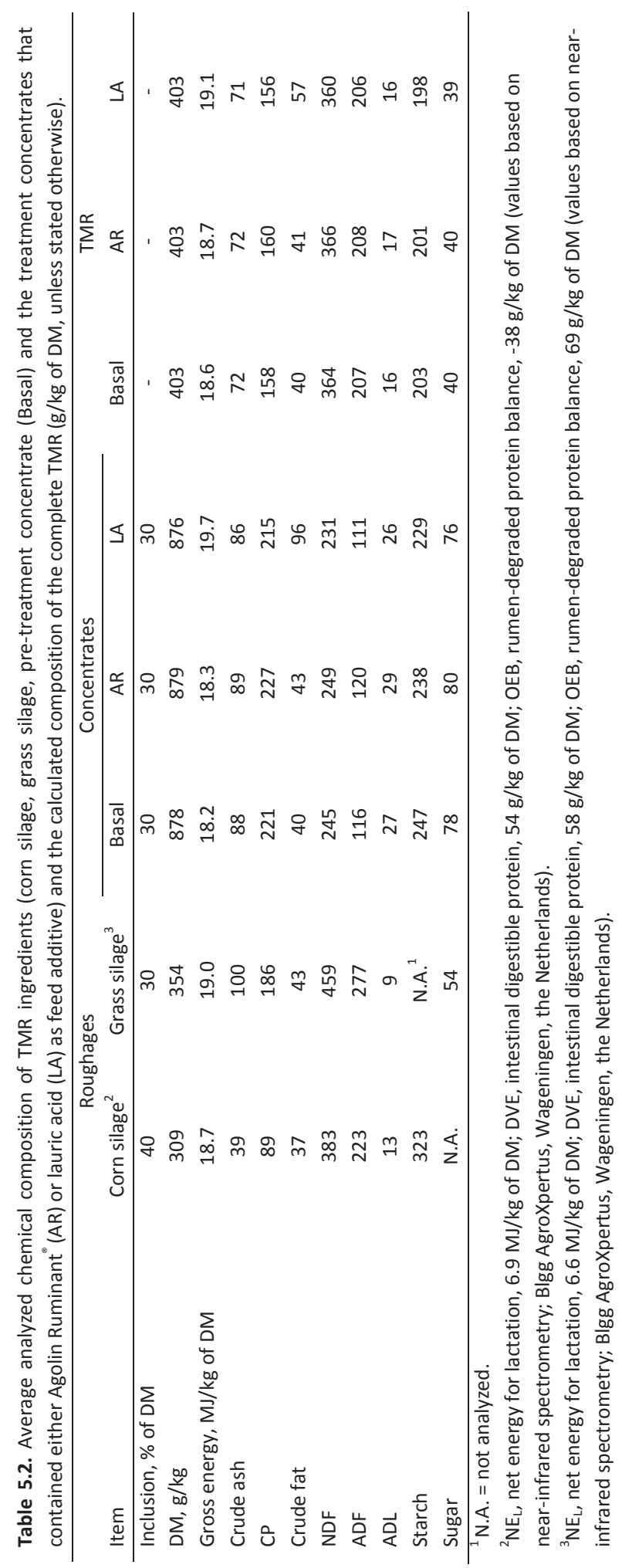




\section{Diets and feeding}

A TMR with basal concentrate was fed during the pre-treatment period. For the AR-AR treatment, the TMR with AR concentrate was fed during all 10 treatment wks, whereas for the AR-LA treatment AR and LA concentrates were rotated on a weekly basis (AR in wk 1 of each period, LA in wk 2 of each period). The AR concentrate contained Agolin Ruminant ${ }^{\bullet}(0.17 \mathrm{~g} / \mathrm{kg}$ of DM) and the LA concentrate contained lauric acid (C12:0; $20 \mathrm{~g} / \mathrm{kg}$ of DM) (Table 5.1). During the experimental period in the tie-stalls and CRC, animals were fed twice daily (at 0600 and $1600 \mathrm{~h}$ ). All cows received their experimental diet as a total mixed ration (TMR), composed of $40 \%$ corn silage, $30 \%$ grass silage, and $30 \%$ concentrate on a DM basis (Table 5.2). Portions of the grass silage and corn silage mixture were weighed in crates twice weekly and stored at $6^{\circ} \mathrm{C}$. Concentrates were weighed separately for each cow and these were manually mixed with the roughage at the time of feeding. The external marker $\mathrm{Cr}_{2} \mathrm{O}_{3}(1.7 \mathrm{~g} / \mathrm{kg}$ of DM) was added to the compound feed (Research Diet Services, Wijk bij Duurstede, the Netherlands) for estimation of apparent total-tract digestibility (ATTD). During the first $8 \mathrm{~d}$ of the pre-treatment period, cows received the basal diet ad libitum. From d 9 onwards, cows received their diet in amounts of $95 \%$ of the average daily intake of the cow with the lowest intake within a pair. This feed restriction was imposed throughout the remainder of the experiment in an effort to avoid confounding effects of $\mathrm{DMI}$ on $\mathrm{CH}_{4}$ production. Cows had free access to water throughout the experiment.

\section{Measurements, sampling and laboratory analyses}

Feed and feces samples

Representative samples of all individual TMR components were collected at the time of feed preparation. Fecal grab samples were collected in the respiration chambers for estimation of ATTD of nutrients. Fecal samples were collected at each milking during the last $4 \mathrm{~d}$ before the moment of concentrate switch.

Samples were stored frozen $\left(-20^{\circ} \mathrm{C}\right)$ pending analysis. After thawing, samples were air dried at $60^{\circ} \mathrm{C}$ until constant weight, and ground to pass a 1-mm screen (Wiley mill; Peppink 100AN, Olst, the Netherlands), before analysis. Dried samples were analyzed for 
DM, crude ash, N, NDF, ADF, ADL, starch, sugar, GE, and chromium. In fresh silage samples, $\mathrm{NH}_{3}$ was analyzed according to the methods described by Klop et al. (2016). Crude fat content of dried feed and feces samples was analyzed based on NEN-ISO 1735 (ISO, 2004). A modification to the standard procedure was that samples were hydrolysed with hydrochloric acid at $75^{\circ} \mathrm{C}$ and subsequently the solution, containing hydrochloric acid and ethanol, was extracted with diethyl ether and petroleum ether. Solvents were removed by distillation before the mass of the extracted material was determined.

Orts were quantitatively collected and weighed daily during the period in the respiration chambers. If the amount comprised more than $4 \%$ of DM supply, a representative subsample was analyzed for DM, ash and crude fat content according to the same methods as the feed samples.

\section{Milk production and milk composition}

Cows were milked twice daily (at $0600 \mathrm{~h}$ and $1600 \mathrm{~h}$ ) throughout the experiment. Milk production was recorded at each milking. For all cows, a subsample of milk from each milking in the CRC was analyzed for fat, protein, lactose, and urea content according to methods described by Hatew et al. (2015a). Average milk composition for each cow was calculated from the weighted average of all samples taken during the measurement period in the CRC. Separate samples were collected for analysis of milk fatty acid (FA) profile through gas chromatography as detailed by van Gastelen et al. (2015). Fat and protein corrected milk yield (FPCM) was calculated according to the formula: FPCM $(\mathrm{kg} / \mathrm{d})$ $=(0.337+0.116 \times$ fat $\%+0.06 \times$ protein $\%) \times$ milk yield $(\mathrm{kg} / \mathrm{d})(C V B, 2008)$.

\section{Rumen content samples}

In each of the tie-stall periods (viz. period 2 and 4), rumen fluid samples were collected from the rumen cannulated cows at the day of concentrate switch and the day thereafter (i.e., d 1, 2, 8, and 9 of each of the two 2-wk periods). Samples were collected at $0 \mathrm{~h}$ (just before), and at 1, 2, 3, 4, 6, 8 and $10 \mathrm{~h}$ after morning feeding on both days. Rumen fluid samples were collected in 3 equal amounts from the front and middle of the ventral sac and from the cranial sac of the rumen. In each sample, $\mathrm{pH}$ was measured immediately after sampling using a portable pH meter (HI 99141, Hannah instruments, IJsselstijn, the 
Netherlands). A $600 \mu \mathrm{L}$ aliquot of rumen fluid was mixed with an equal volume of $0.85 \% \mathrm{M}$ ortho-phosphoric acid, containing iso-caproic acid as internal standard and stored at $-20^{\circ} \mathrm{C}$. After thawing, samples were centrifuged for $10 \mathrm{~min}$ at $10,000 \times g$ at $4^{\circ} \mathrm{C}$. Separation of volatile fatty acids (VFA) was achieved by gas chromatography (Fisons HRGC Mega 2, CE Instruments, Milan, Italy) with $\mathrm{H}_{2}$ as carrier gas as detailed by Dieho et al. (2016).

\section{Statistical Analysis}

All data were analyzed using PROC MIXED (SAS 9.2, SAS Inst. Inc., Cary, NC). For one cow (AR-LA treatment) data from the pre-treatment period were excluded, because the cow had a sudden large drop in milk production, while maintaining feed intake. No clinical signs of disease were observed and milk yield increased again during the following 2 weeks in the tie-stalls. Data for $\mathrm{CH}_{4}$ emission, intake, milk production, milk composition and ATTD all relate to the CRC periods and were averaged per period and cow. Measurements from d 1 (cows entering the chambers around $1400 \mathrm{~h}$ ) and d 8 (cleaning of chambers in the morning) were not included in the analyses. Hence, the pre-treatment period included 2 full $d$ of data, and each CRC period comprised 2 weeks of 6 full $d$ of data each.

The 2 pairs of cows that went into the CRC at the same time throughout the experiment were considered as one block. The following time points were included in the analyses: Pre-treatment (background measurement), period 1 (first 2 weeks of dietary treatment), period 3 (weeks 5 and 6 of dietary treatment) and period 5 (weeks 9 and 10 of dietary treatment). The model contained block, treatment, time and treatment $\times$ time interaction as fixed effects. Repeated measures over time for each cow $\times$ treatment combination were taken into account using a first order autoregressive $[A R(1)]$ covariance structure.

Rumen fluid from two sampling days was pooled before statistical analysis. One cow (ARLA treatment) had access to other feed than the treatment feed allocated to her on the last rumen sampling day of period 4. Therefore, the values of this day were not used to calculate average values for this cow. Rumen data were analyzed using a model with fixed effects of treatment, time, hour, and treatment $\times$ time and treatment $\times$ hour. Cow $\times$ time 
was included as random effect with repeated measurements for each time(cow) combination included, and a spatial power covariance structure was fitted because of unequal time intervals between sampling hours. In all statistical analyses, denominator degrees of freedom were estimated using the Kenward-Roger option. Pairwise comparisons of treatment means were evaluated using the Tukey-Kramer method. In case of significant interaction terms, between-treatment comparisons for each period, or within-treatment comparisons over periods were made using a SLICE statement and $P$ values were corrected using the Tukey-Kramer method. Results are reported as least squares means and significance of effects was declared at $P \leq 0.05$ and trends at $0.05<P \leq$ 0.10 .

\section{RESULTS AND DISCUSSION}

\section{Dry matter intake, milk production, and milk composition}

The main aim of this study was to evaluate the alternate feeding of two $\mathrm{CH}_{4}$ mitigating feed additives (Agolin Ruminant and C12:0; AR-LA treatment) with a different mode of action, compared to feeding a single additive (Agolin Ruminant only; AR-AR treatment) on $\mathrm{CH}_{4}$ emission and performance of dairy cows. Dry matter intake of AR-AR cows did not differ between the pre-treatment and treatment periods. In contrast, despite the restricted feeding regimen, DMI of AR-LA was significantly reduced from period 3 onwards (Table 5.3). In comparison to $\mathrm{C} 14: 0$ and C18:0 supplementation, C12:0 supplementation decreases feed intake (Dohme et al., 2004). In line with the present results, Külling et al. (2002) also observed a reduction in DMI upon supplementation with C12:0. If the palatability of C12:0 is the main reason for the reduced DMI (Külling et al. 2002), encapsulation of the product could provide a solution to avoid reductions in intake.

Milk production was not affected by treatment, but was decreased in period 5 as cows were advancing in lactation. During periods 3 and 5 , but not during the pre-treatment period and period 1, milk protein concentration was reduced in the AR-LA treatment which resulted in a treatment $\times$ time interaction. Feeding digestible lipid in significant amounts is generally known to reduce the concentration of protein in milk (Walker et al., 
2004), but in the present experiment dietary lipid content only increased by $16 \mathrm{~g} / \mathrm{kg}$ of DM. The periods of reduced milk protein content correspond to the periods that AR-LA cows had a reduced DMI. Therefore, the effect was most likely caused by a lower intake of metabolizable energy or protein. Milk urea $\mathrm{N}$ content was not affected by treatment, time, or their interaction.

Milk fat depression following C12:0 supplementation has been reported previously (Faciola and Broderick, 2014; Hristov et al., 2011; Chapter 4). Although in the present study milk fat concentration was numerically lower in periods 3 and 5 with AR-LA, there was no treatment effect on milk fat concentration (Table 5.3). Santos et al. (2010) reported increased milk fat content and production when cows were fed Agolin Ruminant $(0.85 \mathrm{~g} / \mathrm{cow} / \mathrm{d})$ and suggested that this could be the result of an increased acetate:propionate $(A: P)$ ratio in the rumen (which was not measured). However, the cows in their study produced $49 \mathrm{~kg}$ of milk/d with an average DMI of $26 \mathrm{~kg} / \mathrm{cow} / \mathrm{d}$, which is higher than in the present experiment. In Chapter 4 a transient shift towards a larger proportion of propionate was observed in vitro using rumen fluid from cows on a diet containing Agolin Ruminant . As the control cows in the study of Santos et al. (2010) had a numerically higher DMI and a similar milk production level, a plausible explanation for the increased milk fat concentration upon feeding Agolin Ruminant is increased body fat mobilization rather than a shift in VFA profile. The proportion of C12:0 in milk fat of cows on the AR-LA treatment was higher than for AR-AR (Table 5.4), in particular in period 1. The DMI of these cows was only reduced from period 3 onwards, which may explain that the largest proportion of C12:0 in milk fat was observed in period 1. Dohme et al. (2004) observed a higher proportion of C12:0 in milk fat upon supplementing the diet with C12:0 compared with C14:0 and C18:0. Van Zijderveld et al. (2011) also observed an elevated proportion of $\mathrm{C} 12: 0$ in milk fat and a lower proportion of $\mathrm{C} 16: 0$ upon feeding a mixture of additives including $\mathrm{C} 12: 0$. The increased proportion of $\mathrm{C} 12: 0$ and the reduced proportion of C16:0 in milk fat of AR-LA cows in period 3 is in line with findings of Hristov et al. (2011), who supplemented dairy cows with $240 \mathrm{~g} / \mathrm{d}$ of either stearic acid (C18:0; control treatment), C12:0, or myristic acid (C14:0). In their study, but not in the study of Dohme et al. (2004), the proportion of saturated fatty acids (SFA) was lower in cows supplemented 
with $\mathrm{C} 12: 0$ than in cows receiving the $\mathrm{C} 18: 0$ control treatment. In the present study, a tendency for a treatment $\times$ time interaction was found for the proportion of SFA, which was lower in the AR-LA treatment during the treatment periods compared to the pretreatment period, and is opposite to changes between periods in SFA proportions with the AR-AR treatment.

In comparison with other periods, in period 1, when intake of C12:0 was highest, proportions of several C18:1 fatty acids were increased in the AR-LA treatment but not in the AR-AR treatment, resulting in a significant treatment $\times$ time interaction (Table 5.4). Dohme et al. (2004) and Hristov et al. (2011) also reported larger proportions of trans C18:1 and CLA isomers in milk of cows on a C12:0 treatment than in cows on a C18:0 or C14:0 treatment. Apparently, C12:0 causes a larger proportion of biohydrogenation intermediates to escape complete biohydrogenation in the rumen. After intestinal absorption, such intermediates may decrease de novo fatty acid synthesis in the mammary gland (Piperova et al., 2000).

Benchaar et al. (2007) evaluated the effect of a mixture of essential oil compounds (Crina ruminants; includes thymol, eugenol, vanillin, guaiacol, and limonene) in dairy cattle and did not find any effect on milk fatty acid profile. To our knowledge, the effect of Agolin Ruminant on milk fatty acid profile has not been reported previously. In both AR-AR and AR-LA, the proportions of $\mathrm{C} 15: 0$ iso and C15:0 anteiso were reduced in period 1 compared with the pre-treatment period (Table 5.4). Castro Montoya et al. (2011) reported a positive relationship between iso $\mathrm{FA}$ and calculated $\mathrm{CH}_{4}$ production (mmol/mol VFA). Fibrolytic bacteria are generally enriched in iso FA, whereas amylolytic bacteria contain high amounts of linear odd-chain FA and anteiso FA (Vlaeminck et al., 2006). Hence, a positive relation between $\mathrm{CH}_{4}$ emission and iso $\mathrm{FA}$ can be assumed, as well as a negative relation between $\mathrm{CH}_{4}$ emission and linear odd-chain FA and anteiso FA (reviewed by Van Gastelen and Dijkstra, 2016). During period 1, in line with the change in iso-acid content of milk fat, $\mathrm{CH}_{4}$ production was indeed lower than during the pre-treatment period, but in contrast C15:0 anteiso and C17:0 anteiso were reduced in period 3 and C15:0 and C17:0 were not affected by treatment (Table 5.5). Within the AR-AR treatment, also the 


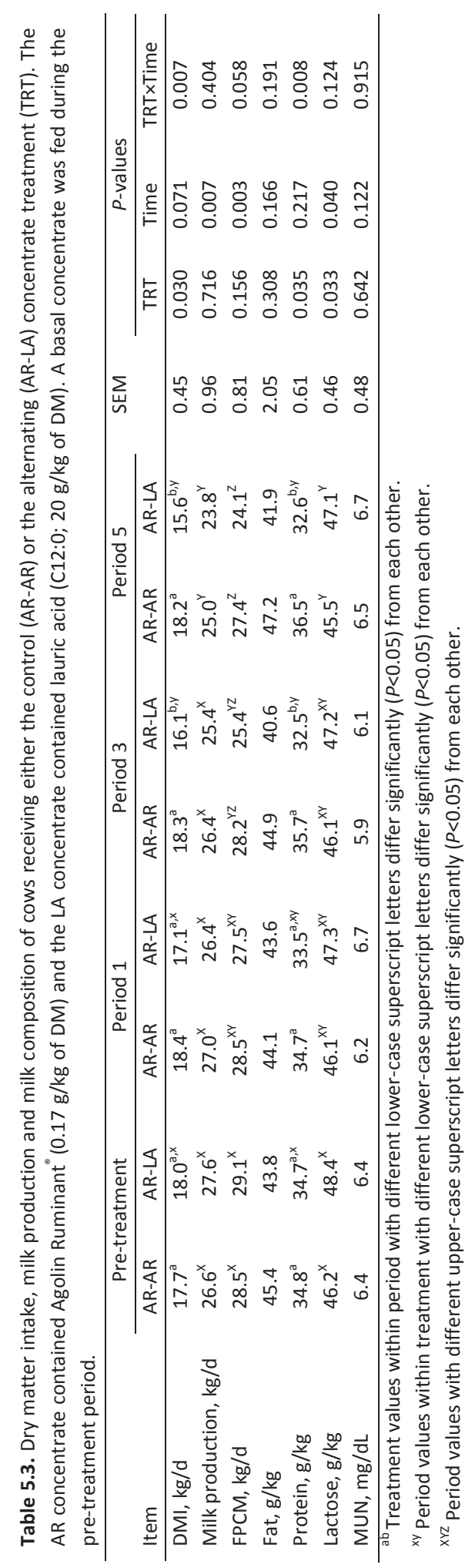




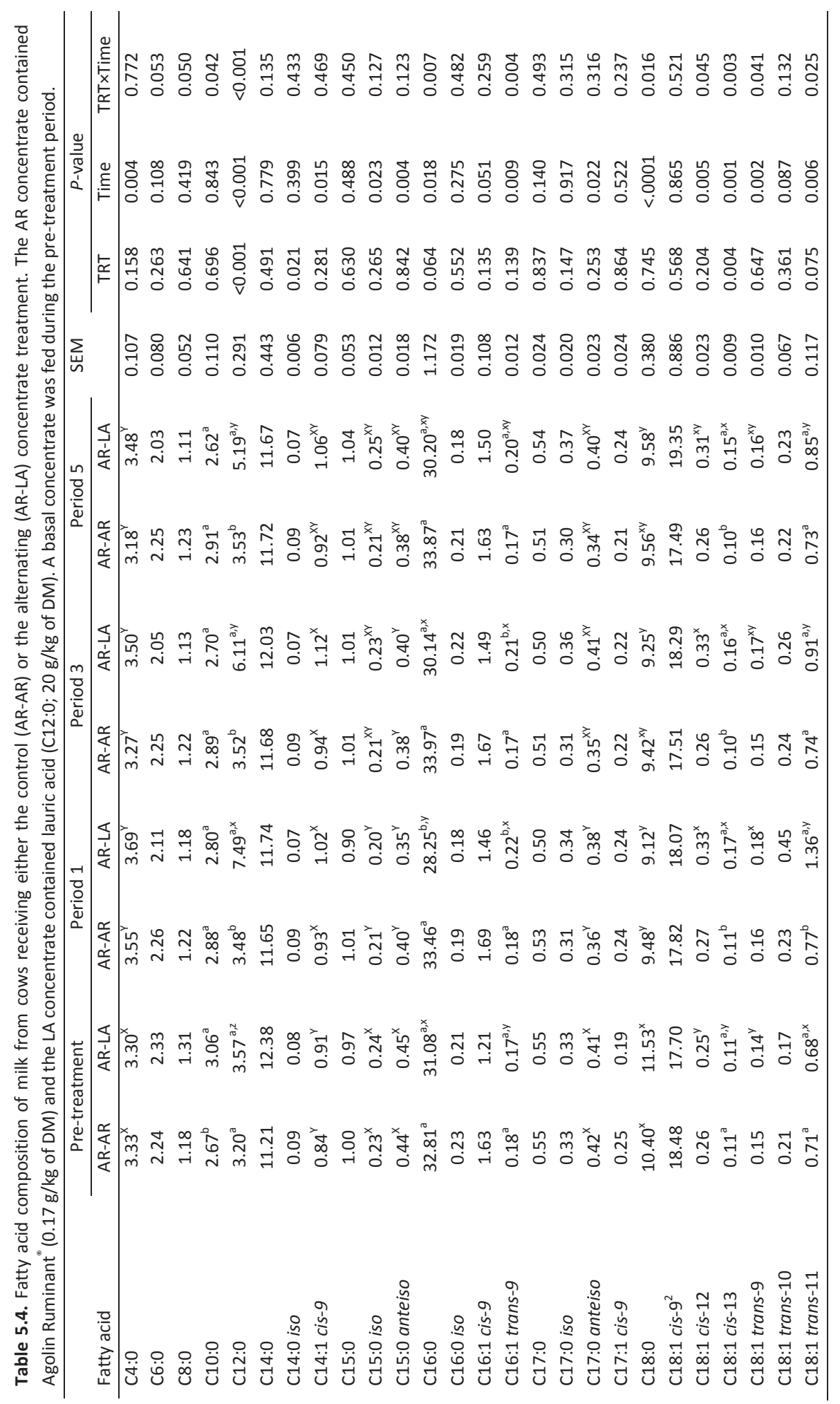




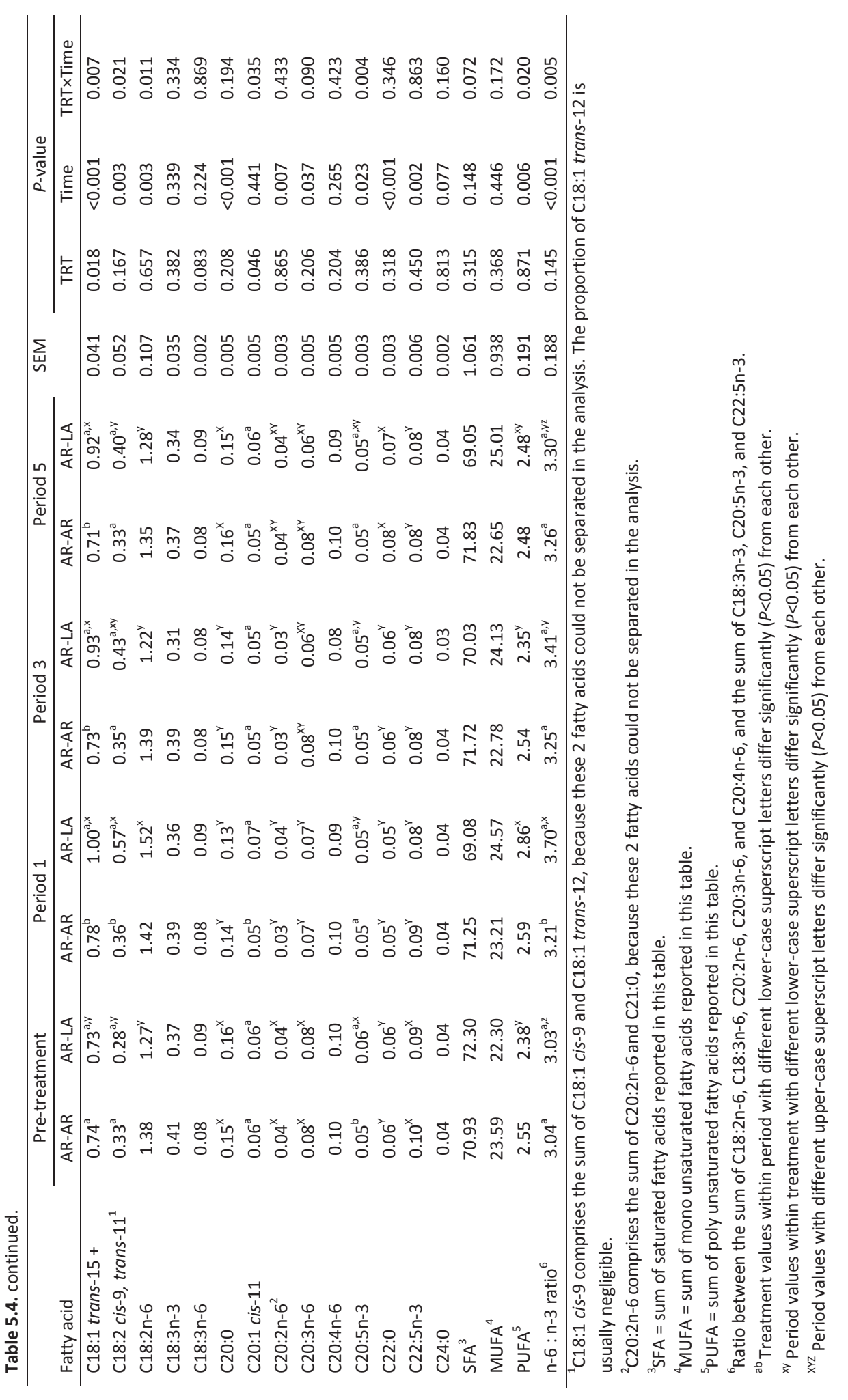




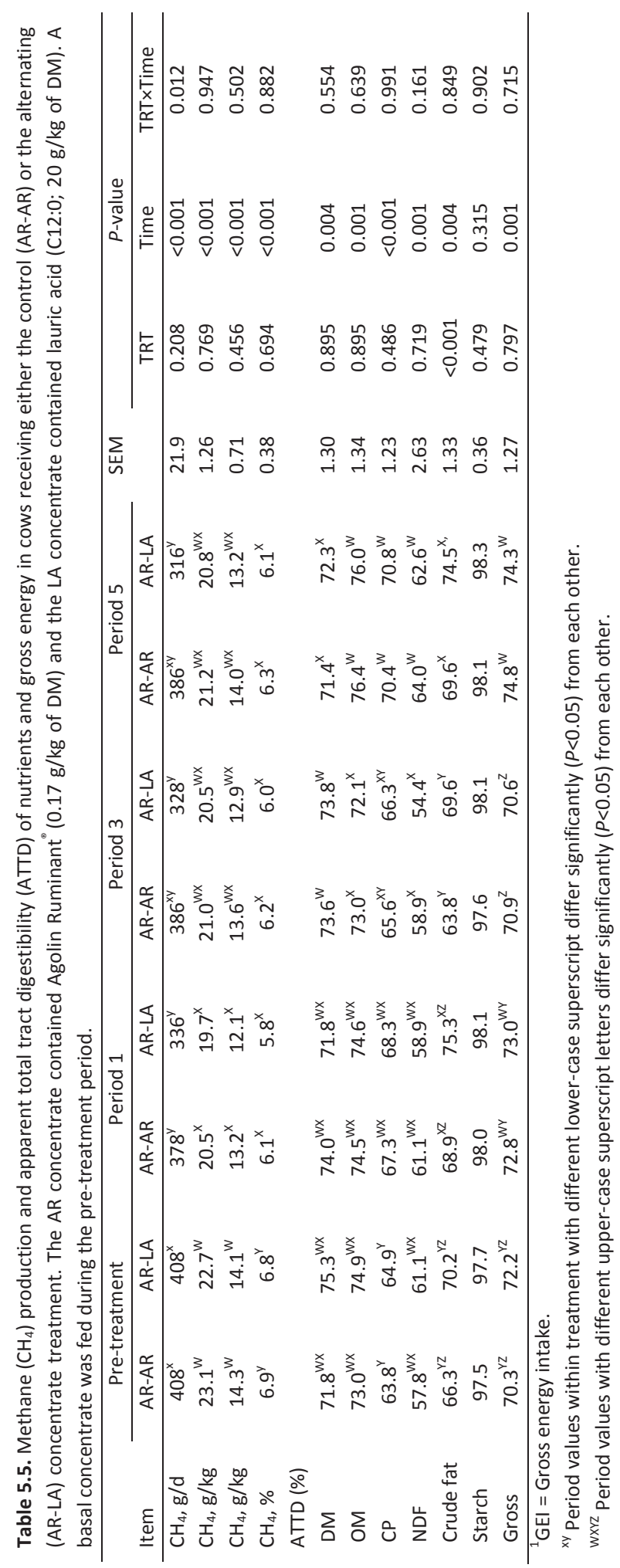


proportion of $\mathrm{C} 18: 0$ in milk fat was reduced in period 1 compared to the pre-treatment period, but not in periods 3 and 5 (Table 5.4). In several studies, milk C18:0 is not related to $\mathrm{CH}_{4}$ production (Van Gastelen and Dijkstra, 2016), but decreases towards the end of a lactation cycle (Stoop et al., 2009). Overall, Agolin Ruminant ${ }^{\circledR}$ does not seem to have caused major shifts in the milk FA profile.

\section{Methane emission}

A significant treatment $\times$ time interaction was observed for $\mathrm{CH}_{4}$ production $(\mathrm{g} / \mathrm{d})(\mathrm{Table}$ 5.5). Methane production with AR-AR in period 1 was lower than in the pre-treatment period ( $7 \%$ lower), but in period 3 and 5 did not differ with the pre-treatment period (5\% lower; numerically only). However, with the AR-LA treatment, methane production in periods 1, 3 and 5 was significantly lower (on average 20\%) than in the pre-treatment period. The reduced DMI in period 3 and 5 with the AR-LA treatment but not with the ARAR treatment offers an explanation for the treatment $\times$ time interaction that was observed for $\mathrm{CH}_{4}$ production. Both $\mathrm{CH}_{4}$ yield $\left(\mathrm{g} / \mathrm{kg}\right.$ of DMI) and $\mathrm{CH}_{4}$ intensity (g/kg FPCM) changed over time, but were not affected by treatment. Methane yield and intensity were significantly lower (12 and 11\%, respectively) in period 1 compared with the pretreatment period, but no significant difference relative to pre-treatment period was observed in period 3 (numerically 9 and 7\% lower, respectively) and in period 5 (numerically 8 and $4 \%$ lower, respectively). Similarly, $\mathrm{CH}_{4}$ energy loss (expressed as a fraction of GE intake) was lower in period 1 compared with pre-treatment period, but in period 3 and 5 the difference with pre-treatment period was not present anymore.

The results suggest that upon continuous feeding of Agolin the $\mathrm{CH}_{4}$ mitigating effect in the initial 2 weeks is larger than from wk 5 onwards, indicating adaptation to the blend of essential oils used. Furthermore, the absence of a more persistent decrease of $\mathrm{CH}_{4}$ yield and intensity with rotational feeding implies that this rotation does not prevent or retard adaptation. In a previous experiment (Chapter 4), in which rumen fluid was collected as inoculum from donor cows fed Agolin Ruminant ${ }^{\circledR}$, in vitro $\mathrm{CH}_{4}$ production was decreased 8 $\mathrm{d}$ after introduction of the additive to the donor cow diet, but no effect was observed after 15 and $21 \mathrm{~d}$. In the same study, feeding C12:0 to donor cows showed a persistent 
decrease in $\mathrm{CH}_{4}$ production in vitro. Based on these in vitro results, in the present experiment we evaluated the hypothesis that in vivo, the AR-AR treatment would result in a transient drop of $\mathrm{CH}_{4}$ production, whereas AR-LA would decrease $\mathrm{CH}_{4}$ persistently. In their review of in vitro batch culture systems, Yáñez-Ruiz et al. (2016) made several recommendations related to potential differences in microbial profile and adaptation, including using the same donor animals as the target species, choosing diets and incubation substrates with similar nutrient composition, adapting donor animals to the experimental diet before rumen fluid collection, rumen fluid collection before morning feeding, and applying a restricted feeding regime to obtain a better interpretation of in vitro data for the in vivo situation. In the experiment described in Chapter 4, many of those criteria were met, but nevertheless the hypothesis based on these vitro results could not be confirmed based on results of the present study. Also Hatew et al. (2015b) observed a poor relationship between in vitro and in vivo $\mathrm{CH}_{4}$ production (expressed in $\mathrm{g} / \mathrm{kg} \mathrm{OM}$ ) when using cows in the in vivo trial as donor animals, although a moderate relationship was obtained when $\mathrm{CH}_{4}$ was expressed per unit rumen fermentable OM. The present results support the conclusion by Yáñez-Ruiz et al. (2016) that results from in vitro incubations have to be interpreted with care, before such mitigation strategies can be translated to the in vivo situation.

Castro-Montoya et al. (2015) supplemented a similar dose of Agolin Ruminant ${ }^{\circ}(1 \mathrm{~g} / \mathrm{cow} / \mathrm{d}$ ) as used in the present study to a diet composed of grass silage (460 g/ $/ \mathrm{kg}$ of DM), corn silage ( $370 \mathrm{~g} / \mathrm{kg}$ of DM), soybean meal $(50 \mathrm{~g} / \mathrm{kg}$ of DM) and concentrates ( $120 \mathrm{~g} / \mathrm{kg}$ of DM) for 6 wk. In their experiment, Agolin Ruminant in wk 2 and 6 after first introduction tended to persistently lessen $\mathrm{CH}_{4}$ production and $\mathrm{CH}_{4}$ yield by 15 and $14 \%$, respectively, but methane intensity was not affected. The overall average $\mathrm{CH}_{4}$ production of $247 \mathrm{~g} / \mathrm{d}$ and $15.8 \mathrm{~g} / \mathrm{kg}$ of DMI during the weeks that Agolin Ruminant was fed was lower than in the present study. Methane expressed per kg milk was similar, because of a higher milk production of cows in the present study. Interestingly, in an experiment with beef cattle of the same authors (Castro-Montoya et al., 2015), daily $\mathrm{CH}_{4}$ production and $\mathrm{CH}_{4}$ yield did not change upon Agolin Ruminant supplementation in wk 2, 4 or 6. 


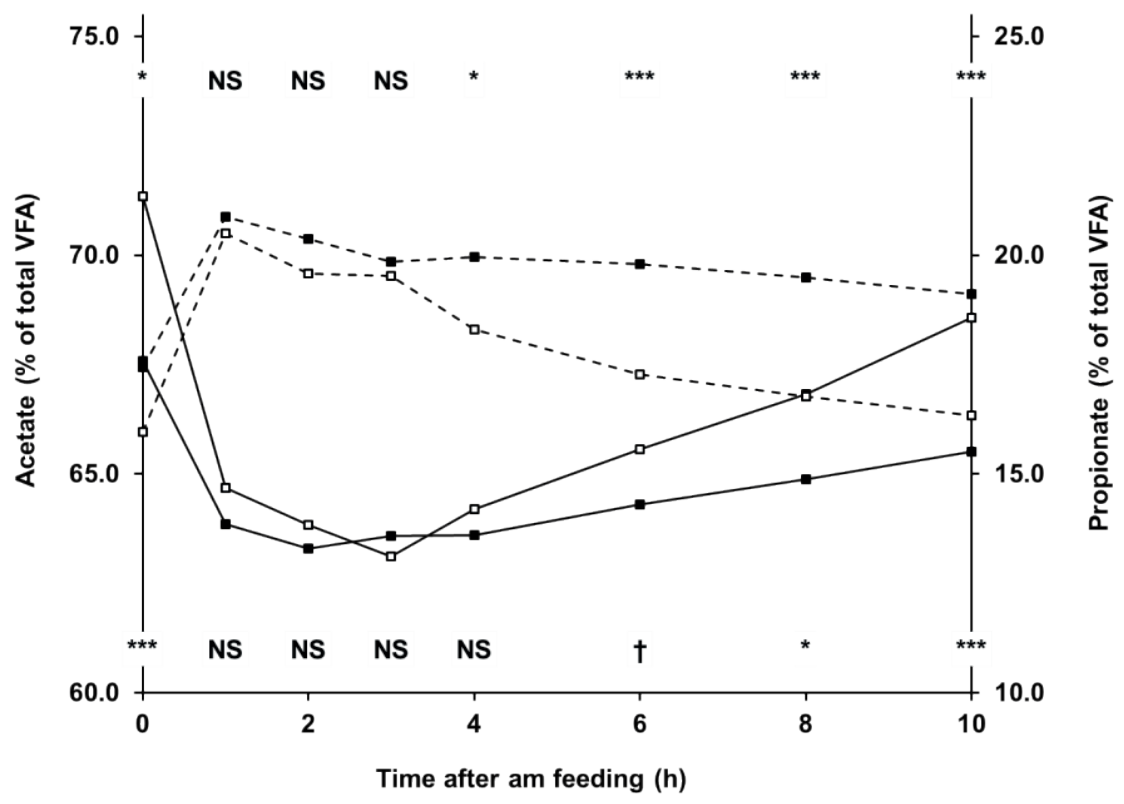

Figure 5.1. Molar percentage of acetate (solid lines) and propionate (dashed lines) as \% of total volatile fatty acids (VFA) in rumen fluid from cows after a.m. feeding of either the AR-AR treatment (Agolin Ruminant $(0.17 \mathrm{~g} / \mathrm{kg}$ of DM; $\square ; n=2)$ ) or the AR-LA treatment (weekly rotation of Agolin Ruminant $^{\circ}(0.17 \mathrm{~g} / \mathrm{kg}$ of DM) and lauric acid $(20 \mathrm{~g} / \mathrm{kg}$ of DM; $\mathbf{\square} ; \mathrm{n}=2)$ ). Each data point represents the treatment average of the pre-treatment period, period 2 and period 4 for the hours indicated. Symbols indicate significance of treatment differences at each time point (NS not significant; $\uparrow 0.05$ $<P<0.10 ; * P<0.05 ; * * P<0.01 ; * * * P<0.001)$. The top row of symbols relates to propionate and the bottom row to acetate. Pooled SEM values were 0.44 and 0.43 for acetate and propionate, respectively.

Van Zijderveld et al. (2011) found that feeding a mixture of additives (C12:0, C14:0, linseed oil, and calcium fumarate) decreased $\mathrm{CH}_{4}$ production and $\mathrm{CH}_{4}$ energy loss as a fraction of gross energy intake, but the additive mixture did not affect $\mathrm{CH}_{4}$ yield or intensity. In the study of Külling et al. (2002), the addition of $\mathrm{C} 12: 0$ (40 g/kg of DM) reduced $\mathrm{DMI}, \mathrm{CH}_{4}$ production and $\mathrm{CH}_{4}$ intensity (expressed in $\mathrm{g} / \mathrm{kg}$ energy corrected milk) compared with the C18:0 control diet. No effect was observed for $\mathrm{CH}_{4}$ yield. Martin et al. (2010) concluded that $\mathrm{C} 12: 0$ and $\mathrm{C} 14: 0$ have a more depressive effect on $\mathrm{CH}_{4}$ emission than other fatty acids. 
However, Grainger and Beauchemin (2011) did not find an effect of type of fatty acid (C12:0, C14:0, C18:1, C18:2, C18:3) on $\mathrm{CH}_{4}$ yield when total fat was restricted to $<80 \mathrm{~g} / \mathrm{kg}$ of DM. The present experiment had a dietary fat content of up to $57 \mathrm{~g} / \mathrm{kg}$ of DM and is within this range.

In view of the transitory decline in $\mathrm{CH}_{4}$ yield and intensity with Agolin Ruminant, and given the negative effects of $\mathrm{C} 12: 0$ on feed intake, it is worthwhile to investigate rotational feeding of Agolin Ruminant in combination with another compound than in the present study.

\section{Digestibility of nutrients}

Apparent total tract digestibility of nutrients was not affected by time $\times$ treatment interaction or treatment, except for crude fat (Table 5.5). The higher fat digestibility in ARLA cows is most likely caused by the difference in fat content between the AR and LA concentrate (Table 5.2). If fat supplementation is higher, the calculated digestibility values are less affected by fecal excretion of endogenous fat sources (Kil et al., 2010). Faciola and Broderick (2014) reported that both ruminal and total tract fiber digestion were depressed following C12:0 supplementation. In general, milk fat depression caused by intermediates of ruminal biohydrogenation may be associated with factors including low rumen $\mathrm{pH}$ and reduced fiber degradation in the rumen (Bauman and Griinari, 2003). The absence of a treatment effect on NDF digestibility in the present study may explain why milk fat content was also not significantly affected with the AR-LA treatment. The period did significantly affect ATTD of most nutrients, with in general a lower digestibility in period 3 than in other periods. The reason for this lower digestibility is unknown.

\section{Rumen $\mathrm{pH}$ and VFA}

Average rumen $\mathrm{pH}$ and total VFA concentration were not affected by treatment (Table 5.6). Molar proportions of acetate and propionate were lower and higher, respectively, in the AR-LA treatment compared with the AR-AR treatment, resulting in a significantly lower $A: P$ ratio with the AR-LA treatment. No treatment $\times$ time interaction was found for these parameters, but the numerical differences between AR-AR and AR-LA were larger during 
the treatment period than during the pre-treatment period (Table 5.6), and in particular the numerical difference in the A:P ratio became larger with advanced period. Molar proportion of acetate in AR-LA was lower at 0,8 and $10 \mathrm{~h}$ after am feeding, and tended to be lower at $6 \mathrm{~h}$ after am feeding compared with that in AR-AR (Figure 5.1). Hristov et al. (2011) and Faciola and Broderick (2014) reported reduced VFA concentrations (123 and $128 \mathrm{mM}$ for $\mathrm{C} 12: 0$ and control, respectively), and in line with the present results reported reduced molar proportion of acetate $(63.7$ and $65.0 \%$ of total VFA for C12:0 and control, respectively) following $\mathrm{C} 12: 0$ supplementation. In both studies rumen samples were collected at multiple time points relative to feeding, but only averaged values were reported.

In the present study, the molar proportion of propionate was higher in the AR-LA treatment than in the AR-AR treatment from $4 \mathrm{~h}$ post feeding onwards at the expense of acetate (Figure 5.1). Feeding C12:0 often reduces protozoa counts in rumen fluid (Hristov et al., 2011; Faciola et al., 2014). In the meta-analysis by Eugène et al. (2008) defaunation resulted in a decreased molar proportion of acetate and butyrate, and an increased molar proportion of propionate in rumen fluid, which might be associated with less $\mathrm{CH}_{4}$ production. Impaired fiber degradation in the rumen may also cause a relative increase in propionate proportion. Apparent total tract digestibility of NDF was not affected by additive treatment in this study, although numerically values were lower for AR-LA than AR-AR during periods 1, 3 and 5 (Table 5.5). As discussed by Van Zijderveld et al. (2011) a negative effect of a treatment on ruminal fiber degradation may be partly compensated by fermentation in the hindgut. The latter will yield less nutrients to support milk production than rumen degradation of fiber. Probably the lower DMI of the AR-LA treatment in the present study resulted in longer rumen retention time of feed. This might have alleviated treatment effects on NDF digestibility. 


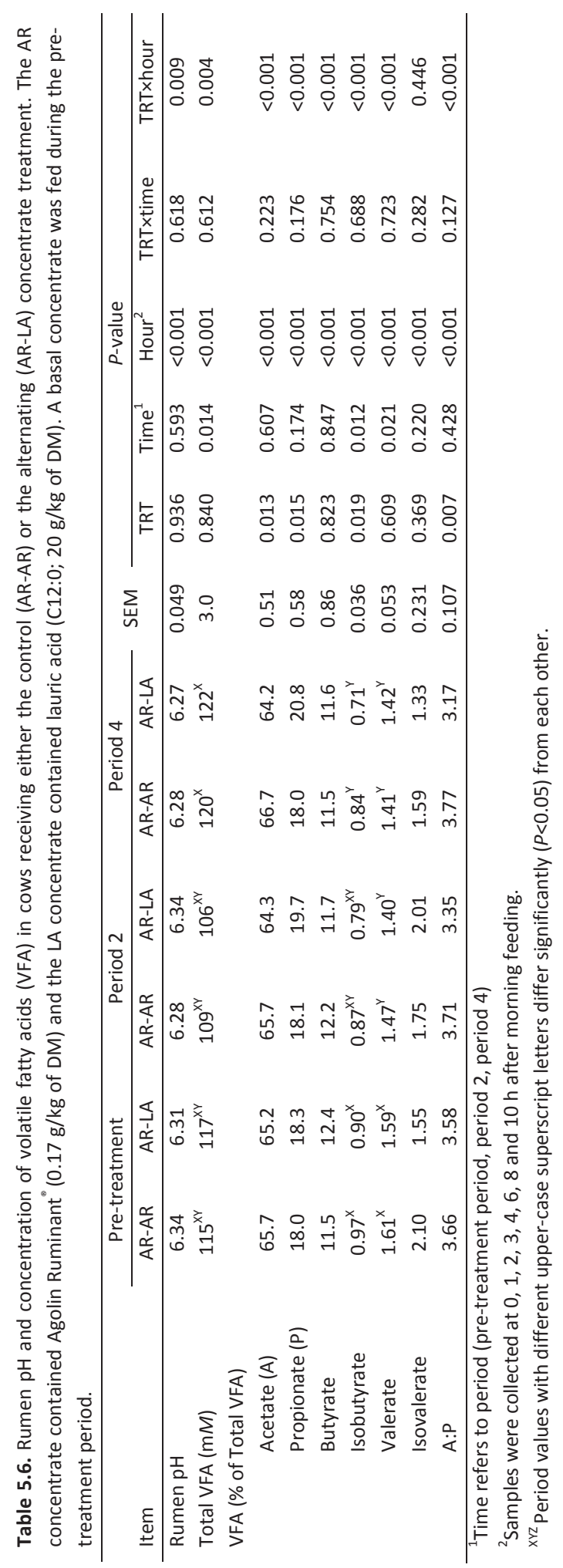




\section{CONCLUSIONS}

In the present study, continuous feeding of Agolin Ruminant as well as rotational feeding of Agolin Ruminant and $\mathrm{C} 12: 0$ resulted in a transient decline in $\mathrm{CH}_{4}$ yield and intensity. The rotational feeding of Agolin Ruminant and C12:0 did not improve the extent and persistency of $\mathrm{CH}_{4}$ mitigation compared with Agolin Ruminant ${ }^{\circledR}$ only. Dietary levels of C12:0 appeared to be too high for application in practice, as DMI was reduced in the rotation treatment. Future research should clarify if rotational feeding of $\mathrm{CH}_{4}$ mitigating additives (with a transient effect) can result in a persistent mitigation effect.

\section{ACKNOWLEDGEMENTS}

Stefan Regelink and Sanne Klerx (Wageningen University, The Netherlands) and the staff of the experimental facilities 'Carus' are gratefully acknowledged for their assistance during the experiment. This study is part of the 'Low Emission Animal Feed' project. Authors acknowledge financial support of the Dutch Ministry of Economic Affairs (The Hague, the Netherlands), Product Board Animal Feed (Zoetermeer, the Netherlands) and the Dutch Dairy Board (Zoetermeer, the Netherlands), and acknowledge the TI Food and Nutrition project 'Reduced methane emission of dairy cows' for providing milk FA data.

\section{REFERENCES}

Bauman, D. E., and J. M. Griinari 2003. Nutritional regulation of milk fat synthesis. Annu. Rev. Nutr. 23:203-227.

Beckie, H. J. 2006. Herbicide-resistant weeds: management tactics and practices. Weed Technol. 20:793-814.

Benchaar, C., H. V. Petit, R. Berthiaume, D. R. Ouellet, J. Chiquette, and P. Y. Chouinard. 2007. Effects of essential oils on digestion, ruminal fermentation, rumen microbial populations, milk production, and milk composition in dairy cows fed alfalfa silage or corn silage. J. Dairy Sci. 90:886-897. 
Castro Montoya, J., A. M. Bhagwat, N. Peiren, S. De Campeneere, B. De Baets, and V. Fievez. 2011. Relationships between odd- and branched-chain fatty acid profiles in milk and calculated enteric methane proportion for lactating dairy cattle. Anim. Feed Sci. Technol. 166:596-602.

Castro-Montoya J., N. Peiren, J. W. Cone, B. Zweifel, V. Fievez, and S. De Campeneere. 2015. In vivo and in vitro effects of a blend of essential oils on rumen methane mitigation. Livest. Sci. 180:134-142.

Chapman, H. D. 2001. Use of anticoccidial drugs in broiler chickens in the USA: Analysis for the years 1995 to 1999. Poultry Sci. 80:572-580.

CVB. 2008. CVB Table booklet feeding of ruminants. CVB series no. 43. Centraal Veevoederbureau, Lelystad, the Netherlands.

Dieho, K., J. Dijkstra, J. T. Schonewille, and A. Bannink. 2016. Changes in ruminal volatile fatty acid production and absorption rate during the dry period and early lactation as affected by rate of increase of concentrate allowance. J. Dairy Sci. 99:5370-5384.

Dohme, F., A. Machmüller, F. Sutter, and M. Kreuzer. 2004. Digestive and metabolic utilization of lauric, myristic and stearic acid in cows, and associated effects on milk fat quality. Arch. Anim. Nutr. 58:99-116.

Eugène, M., H. Archimède, and D. Sauvant. 2004. Quantitative meta-analysis on the effects of defaunation of the rumen on growth, intake and digestion in ruminants. Livest. Prod. Sci. 85:8581-8597.

Faciola, A. P., and G. A. Broderick. 2014. Effects of feeding lauric acid or coconut oil on ruminal protozoa numbers, fermentation pattern, digestion, omasal nutrient flow, and milk production in dairy cows. J. Dairy Sci. 97:5088-5100.

Grainger, C. and K. A. Beauchemin. 2011. Can enteric methane emissions from ruminants be lowered without lowering their production? Anim. Feed Sci. Technol. 166-167:308-320.

Guan, H., K. M. Wittenberg, K. H. Ominski, and D. O. Krause. 2006. Efficacy of ionophores in cattle for mitigation of enteric methane. J. Anim. Sci. 84:1896-1906.

Hatew, B., S. C. Podesta, H. van Laar, W. F. Pellikaan, J. L. Ellis, J. Dijkstra, and A. Bannink. $2015 a$. Effects of dietary starch content and rate of fermentation on methane production in lactating dairy cows. J. Dairy Sci. 98:486-499.

Hatew B, J. W. Cone, W. F. Pellikaan, S. C. Podesta, A. Bannink, W. H. Hendriks, and J. Dijkstra. 2015b. Relationship between in vitro and in vivo methane production measured simultaneously with different dietary starch sources and starch levels in dairy cattle. Anim. Feed Sci. Technol. 202:20-31. 
Hristov, A. N., C. Lee, T. Cassidy, M. Long, K. Heyler, B. Corl, and R. Forster. 2011. Effects of lauric and myristic acids on ruminal fermentation, production, and milk fatty acid composition in lactating dairy cows. J. Dairy Sci. 94:382-395.

ISO 2004. NEN-EN-ISO 1735:2004. Cheese and processed cheese products - Determination of fat content - Gravimetric method (reference method). International Standards Organization. Geneva. Switzerland.

Kil, D. Y., T. E. Sauber, D. B. Jones, and H. H. Stein. 2010. Effect of the form of dietary fat and the concentration of dietary neutral detergent fiber on ileal and total tract endogenous losses and apparent and true digestibility of fat by growing pigs. J. Anim. Sci. 88:2959-2967.

Klop, G., B. Hatew, A. Bannink, and J. Dijkstra. 2016. Feeding nitrate and docosahexaenoic acid affects enteric methane production and milk fatty acid composition in lactating dairy cows. J. Dairy Sci. 99:1161-1172.

Külling, D. R., F. Dohme, H. Menzi, F. Sutter, P. Lischer, and M. Kreuzer. 2002. Methane emissions of differently fed dairy cows and corresponding methane and nitrogen emissions from their manure during storage. Environ. Monit. Assess.79:129-150.

Martin, C., D. P. Morgavi, and M. Doreau. 2010. Methane mitigation in ruminants: from microbe to the farm scale. Animal 4:351-365.

Piperova, L. S., B. B. Teter, I. Bruckental, J. Sampugna, S. E. Mills, M. P. Yurawecz, J. Fritsche, K. Ku, and R. A. Erdman. 2000. Mammary lipogenic enzyme activity, trans fatty acids and conjugated linoleic acids are altered in lactating dairy cows fed a milk fat-depressing diet. J. Nutr. 130:2568-2574.

Santos, M. B., P. H. Robinson, P. Williams, and R. Losa. 2010. Effects of addition of an essential oil complex to the diet of lactating dairy cows on whole tract nutrient digestion and productive performance. Anim. Feed Sci. Technol. 157:64-71.

Stoop, W. M., H. Bovenhuis, J. M. L. Heck, and J. A. M. van Arendonk. 2009. Effect of lactation stage and energy status on milk fat composition of Holstein-Friesian cows. J. Dairy Sci. 92:14691478.

Van Gastelen, S., E. C. Antunes-Fernandes, K. A. Hettinga, G. Klop, S. J. J. Alferink, W. H. Hendriks, and J. Dijkstra. 2015. Enteric methane production, rumen volatile fatty acid concentrations, and milk fatty acid composition in lactating Holstein-Friesian cows fed grass silage- or corn silage-based diets. J. Dairy Sci. 98:1915-1927.

Van Gastelen, S., and J. Dijkstra. 2016. Prediction of methane emission from lactating dairy cows using milk fatty acids and mid-infrared spectroscopy. J. Sci. Food Agric. In press. http://dx.doi.org/10.1002/jsfa.7718. 
Van Zijderveld, S. M., B. Fonken, J. Dijkstra, W. J. J. Gerrits, H. B. Perdok, W. Fokkink, and J. R. Newbold. 2011. Effects of a combination of feed additives on methane production, diet digestibility, and animal performance in lactating dairy cows. J. Dairy Sci. 94:1445-1454.

Vlaeminck, B., V. Fievez, A. R. J. Cabrita, A. J. M. Fonseca, and R. J. Dewhurst. 2006. Factors affecting odd- and branched-chain fatty acids in milk: a review. Anim. Feed Sci. Technol. 131:389-417.

Walker G. P., F. R. Dunshea, and P. T. Doyle. 2004. Effects of nutrition and management on the production and composition of milk fat and protein: a review. Austr. J. Agric. Res. 55:1009_ 1028.

Yáñez-Ruiz, D. R., A. Bannink, J. Dijkstra, E. Kebreab, D. P. Morgavi, P. O’Kiely, C. K. Reynolds, A. Schwarm, K. J. Shingfield, Z. Yu, and A. N. Hristov. 2016. Design, implementation and interpretation of in vitro batch culture experiments to assess enteric methane mitigation in ruminants - a review. Anim. Feed Sci. Technol. 216:1-18. 


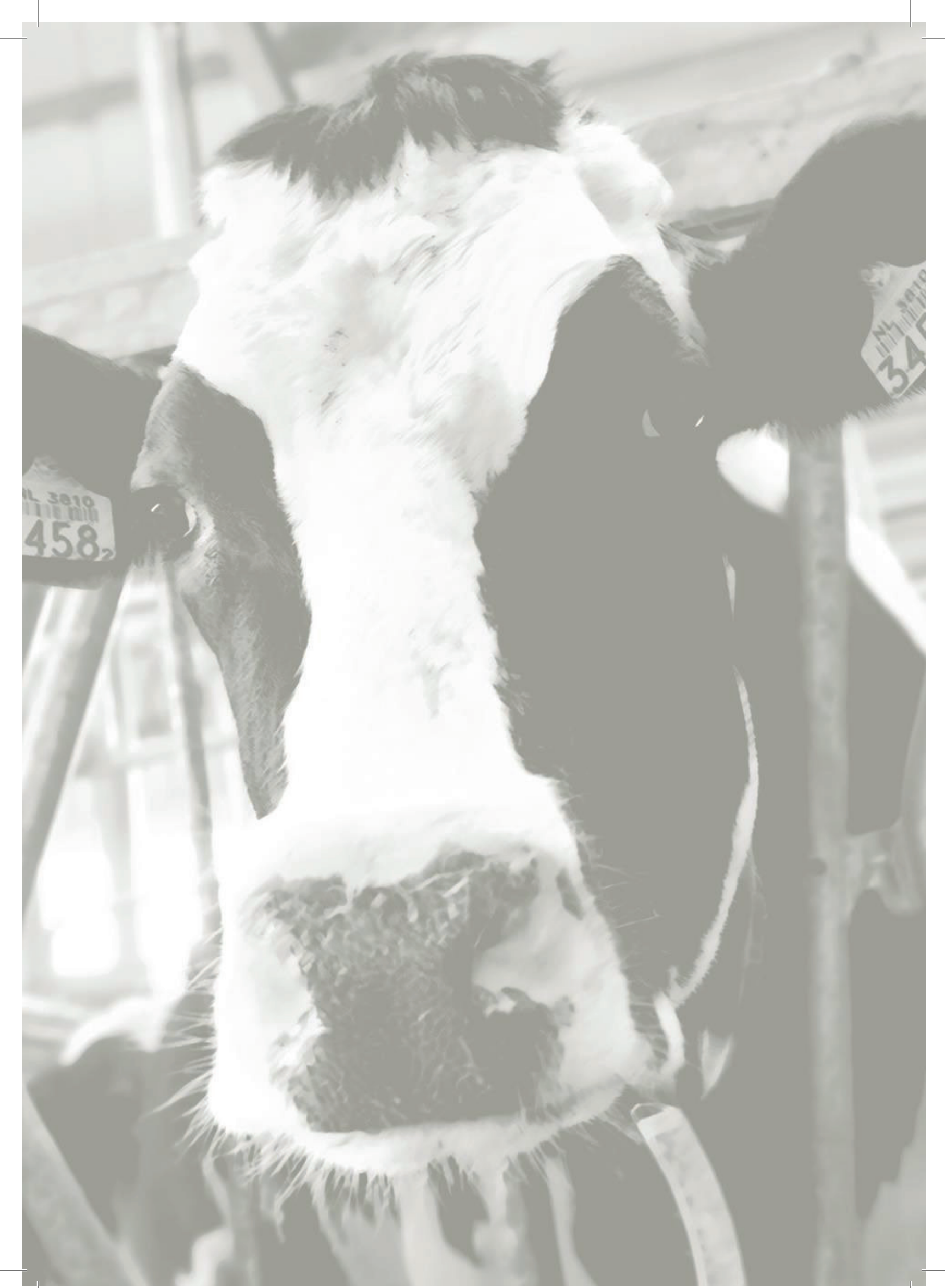


Chapter 6

General discussion 


\section{GENERAL DISCUSSION}

\section{Background and aims of this thesis}

Over the past decades, there have been extensive research efforts aimed at identifying and developing feed additives to mitigate enteric $\mathrm{CH}_{4}$ production by ruminants. According to Regulation (EC) No 1831/2003 on additives for use in animal nutrition, feed additives can be defined as substances, micro-organisms or preparations, other than feed material and premixtures, which are intentionally added to feed or water in order to perform one of the particular functions listed in the regulation. One of these functions is that the additive shall favorably affect the environmental consequences of animal production, and this aspect is relevant to the research described in this thesis. Methane production is often expressed as $\mathrm{CH}_{4}$ yield ( $\mathrm{g} / \mathrm{kg}$ of $\left.\mathrm{DMI}\right)$ and $\mathrm{CH}_{4}$ intensity $[\mathrm{g} / \mathrm{kg}$ fat- and protein-corrected milk (FPCM)]. At present, the search and development of enteric $\mathrm{CH}_{4}$ mitigate additive is ongoing and it has become clear that several issues have to be resolved before such feed additives can be applied as a viable mitigation strategy. These issues include for example, long term efficacy, interaction with diet and other additives, safety, environmental tradeoffs and adverse effects on animal health and performance.

Feeding nitrate is an example of an effective feed additive-based mitigation strategy that also may have some undesirable side effects. It is commonly agreed that feeding nitrate to ruminant animals decreases $\mathrm{CH}_{4}$ production (see Van Zijderveld et al., 2011b; Lund et al., 2014; Guyader et al., 2015, 2016; Troy et al., 2015; Olijhoek et al., 2016). However, feeding nitrate imposes several restrictions on the formulation of the total diet. To avoid trade-offs in nitrogen $(\mathrm{N})$ emissions to the environment, the basal diet should be low in rumen degradable $\mathrm{N}$ (e.g. corn silage based). This limits the applicability in countries with $\mathrm{N}$-rich pasture based systems, or diets containing relatively large amounts of high quality grass silage.

Besides economic aspects and the possible trade-offs in environmental impact, feeding relatively high doses of nitrate increases the risk of methemoglobinemia. This condition may occur when nitrite, an intermediate in the nitrate reduction process, accumulates in 
the rumen and enters the bloodstream. Nitrite causes the conversion of hemoglobin into methemoglobin, with the latter being unable to transport oxygen. Although there is considerable evidence that gradual adaptation and feeding regime (reviewed by Lee and Beauchemin, 2014) successfully alleviates the risk of methemoglobinemia, it remains a potential health risk associated with nitrate supplementation. A third aspect that may be negatively affected is DMI (Newbold et al., 2014; Lee et al., 2015), which lowers reduction in $\mathrm{CH}_{4}$ intensity due to a reduced animal performance.

Despite aforementioned side effects, an important advantage of nitrate as a $\mathrm{CH}_{4}$ mitigation strategy is that the effects persist over time (Van Zijderveld et al., 2011b). Persistency is an important criterion in the search for feed additive-based $\mathrm{CH}_{4}$ mitigation strategies because adaptation of the rumen microbes to the additive may occur, and an initial reduction in $\mathrm{CH}_{4}$ production may become much smaller or even absent in the longer term. For example, promising results on $\mathrm{CH}_{4}$ reduction using essential oils or their active ingredients have been obtained using in vitro batch cultures, whereas no or only a temporary effect on fermentation characteristics was found in continuous cultures or in vivo (Benchaar and Greathead, 2011; Van Zijderveld et al., 2011a). Cardozo et al. (2004) reported a transient effect of plant extracts on fermentation characteristics that disappeared after six days. The latter indicates that microbial adaptation can occur after short term exposure.

In summary, the application of $\mathrm{CH}_{4}$ mitigation feed additives may have several negative side effects including trade-offs on other environmental impacts, negative effects on animal health and performance, and lack of persistency of the mitigating effect. The overall aim of this project was to investigate these aspects of application of feed additives as a $\mathrm{CH}_{4}$ mitigation strategy, going beyond the evaluation of the effect of single feed additives commonly reported in literature. This thesis had the following objectives, which address aspects of interaction between feed additives, adaptation of the rumen microbiota to feed additives, and consequences of an alternating application of feed additives: 
1. To investigate if the effects of two different feed additives, with different modes of action on $\mathrm{CH}_{4}$ production, are additive.

2. To study adaptation to potential $\mathrm{CH}_{4}$ mitigating feed additives in vivo, using the in vitro gas production technique.

3. To compare $\mathrm{CH}_{4}$ production and performance of dairy cows fed either a single feed additive, or two different additives according to a rotation schedule.

\section{Additivity}

Nitrate is effective in decreasing $\mathrm{CH}_{4}$ production (Hristov et al., 2013), but unwanted side effects hamper wide spread adoption. Moreover, the strategy is not cost-effective yet (Van Middelaar et al., 2014). Fat supplementation is also known to have $\mathrm{CH}_{4}$ mitigating effects (Grainger and Beauchemin, 2011; Patra, 2013), but high inclusion levels of fat or specific fatty acids may adversely affect DMI, fiber digestion and milk fat or protein concentration. Usually the negative effects of feed additives occur at higher inclusion levels (Walker et al., 2004) and, therefore, it is worth investigating if the mitigating effects of two additives in the rumen are additive. If so, a similar decrease in $\mathrm{CH}_{4}$ production can be achieved by combining a lower dose of both individual additives, to alleviate the risk of these negative side effects.

Van Zijderveld et al. (2010) reported an additive effect of nitrate and sulfate on $\mathrm{CH}_{4}$ production. However, these additives both act as an alternative hydrogen $\left(\mathrm{H}_{2}\right)$ sink and the inclusion level of sulfate in ruminant diets is limited to avoid the occurrence of polioencephalomalacia (Gould, 1998; NRC, 2001). Recently, after completion of the experiment described in Chapter 2, Guyader et al. (2015) reported additive effects of nitrate and linseed oil, additives with different modes of action, on $\mathrm{CH}_{4}$ emission, with a trend $(P=0.07)$ for an interaction effect when $\mathrm{CH}_{4}$ was expressed per unit digested NDF.

In the experiment described in Chapter 2, the additivity of the effects of nitrate and docosahexaenoic acid (C22:n-6; DHA) on $\mathrm{CH}_{4}$ production and performance was investigated in lactating dairy cows. These additives have a different mode of action in the rumen, where nitrate acts as an alternative $\mathrm{H}_{2}$ sink (Van Zijderveld et al., 2010) and DHA 
has an effect on microbial metabolism in the rumen (Boeckaert et al., 2008a). In vitro $\mathrm{CH}_{4}$ production was reduced upon DHA supplementation (Fievez et al., 2007), but these results have not (yet) been confirmed in vivo (Moate et al., 2013). If DHA would decrease $\mathrm{CH}_{4}$ production, the inclusion level has to be limited as high inclusion levels of DHA were shown to induce severe milk fat depression and reduce DMI (Boeckaert et al., 2008b; Moate et al., 2013).

The results of the experiment described in Chapter 2 indicate that there was no interaction between the additives in affecting $\mathrm{CH}_{4}$ production (and their effect is hence additive). However, DHA did not reduce $\mathrm{CH}_{4}$ production in $\mathrm{g} / \mathrm{kg} \mathrm{DMI}$, and even increased $\mathrm{CH}_{4}$ production in $\mathrm{g} / \mathrm{kg}$ FPCM, largely as a result of milk fat depression. Therefore, this particular combination of feed additives does not allow for a lower inclusion level of nitrate. Guyader et al. (2015) tested the additivity of the effects of nitrate and linseed oil on $\mathrm{CH}_{4}$ production in non-lactating cows. They concluded that effects on $\mathrm{CH}_{4}$ production were additive, although a trend was observed for $\mathrm{CH}_{4}$ production per unit digested NDF, and the reduction in $\mathrm{CH}_{4}$ yield with nitrate and linseed oil combined (-31\%) was numerically smaller than the sum of individual reductions (nitrate, $-22 \%$; linseed oil, $-17 \%$ ). In a follow-up study the effect of a combination of nitrate and linseed oil on enteric $\mathrm{CH}_{4}$ production and nitrate and nitrite residuals in milk was compared to a control diet (Guyader et al., 2016). The combination of nitrate and linseed reduced $\mathrm{CH}_{4}$ yield (-30\%), but also reduced DMI $(-13 \%)$, milk protein yield $(-15 \%)$, total volatile fatty acid $(-12 \%)$ and propionate $(-31 \%)$ concentrations, which indicates that the applied doses $(1.8 \%$ nitrate and $3.5 \%$ fat from linseed on a DM basis) where probably still too high to avoid adverse effects.

Although in the study described in Chapter 2 no interaction effect on $\mathrm{CH}_{4}$ production was observed, the effects of nitrate and DHA on apparent total tract digestibility of NDF where not additive, as discussed in Chapters 2 and 3. The presence of DHA seemed to alleviate negative effects of nitrate on fiber digestion. Guyader et al. (2015) observed a trend of reduced total tract NDF digestibility with linseed oil, without an effect of nitrate or linseed $x$ nitrate interaction. Numerically, the decline in NDF digestion with linseed oil and nitrate 
together was larger (-10\%) than the effect of linseed oil $(-1 \%)$ or nitrate $(+1 \%)$ only. In the experiment described in Chapter 2, a restricted feeding regime was imposed to avoid a confounding effect of DMI on $\mathrm{CH}_{4}$ production. Therefore, it is not certain if this interaction effect would also have been present if no feed restriction was applied. The applied treatments in Chapter 2 were: Control (CON); $\mathrm{NO}_{3}$ [21 g of nitrate/kg dry matter (DM)]; DHA [3 g of docosahexaenoic acid (DHA)/kg of DM]; or $\mathrm{NO}_{3}+\mathrm{DHA}$ (21 g of nitrate/kg of DM and $3 \mathrm{~g}$ of $\mathrm{DHA} / \mathrm{kg}$ of DM). Based on visual observations in the tie-stalls, the feed intake pattern of cows receiving $\mathrm{NO}_{3}, \mathrm{DHA}$ or $\mathrm{NO}_{3}+\mathrm{DHA}$ was more gradual than that of control cows. Cows on the control treatment were most restricted in their voluntary intake level which may explain why they consumed their meals faster. Although in the applied experimental setup it was not possible to quantify the difference in intake pattern, the diurnal pattern of the respiration quotient (Chapter 3) supports the visual observation of differences in the rate of feed intake. Further indications of differences in intake pattern are provided by rumen $\mathrm{pH}$ and volatile fatty acids (VFA) data. Table 6.1 and Figure 6.1 contain unpublished data from the experiment described in Chapter 2, in which rumen samples were collected during 2 consecutive days from the rumen-cannulated cows. When cows are fed twice daily, it is typically expected that rumen $\mathrm{pH}$ will decrease after a meal, and propionate as a fraction of total VFA will increase. This pattern was indeed observed in the control cows, but not in cows receiving one of the nitrate treatments. In particular, the VFA profile on the $\mathrm{NO}_{3}+\mathrm{DHA}$ treatment indicates a gradual, constant rate of fermentation, whereas in the control treatment there seems to be a sharp increase in fermentation shortly after feeding. These observations further support differences in feed intake pattern between treatments.

For molar proportions of propionate, acetate (and [acetate + butyrate]:propionate ratio; data not shown) a significant nitrate $\times$ time interaction was found (Table 6.1). The molar proportion of propionate in rumen fluid from cows receiving $\mathrm{NO}_{3}+\mathrm{DHA} 2 \mathrm{~h}$ after a.m. feeding was not different compared to the $\mathrm{NO}_{3}$ treatment, but was significantly lower than in cows receiving no nitrate (Figure 6.1). The absence of an increase in propionate proportion immediately after feeding nitrate seems to be the main reason for the overall reduction in molar proportion of propionate in the full period in between meals. 
Interestingly, Guyader et al. (2015) observed no effects of nitrate $\times$ DHA interaction on VFA parameters obtained immediately prior to the morning feeding, but a trend for an interaction was observed for molar proportion of propionate and the [acetate + butyrate]:propionate ratio, $3 \mathrm{~h}$ after morning feeding. Overall, some interesting differences were observed, including a non-additive effect of nitrate and DHA on the molar proportion of propionate (Table 6.1).

Aschenbach et al. (2009) reported that nitrate impaired acetate uptake through the rumen wall in vitro. Nolan et al. (2016) suggested this to be a possible explanation for a shift in VFA profile towards acetate that has been reported upon nitrate supplementation, both in vitro and in vivo (Zhou et al., 2012; Guyader et al., 2015, 2016; de Raphélis-Soissan et al., 2016a). However, in the study of Aschenbach et al. (2009) only acetate uptake was measured, and not uptake of propionate and butyrate. As the VFA uptake mechanisms generally are not VFA specific, it is likely that nitrate will also have inhibited the uptake of other VFA, instead of being specific for acetate.

Nolan et al. (2016) showed that methemoglobin (MetHb) levels in sheep receiving a diet containing $2 \%$ nitrate remained constant and low $(>12 \%$ of $\mathrm{Hb}$ ) until $10 \mathrm{~h}$ after the first meal, when the diet was fed in hourly portions of $42 \mathrm{~g}$. The MetHb levels in sheep receiving the same amount of feed $(1 \mathrm{~kg} / \mathrm{d})$ not in hourly portions, but in either one or two meals per day, peaked during the hours after feeding. The authors discuss that the rate of nitrate reduction is increased when animals eat rapidly and/or when a feed restriction is applied. The MetHb levels determined in the study described in Chapter 2, also remained below the threshold for a subclinical disorder, but these were determined during the period that no feed restriction was yet imposed. The formation of MetHb occurs as a result of nitrite absorption into the bloodstream. It is, therefore, likely that a more gradual intake pattern will alleviate nitrite accumulation in the rumen, and subsequent negative effects on digestion and animal health (Lee and Beauchemin, 2014; Nolan et al., 2016). Such an alteration in feed intake pattern may provide an explanation for the interaction effect between nitrate and DHA on fiber digestion (Chapter 2, and 3). 
Table 6.1. Total VFA concentration and VFA molar proportions in cows fed the control $(C O N ; n=2)$ diet or diets with nitrate $\left(\mathrm{NO}_{3} ; 21 \mathrm{~g} / \mathrm{kg} \mathrm{DM} ; \mathrm{n}=1\right)$, docosahexaenoic acid $(\mathrm{DHA} ; 3 \mathrm{~g} / \mathrm{kg} \mathrm{DM} ; \mathrm{n}=2)$ or nitrate and $\mathrm{DHA}\left(\mathrm{NO}_{3}+\mathrm{DHA}\right.$; $21 \mathrm{~g} / \mathrm{kg} \mathrm{DM}$ and $3 \mathrm{~g} / \mathrm{kg} \mathrm{DM} ; \mathrm{n}=2$ ) as feed additives

\begin{tabular}{|c|c|c|c|c|c|c|c|c|}
\hline \multirow[b]{2}{*}{ Item } & \multicolumn{4}{|c|}{ Treatment } & \multirow[b]{2}{*}{ SEM } & \multicolumn{3}{|c|}{$P$-value } \\
\hline & CON & $\mathrm{NO}_{3}$ & DHA & $\mathrm{NO}_{3}+\mathrm{DHA}$ & & $\mathrm{NO3}$ & DHA & $\mathrm{NO}_{3} \times \mathrm{DHA}$ \\
\hline Rumen $\mathrm{pH}$ & $6.4^{b}$ & $6.6^{\mathrm{a}}$ & $6.4^{b}$ & $6.4^{b}$ & 0.03 & 0.031 & 0.016 & 0.001 \\
\hline Total VFA (mM/L) & $102^{\mathrm{b}}$ & $95^{\mathrm{b}}$ & $101^{\mathrm{b}}$ & $110^{\mathrm{a}}$ & 2.0 & 0.752 & 0.006 & 0.001 \\
\hline \multicolumn{9}{|l|}{ VFA (mol/100 mol) } \\
\hline Acetate (A) & 66.6 & 66.5 & 64.9 & 66.1 & 0.43 & 0.242 & 0.043 & 0.152 \\
\hline Propionate & $17.3^{\mathrm{ab}}$ & $16.3^{\mathrm{bc}}$ & $18.9^{\mathrm{a}}$ & $14.4^{\mathrm{c}}$ & 0.41 & $<0.001$ & 0.730 & 0.005 \\
\hline Butyrate(B) & 12.4 & 14.1 & 12.4 & 15.8 & 0.69 & 0.017 & 0.272 & 0.268 \\
\hline$(A+B): P$ & $4.6^{\mathrm{b}}$ & $5.0^{\mathrm{ab}}$ & $4.2^{b}$ & $5.7^{\mathrm{a}}$ & 0.18 & 0.005 & 0.544 & 0.025 \\
\hline
\end{tabular}

${ }^{\mathrm{a}-\mathrm{c}}$ Means within a row with different superscripts differ $(P<0.05)$.

More recently, 3-nitrooxypropanol (3NOP) received considerable attention as newly developed $\mathrm{CH}_{4}$ mitigating feed additive. The compound has been specifically designed to inhibit methyl coenzyme-M Reductase, which is the enzyme that catalyzes the last step of methanogenesis in rumen archaea. As reviewed by Latham et al. (2016), several in vivo experiments have been conducted to evaluate the effect of 3NOP on methane production in dairy and beef cattle. Methane production per kg DMI decreased between 6-60\% compared to the control treatments (Haisan et al., 2014; Reynolds et al., 2014; RomeroPerez et al., 2014, 2015; Hristov et al., 2015). Although there seems to be an overall mitigating effect after 3NOP supplementation, the variation in the size of the effect is large. Latham et al. (2016) discussed that this is most likely a result from differences in the method of application and methane measurement techniques.

Further research on additivity of the effect of feed additives might focus on the combination of nitrate and 3NOP. It was discussed by Van Zijderveld (2011) that decreasing $\mathrm{CH}_{4}$ production may rather divert energy losses toward other reducing processes during which more heat is produced than during methanogenesis. The mode of action of 3NOP and nitrate may complement each other in this respect. 3Nitrooxypropanol inhibits the activity of methanogens and methanogenesis, leading to an increased accumulation of $\mathrm{H}_{2}$. Nitrate reduction is energetically more favourable than methanogenesis, and may take away the $\mathrm{H}_{2}$ as a substrate for methanogens. Moreover, the required inclusion level of 3NOP can be very low and, therefore, it likely does not impose a strong restriction directly on the formulation of the basal diet. If the effects are 

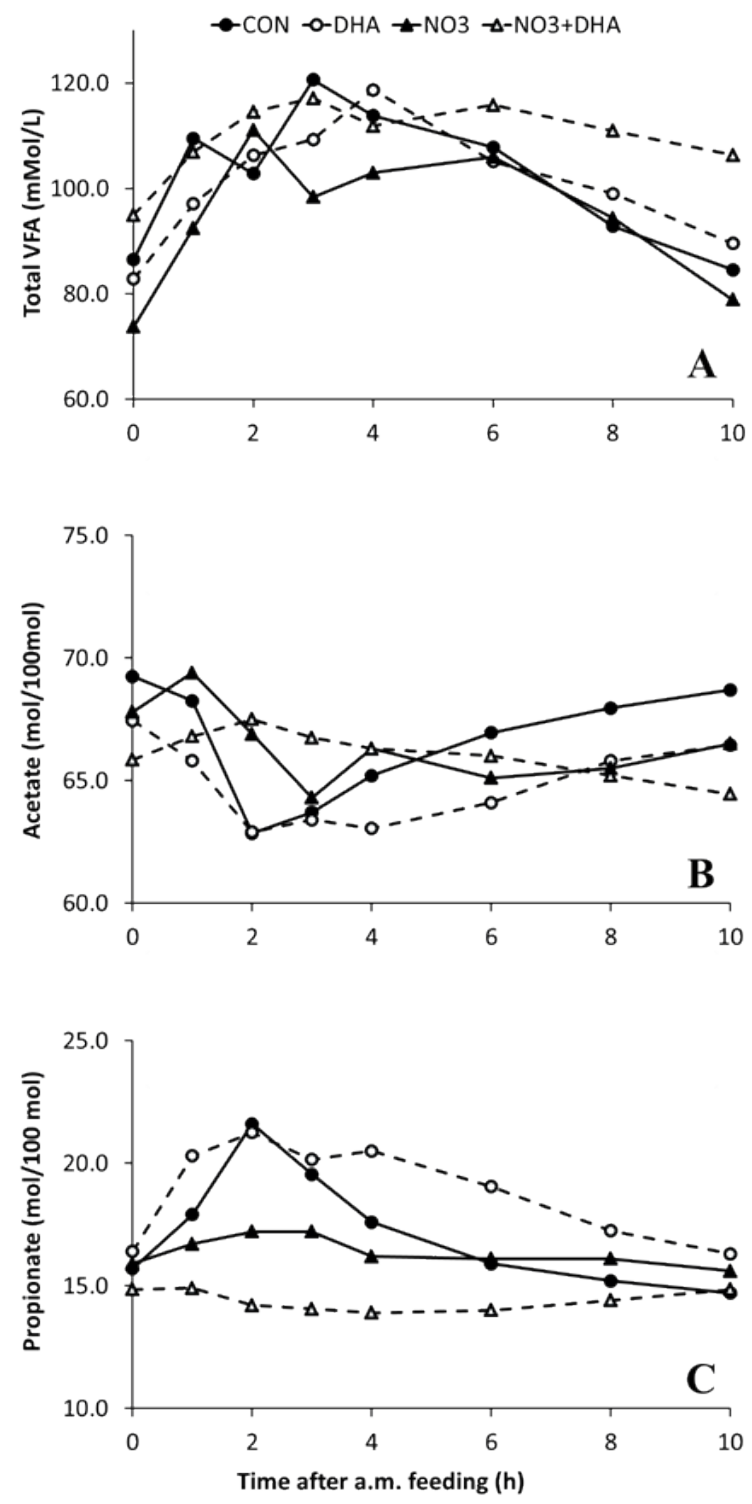

Figure 6.1. Total VFA concentration $(\mathrm{mMol} / \mathrm{L})(\mathbf{A})$, Molar proportion of acetate (B), and propionate (C) in rumen fluid from cows after a.m. feeding of one of the following TMR's: Control (CON; $\bullet$; urea as alternative NPN source; $n=2)$, Nitrate $\left(\mathrm{NO}_{3} ; \boldsymbol{\Delta}\right.$; at a level of $21 \mathrm{~g}$ per $\left.\mathrm{kg} \mathrm{DM} ; \mathrm{n}=1\right)$, docosahexaenoic acid (DHA; $O$; at a level of $3 \mathrm{~g}$ per $\mathrm{kg}$ DM and urea as alternative NPN source; $n=2$ ), or both nitrate and DHA $\left(\mathrm{NO}_{3}+\mathrm{DHA} ; \Delta\right.$; at the same inclusion levels as in the single additive treatments; $\mathrm{n}=2$ ). 
additive, a lower dose of nitrate in combination with $3 \mathrm{NOP}$ may effectively reduce $\mathrm{CH}_{4}$ production, without adverse effects of environmental trade-offs, or an impaired animal health and productivity.

\section{Adaptation}

As outlined in this thesis, adaptation of the rumen microbes may cause effects of feed additives on $\mathrm{CH}_{4}$ production to be transient. Adaptation is especially expected to additives that exert an anti-microbial effect. For example, in dual flow continuous culture systems, several effects of essential oils on fermentation disappeared after 6-7 d (reviewed by Benchaar et al., 2008). In Chapter 2, the effect of $\mathrm{DHA}$ on $\mathrm{CH}_{4}$ production was investigated after a 13-day adaptation period. In that experiment, no effect of $\mathrm{DHA}$ on $\mathrm{CH}_{4}$ production was found. The absence of an effect of $\mathrm{DHA}$ on $\mathrm{CH}_{4}$ production in vivo after an adaptation period, does not exclude a transient effect of $\mathrm{DHA}$ on $\mathrm{CH}_{4}$ production during that adaptation period. However, this was not determined in the study described in Chapter 2. Moate et al. (2013) also did not observe a lower $\mathrm{CH}_{4}$ production of cows fed different levels of DHA after a 2-3 week adaptation period. It is known from in vitro experiments that DHA has a marked effect on microbial metabolism in the rumen (Boeckaert et al., 2008a).

In the scientific literature, the search for mitigating feed additives often focuses on the aim to achieve a persistent decrease in $\mathrm{CH}_{4}$ production by a single additive. In this type of experiments, $\mathrm{CH}_{4}$ production is determined after an adaptation period to the experimental diet that includes the feed additive. In this way, with the absence of an effect, a transient effect that may have occurred during the first days of the adaptation period (when $\mathrm{CH}_{4}$ production was not measured) cannot be ruled out.

Adaptation over time was investigated and described in Chapter 4. Feeding a commercial blend of essential oils decreased in vitro $\mathrm{CH}_{4}$ production after 8 days of dietary inclusion, but not after 15 and 22 days. No such adaptation was observed for lauric acid (C12:0), which persistently reduced in vitro $\mathrm{CH}_{4}$ production between 4 and 22 days after dietary inclusion. In vivo observations upon weekly rotation of this blend of essential oils and 
C12:0 also did not result in a persistently lower $\mathrm{CH}_{4}$ production, $\mathrm{CH}_{4}$ yield and $\mathrm{CH}_{4}$ intensity compared with feeding the essential oils blend only (Chapter 5).

As recently reviewed by Yáñez-Ruiz et al. (2016), in vitro and in vivo results for the same additives are usually poorly related, and mitigating effects of additives on $\mathrm{CH}_{4}$ production were usually much more pronounced in vitro compared with in vivo. The authors provided a summary of technical recommendations on the use of in vitro gas production methods for measuring methane production. One of their recommendations that was not met in the experiment described in Chapter 4 was the minimum of 3 independent incubation runs as replications. The effects of time point and incubation run on the gas production measurements were fully confounded, because rumen fluid had to be collected along the course of adaptation to the experimental diets. An important finding of this study was that in general, feed additives in the donor cow diet had a larger effect on gas and $\mathrm{CH}_{4}$ production than the same additives in the incubation substrate. Incubation substrate affected asymptotic GP, half-time of asymptotic $\mathrm{CH}_{4}$ production, total volatile fatty acid (VFA) concentration, molar proportions of propionate and butyrate, and degradation of organic matter (OMD), but did not affect the amount of $\mathrm{CH}_{4}$ produced $(\mathrm{mL} / \mathrm{g} \mathrm{OM})$. This corresponds to the conclusion of Yáñez-Ruiz et al. (2016), who indicated that using rumen fluid from adapted versus non-adapted animals significantly affects in vitro results, and recommended donor animals to be fed the same diet as incubated or of similar nutrient composition. This should also be considered when translating in vitro results to an in vivo situation.

\section{Rotation}

As discussed in the 'adaptation' section, the absence of a mitigating effect of a feed additive (in this case DHA) after an adaptation period does not exclude the possibility that a short-term mitigating effect occurred. However, even if such an effect would have existed the mitigation benefit would probably not have outweighed the negative effects observed on FPCM yield. Nevertheless, short-term mitigating effects of feed additives could still be beneficial if these additives can be applied in a (short term) rotation schedule. Similar to application of rotation schedules in herbicide use (Beckie et al., 2006) or for 
anticoccidial compounds in broilers (Chapman, 2001), the rotational application of two or more $\mathrm{CH}_{4}$ reducing feed additives with a short-term effect and with different modes of action could alleviate the diminishing effect on $\mathrm{CH}_{4}$ reduction due to microbial adaptation in the rumen.

In e.g. herbicide rotations, effective rotation schedules may also become ineffective in the long run as a result of microbial adaptation. The most important reason for development of herbicide resistance is overreliance on a single herbicide or on a group of herbicides that share the same mode of action (Norsworthy et al., 2012). If a suitable combination of mitigating additives can be found, the search for alternatives should, therefore, be continued. The aim of the study described in Chapter 5 was to compare in vivo $\mathrm{CH}_{4}$ production and performance of dairy cows receiving either Agolin Ruminant ${ }^{\circledR}$ only and continuously (AR; $0.05 \mathrm{~g} / \mathrm{kg}$ total DM; AR-AR treatment), or AR and lauric acid (C12:0; 20 $\mathrm{g} / \mathrm{kg}$ total DM; AR-LA treatment) using a weekly rotation schedule. After introduction of the treatment additives in the diet, the experiment comprised five two-week periods. In periods 1, 3, and 5, cows were housed in respiration chambers for continuous measurement of $\mathrm{CH}_{4}$ production. A feed restriction was imposed already in the pretreatment period to avoid confounding effects of $\mathrm{DMI}$ on $\mathrm{CH}_{4}$ production. As the experimental facilities did not allow additional treatment groups, no control group (none of the additives fed) and no group that received only C12:0 could be included. Therefore, the comparison was between continuous feeding of $A R$ and rotation of $A R$ with $C 12: 0$ based on two-week averages, and the specific effect of the single additives could not be statistically evaluated within the experimental design. The changes in $\mathrm{DMI}$ and $\mathrm{CH}_{4}$ production on a weekly basis for the AR-LA rotation, though not statistically evaluated, are presented in Figure 6.2.

The DMI in the weeks that the AR diet was fed are similar to those from the pre-treatment period, whereas the numerical differences in DMI between the pre-treatment periods and the $\mathrm{C} 12: 0$ weeks are substantial. The $\mathrm{CH}_{4}$ yield $(\mathrm{g} / \mathrm{kg} \mathrm{DMI})$ in the $\mathrm{AR}$ weeks keeps declining over time (from 21.4 to $18.9 \mathrm{~g} / \mathrm{kg} \mathrm{DM}$ in period 1 and 5, respectively; Figure 6.2), but increased from 18.1 (period 1) to $22.7 \mathrm{~g} / \mathrm{kg}$ DMI (period 5) for the weeks that C12:0 was fed. 

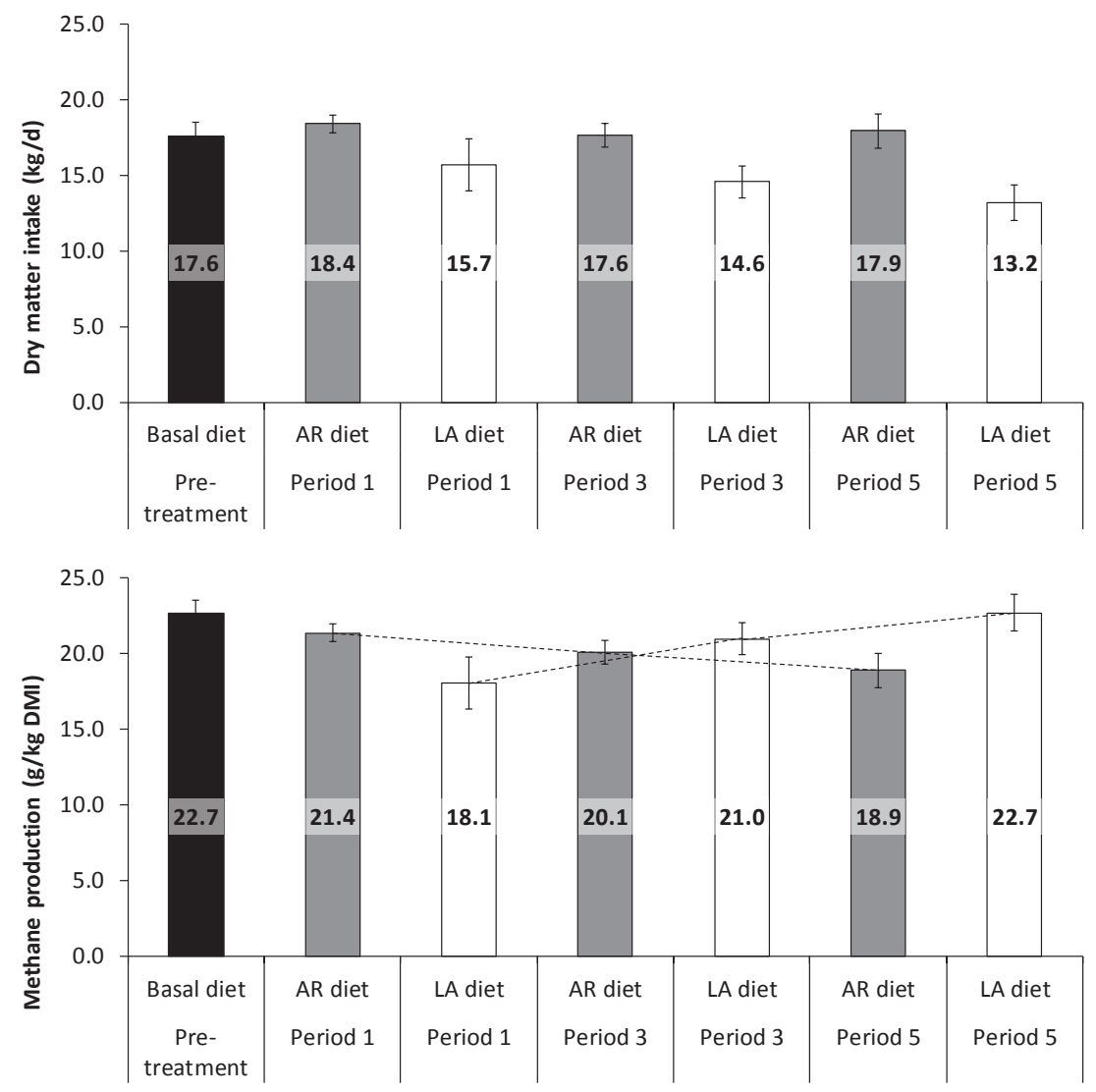

Figure 6.2. Average dry matter intake ( $\mathrm{DMl}$; top figure) and methane yield ( $\mathrm{g} / \mathrm{kg} \mathrm{DMl}$; bottom figure) of cows receiving a diet with $30 \%$ treatment concentrate on a DM basis following a weekly rotation schedule (first week of each period, AR diet; second week of each period, LA diet). The AR concentrate contained Agolin Ruminant ${ }^{\circledast}(0.17 \mathrm{~g} / \mathrm{kg}$ DM) and the LA concentrate contained lauric acid (C12:0; $65 \mathrm{~g} / \mathrm{kg} \mathrm{DM})$. A basal concentrate was fed during the pre-treatment period ( $\mathrm{n}=3$ for pre-treatment period, and $\mathrm{n}=4$ for periods 1,3 , and 5). Error bars represent standard errors. 


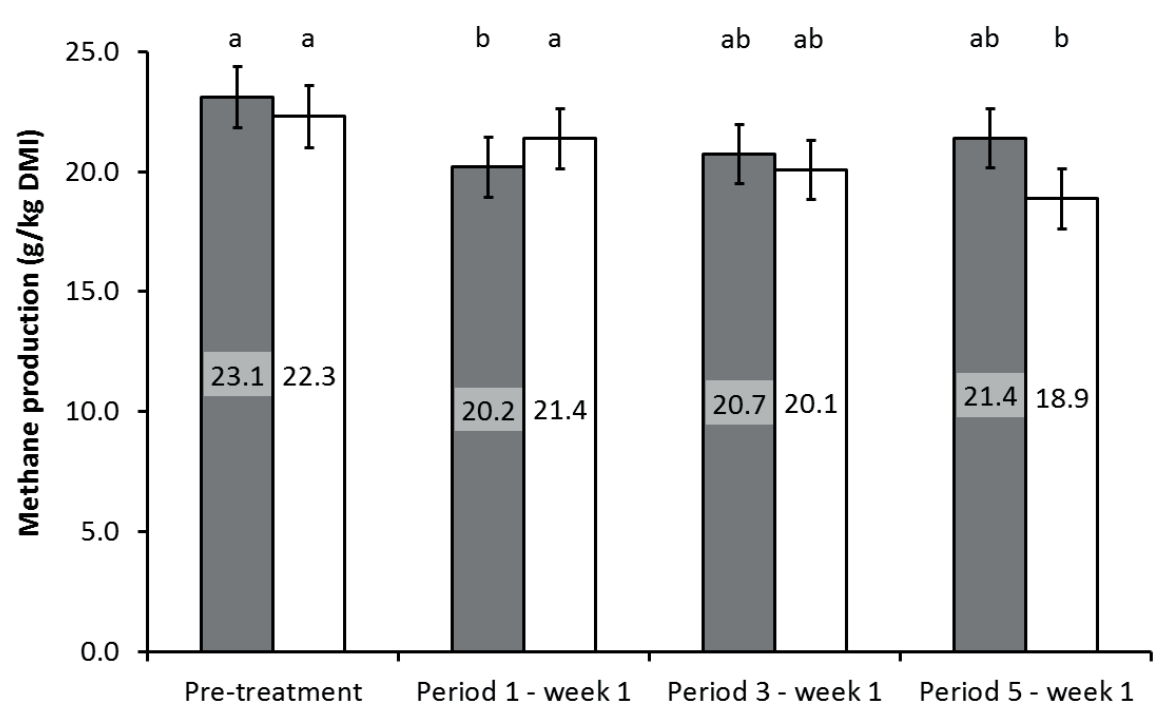

Figure 6.3. Methane production in $\mathrm{g} / \mathrm{kg}$ dry matter intake (DMI) of cows ( $\mathrm{n}=4$ per treatment) during the weeks that both treatment groups received the AR concentrate, which contained Agolin Ruminant $^{\circledR}(0.17 \mathrm{~g} / \mathrm{kg} \mathrm{DM})$ for periods 1,3 , and 5.). The diet contained $30 \%$ concentrate on a DM basis. Grey bars represent the treatment group that received AR for a period of 10 weeks, white bars represent the group that received both $A R$ and lauric acid (C12:0; $65 \mathrm{~g} / \mathrm{kg}$ concentrate DM) following a weekly rotation schedule (see Chapter 5). Error bars represent SEM. Periods within treatment with different superscript letters differ $(P<0.05)$.

The latter may be explained by an increment in time in the selection of components of the TMR. Based on chemical analysis of feed refusal samples, upon feeding the C12:0 diet, the concentrate proportion in the refusal was larger than in the offered TMR. This increases the relative contribution of fiber to total DMI. A low intake level may also increase rumen retention time during which fiber fermentation by rumen microbes increases. In this scenario it is plausible that $\mathrm{CH}_{4}$ yield is higher during LA feeding than with AR feeding for which a higher DMI and a relatively larger proportion of concentrate in the diet was achieved.

Weekly rotation of $\mathrm{AR}$ and $\mathrm{C} 12: 0$ did not result in a persistently lower $\mathrm{CH}_{4}$ production compared to feeding AR only. However, using the same statistical model as for the 
complete data (as described in Chapter 5) on only the pre-treatment period and the weeks in which AR was fed to both the AR-LA and AR treatment groups may also provide some further insight in the applicability of the concept of rotation as a mitigation strategy (Figure 6.3). The effect of treatment was not significant, but a significant effect of period and a significant treatment $\times$ period interaction was observed. In period 5 , but not in period 1 and 3, feeding AR in the AR-LA rotation treatment significantly reduced $\mathrm{CH}_{4}$ yield compared with the pre-treatment period. This may indicate that alternate feeding of C12:0 and Agolin does result in reduced $\mathrm{CH}_{4}$ yield in the week that Agolin is fed. However, it cannot be excluded that any carry-over effects of $\mathrm{C} 12: 0$ in the second week of the previous period have affected the $\mathrm{CH}_{4}$ yield upon feeding Agolin in the subsequent week, as it is known that C12:0 can also have strong anti-bacterial and anti-methanogenic effects (Hristov et al., 2011; Zhou et al., 2013). Nevertheless, the initial mitigating effect of AR seems to be repeatable after a week of feeding C12:0.

\section{Effects of feed additives on animal performance}

\section{Efficient mitigation?}

The work described in this thesis focuses on $\mathrm{CH}_{4}$ yield (expressed per unit of DMI) and intensity (expressed per unit of FPCM produced). These metrics indicate an efficiency, as the emissions are scaled relative to intake or to production. However, one can view efficiency in dairy cow nutrition from different perspectives.

A commonly used approach is to evaluate feed efficiency (defined as $\mathrm{kg}$ FPCM yield/kg DMI), which does not directly apply to optimal microbial efficiency or resource use efficiency. In swamps for example, where the concept of passage rate does not apply as in the rumen, human inedible materials are slowly degraded by microbes. In this scenario, a lot of acetate and methane can be formed from fibrous substrate, which could be considered as polluting. However, the extent to which available nutrients are extracted from the substrate is maximized. Feed intake capacity is a factor of interest in selection for economic efficiency of dairy cows (Veerkamp, 1998). Higher feed intake will increase the passage rate of feed, which gives the microbes less time to degrade feedstuffs. It is thus important to realize that the current situation is not inherent to the nature of ruminants, 
but has been imposed by humans through breeding and selection. If modern dairy cows are fed in an appropriate manner, more nutrients will be available for milk production, for maintenance energy requirements are diluted. However, present dairy cow diets often include a larger proportion of human edible resources. Hence, increasing feed efficiency is not necessarily the same as maximizing the efficiency of utilization of human inedible resources by rumen microbes, to obtain human edible energy and protein.

The often observed negative effects of additive-based $\mathrm{CH}_{4}$ mitigation strategies on fiber digestion (Latham et al., 2016; Chapter 2, 3), further add to the less efficient use of human inedible resources to obtain human edible energy and protein. In order to unite the different viewpoints on efficiency, it is important to understand mechanisms underlying a certain response upon a mitigation strategy. This mechanistic understanding is also important to predict the response to an additive under different conditions than the experimental conditions of the research described in this thesis. With the mechanisms unknown, all combinations have to be tested, which is usually not feasible in terms of available time, funds and labour. Before a strategy can be implemented in practice, the response under varying circumstances has to become a predictable one.

\section{Effects of additives on performance in relation to the basal diet}

Medium chain fatty acids (MCFA) may exert a stronger effect on $\mathrm{CH}_{4}$ production when supplemented to a diet that is relatively low in NDF. Machmüller et al. (2001) tested the effect of MCFA on in vitro $\mathrm{CH}_{4}$ production using incubation substrates with high or low concentrations of fiber. Pure C12:0 strongly ( 80\%) depressed $\mathrm{CH}_{4}$ production independent of the basal-diet type used. However, when expressed per unit of NDF fermented, $\mathrm{CH}_{4}$ production was only significantly reduced when $\mathrm{C} 12: 0$ was added to the low fiber substrate. Results of Machmüller et al. (2001) may imply that results of the experiment described in Chapter 5 could have been different if the basal diet would have contained relatively more starch and sugars and less NDF. Interactions between $\mathrm{CH}_{4}$ mitigation additives and basal substrates on $\mathrm{CH}_{4}$ and VFA production have also been investigated by Castro-Montoya et al. (2012) using an in vitro approach. In their study, both the mitigating effect as well as the fermentation depressing effect of MCFA were 
largest when added to a corn silage substrate. However, the strong inhibition of fermentation by MCFA, impaired appropriate evaluation of the most promising substrate $x$ additive combination. Benchaar et al. (2015) investigated the effect of linseed oil supplementation to red clover silage- or corn silage-based diets on $\mathrm{CH}_{4}$ production in lactating dairy cows. The treatment effect was more pronounced in the corn silage-based diet, which implies that the type of forage included in the basal diet is an important aspect to consider when using fat supplementation as a mitigation strategy. Livingstone et al. (2015) evaluated effects of linseed supplementation on grass silage or maize silage based diets, and concluded that basal diet (fibre rich grass silage vs starch rich maize silage) did not alter the methane emission in response to the linseed supplementation. However, in their experiment, the amount of supplemental lipid provided by linseed was small.

Interaction effects between the feed additive and the composition of the basal diet also have large implications for application of these additives in practice. For example, if an additive only reduces $\mathrm{CH}_{4}$ emission when it is supplemented to a diet with a large proportion of concentrates, feeding a concentrate rich diet may increase feed costs for the farmer. Moreover, the applicability of such a feeding strategy also depends on lactation stage of the cows, as late lactation or dry cows usually receive no or only small amounts of concentrates. Moreover feeding more concentrates may lead to trade-offs in environmental impacts of ruminant product (Hristov et al., 2013) and may reduce human edible efficiency.

\section{Effects of feed additives on DMI}

After introducing the different efficiency perspectives from which the effect of additives on animal performance can be viewed, it is obviously relevant to also compare responses to mitigation strategies observed in the work of this thesis and to speculate about the underlying mechanisms.

As discussed in Chapter 3, accumulation of $\mathrm{H}_{2}$ in the rumen may impair fiber digestion. If fiber degradation in the rumen is impaired, retention time may increase (Hollman and Beede 2012), which subsequently may lower feed intake. The negative effects of nitrate 
and C12:0 (either fed as a single additive or in a rotation schedule) on DMI are likely related to impaired fiber degradation in the rumen. Nitrate and C12:0 may have a direct toxic effect on methanogens in the rumen (Zhou et al., 2013; Latham et al., 2016). Even when an additive acting as an alternative $\mathrm{H}_{2}$ sink, such as nitrate, is fed, $\mathrm{H}_{2}$ may still accumulate when methanogens are inhibited at the same time. Increased $\mathrm{H}_{2}$ levels upon feeding nitrate have been observed previously (e.g., Van Zijderveld et al., 2011b; Lund et al., 2014; Troy et al., 2015; Guyader et al., 2015), and $\mathrm{H}_{2}$ production increases quadratic with increased nitrate levels in the diet (Olijhoek et al., 2016). Similarly, lauric acid resulted in increased $\mathrm{H}_{2}$ emissions in vitro (O'Brien et al., 2014).

Petersen et al. (2015) measured a transient increase in ruminal nitrite concentrations in cows receiving the medium (13.6 g nitrate/kg DM) and high (21.1 g nitrate/kg DM) nitrate diets in the study of Olijhoek et al. (2016). As discussed by the latter authors and in Chapter 3 of this thesis, nitrite may exert toxic effects on methanogens. The increased $\mathrm{H}_{2}$ emissions measured in nitrate fed cows support this hypothesis. Moreover, Latham et al. (2016) discussed that calcium nitrate (often used in animal experiments) is not very soluble in the normal $\mathrm{pH}$ range of the rumen. This would imply that not all nitrate will be reduced, especially not at higher fractional passage rates that may occur upon increases in DMI. Therefore, it is likely that nitrate supplementation may reduce $\mathrm{CH}_{4}$ emission not just by nitrate being an alternative $\mathrm{H}_{2}$ sink, but also by other (indirect) mechanisms.

In view of the potentially toxic effects of nitrite, Nolan et al. (2016) discussed several control points in nitrate metabolism in the rumen with the goal to alleviate toxic effects of nitrite. Slowing the rate of presentation of nitrate to rumen microbes reduces the risk of nitrite accumulation. Coating of nitrate may result in such a slower release rate of nitrate in the rumen. However this should not lead to increased outflow of nitrate from the rumen before being reduced to ammonia. Frequent feeding will also reduce the peak levels of MetHb in blood, with much lower peak levels in sheep fed once a day compared with sheep fed meals at hourly intervals (de Raphélis-Soissan et al., 2016b). The likelihood of nitrate poisoning is reduced by the inclusion of fermentable energy sources (concentrates) in nitrate-containing diets (Nolan et al., 2016). However, substituting fibre 
rich feeds for starch or sugar rich concentrates may not be attractive from a human-edible feed efficiency viewpoint.

Nitric oxide may also induce a DMI response in nitrate supplemented animals (Nolan et al., 2016). The authors explained that nitric oxide can be produced from the reduction intermediate nitrite, and elevated concentrations may reduce rumen primary contractions and digesta turnover rate. The latter could explain the reduction in meal size (Lichtenwalner et al., 1973), or the (tendency for) lower feed intake upon nitrate supplementation (Lund et al., 2014; Newbold et al., 2014; Chapter 2, 3). It can be argued that the latter is also a mechanism to avoid toxicity, as reduced feed intake also reduces nitrate intake which consequently may lower the risk of nitrite formation.

\section{Effects on milk production and milk composition}

Except for AR, all other additives tested in in vivo experiments described in this thesis (viz. nitrate, $\mathrm{DHA}$, and $\mathrm{C} 12: 0)$ exerted negative effects on milk production or milk composition (Table 6.2). In some cases the effects were not statistically significant, but the numerical differences between the additive and the control treatment were still considerable. E.g. average FPCM production of cows receiving DHA was around $4 \mathrm{~kg}$ lower than the control treatment which would impose an important trade-off in case of practical application.

Impaired fiber degradation upon feeding C12:0 may not only lower voluntary DMI, but may also induce milk fat depression. In Chapter 4, fiber degradation was not determined in vivo, but $\mathrm{C} 12: 0$ in the diet of the donor cows reduced organic matter degradation in vitro. The observed lower DMI and milk fat concentration in donor cows receiving C12:0 was, therefore, likely related to impaired fiber degradation in the rumen. As discussed in Chapters 4 and 5, others also observed negative effects of C12:0 on fiber digestibility (Dohme et al., 2001, Faciola and Broderick, 2014).

Table 6.2 shows that none of the additives positively affected milk production parameters. In all experiments described in this thesis, a light feed restriction was imposed to avoid confounding effects of $\mathrm{DMI}$ on $\mathrm{CH}_{4}$ production and without detrimental effects on the 
Table 6.2. Effects of feed additives investigated in this thesis on dry matter intake (DMI), fat- and proteincorrected milk (FPCM) production and milk composition.

\begin{tabular}{|c|c|c|c|c|c|}
\hline Additive (dose) & Chapter & $\begin{array}{l}\text { DMI } \\
(\mathrm{kg} / \mathrm{d})\end{array}$ & $\begin{array}{l}\text { FPCM production } \\
(\mathrm{kg} / \mathrm{d})\end{array}$ & $\begin{array}{l}\text { Milk fat } \\
\text { (g/kg) }\end{array}$ & $\begin{array}{l}\text { Milk protein } \\
\text { (g/kg) }\end{array}$ \\
\hline Nitrate (21 g/kg DM) & 2,3 & - & $=$ & $=$ & - \\
\hline $\mathrm{DHA}^{1}(3 \mathrm{~g} / \mathrm{kg} \mathrm{DM})$ & 2,3 & + & $={ }^{*}$ & - & $=$ \\
\hline Lauric acid (30 g/kg DM) & 4 & - & - & - & $={ }^{*}$ \\
\hline $\begin{array}{l}\text { Agolin ruminant } \\
(0.05 \mathrm{~g} / \mathrm{kg} \mathrm{DM})=+/-\end{array}$ & 4 & $=$ & $=$ & $=$ & $=$ \\
\hline $\begin{array}{l}\text { Agolin ruminant } \\
(0.05 \mathrm{~g} / \mathrm{kg} \mathrm{DM}=+/-)\end{array}$ & 5 & $=$ & $=$ & $=$ & $=$ \\
\hline $\begin{array}{l}\text { Lauric acid / Agolin Ruminant } \\
\text { rotation }\end{array}$ & 5 & - & $=$ & $=$ & - \\
\hline
\end{tabular}

cows. In view of this feed restriction, an increase in animal performance is unlikely. The seemingly positive effect of DHA on DMI was numerically very small $(0.4 \mathrm{~kg})$. As the variation in DMI is strongly reduced with a restricted feeding regimen, this effect is not very likely to occur with ad libitum feeding. Nitrate and C12:0 negatively affected intake even though a feed restriction was imposed. However, although in some cases lower $\mathrm{CH}_{4}$ production was observed, the lower amount of energy lost in $\mathrm{CH}_{4}$ was not compensated

by an increased milk production. For nitrate, this is in line with findings by Van Zijderveld et al. (2011b) and Lee and Beauchemin (2014), who reported that the consistent decline in $\mathrm{CH}_{4}$ yield upon feeding nitrate appears to be without directing additional energy toward animal production.

\section{Implementation of additive-based mitigation strategies}

Animal nutrition research into mitigation of enteric $\mathrm{CH}_{4}$ production usually focuses on the effect of a nutritional strategy on $\mathrm{CH}_{4}$ yield or intensity. Before effective feeding strategies can be successfully implemented in practice, it should be investigated if there are no trade-offs with other environmental impact factors. This should not only be evaluated at the animal level, but also at the farm and dairy production chain level (e.g., Van Middelaar et al., 2013). Trade-offs may hamper wide spread adoption of a mitigation strategy, but also negative effects related to food safety and food processing may preclude adoption of 
a $\mathrm{CH}_{4}$ reducing additive. Finally, the economic feasibility of a strategy should also be evaluated (Van Middelaar et al., 2014), because strategies with a negative return on investment are unlikely to be adopted by farmers and industry.

\section{Residues in animal products}

Nitrate is effective in reducing $\mathrm{CH}_{4}$ production, but overconsumption of nitrate by humans may impose health risks. Therefore, the European Food Safety Authority has established rules to keep consumption of nitrate and nitrate residuals within the maximum daily allowances (EFSA, 2009). The maximum nitrate concentration allowed in drinking water in Europe is $50 \mathrm{mg} / \mathrm{L}$. Guyader et al. (2016) examined the effect of feeding nitrate and linseed on the presence of nitrate residuals in milk products during a 17-week experiment. The nitrate + linseed diet in their study contained $1.8 \%$ nitrate on a DM basis. In curd from the control treatment in week 17 and in cheese from both treatments in week 9, low nitrite concentrations were detected $(1.5 \mathrm{mg} / \mathrm{kg})$, but in the vast majority of milk and milk product samples nitrate and nitrite concentrations were below the detection limit. Similarly, El-Zaiat et al. (2013) did not observe a difference in nitrate residuals in meat of lambs fed either a control diet, a nitrate diet with $4.51 \%$ of encapsulated calcium nitrate in dietary DM, $4.51 \%$ of encapsulated calcium nitrate containing cashew nut shell liquid $(2.96 \%$ in the product DM). Nitrite was not detected in meat from any of the treatments. Olijhoek et al. (2016) reported a linear increase in milk nitrate concentration (from 0.13 to 1.56 $\mathrm{mg} / \mathrm{l}$ ) with increasing dietary nitrate levels (from 0 to $21 \mathrm{~g} / \mathrm{kg} \mathrm{DM}$ ), whereas nitrite concentrations in milk were below the detection limit $(<30 \mu \mathrm{g} / \mathrm{L})$.

Essential oils and other plant secondary compounds have been studied to examine their mitigating potential, but the main reason for the increasing interest of the feed industry in those compounds relates to the change in legislation on so-called medical feed additives (Greathead, 2003). As outlined by Greathead (2003), these changes are an attempt to prevent development of microbial resistance to antibiotics, but also the increasing pressure from consumers is an important driver. Consumers consider consumption of residues from antibiotics, other drugs, pesticides etc. as a major threat to their health. The advantage of essential oils is that they are of natural origin and, therefore, more likely to 
be accepted by consumers. However, the nature of essential oils is that they influence the organoleptic properties of the plant they belong to (Benchaar and Greathead, 2011). Therefore, they may also change organoleptic properties of animal products in a negative way, which will hamper consumer acceptance. For example, in the study of Van Zijderveld et al. (2011a) diallyl disulfide supplementation at a level that did not decrease $\mathrm{CH}_{4}$ production, already resulted in a clear garlic taint in milk.

\section{Effect on milk processing parameters}

Feeding DHA to lactating dairy cows has been reported to increase the proportions of conjugated linoleic acid (CLA) and DHA in milk fat (Boeckaert et al., 2008b, Chapter 2). From a human health perspective, such an alteration in milk composition is of interest (Shingfield et al., 2013). However, alteration of the milk FA profile can also affect milk processing parameters. Tzompa-Sosa et al. (2016a) investigated the association between the ratio of $\mathrm{C} 16: 0$ and $\mathrm{C} 18: 1$ cis-9 and the triacylglycerol (TAG) profile of milk. C16:0 and C18:1cis-9 have an opposite effect on physical properties of milk fat (e.g. on solid fat content). In the experiments reported in Chapter 2 and 5 of this thesis, this ratio was affected by some of the dietary treatments applied. The TAG profile also affects solid fat content of milk (Tzompa-Sosa et al., 2016b). From a milk processing perspective, highly unsaturated milk fat with a low C16:0/C18:1cis-9 ratio is less desired. In this milk, the type of crystals formed are long and give a sandy taste, whereas in more saturated milk shorter crystals are formed that can form a network of solid fat. Solid fat is an important processing parameter, because it positively influences sensory perception, functionality and structure of fat-rich foods (e.g. muffins, puff pastry, ice cream) (Tzompa-Sosa et al., 2016b). The alteration in milk FA profile towards more unsaturated fatty acids upon

feeding DHA is, therefore, desirable from a human health perspective, but not from a processing perspective. Feeding of $\mathrm{C} 12: 0$ reduced the proportion of $\mathrm{C} 16: 0$ in milk fat at the expense of C12:0. This fatty acid is associated with increases in low-densitylipoproteins (LDL) cholesterol. This LDL represents the primary source of cholesterol that accumulates in the artery wall, which negatively affects cardiovascular health (Salter, 2013; Siri-Tarino et al., 2015). 
As discussed in Chapter 2, milk protein concentration and yield were lowered upon nitrate feeding. As propionate proportion was lowered, this decline may result from a decrease in glucogenic precursors (Rigout et al., 2003), because glucose is an important factor in signaling pathways that regulate milk protein synthesis (Rius et al., 2010). As protein is generally the most valuable milk component, an additive that decreases milk protein production may reduce interest in its adoption in practice. Guyader et al. (2016) also reported reduced milk protein yield when a combination of nitrate and linseed was fed. Van Zijderveld et al. (2011) found reduced milk protein concentration upon nitrate feeding, whereas protein yield remained unaffected. Milk protein yield was not reported by Olijhoek et al. (2016), but milk yield and milk protein concentration were not affected by nitrate feeding although propionate molar proportion in the rumen linearly decreased with increased dietary nitrate levels. As results are not consistent across studies, this aspect as well as options to alleviate the negative effects on milk protein, requires further investigation.

Moate et al. (2016) pointed out that the efficacy of 3NOP in grazing animals has not yet been evaluated. The authors emphasize that the primary focus should be on testing if using the compound does not lead to food safety problems (e.g. residues in animal products). This holds not only for 3NOP, but for any potential mitigating additive. Herrero et al. (2016) recently stressed the importance of issues related to environmental sideeffects, as well as consumer acceptance, as such issues may prevent widespread adoption of $\mathrm{CH}_{4}$ mitigating feed additives.

\section{Conclusions and recommendations}

The research described in this thesis addresses issues that are frequently reported to hamper the application of feed additive-based mitigation strategies. The main focus was on investigating additivity of the $\mathrm{CH}_{4}$ mitigating effect of feed additives, on the adaptation of rumen microbes to long term feeding of feed additives, and on exploring the potential of rotational feeding of additives to avoid adaptation. In summary, the following conclusions and recommendations are drawn: 
- The effects of nitrate and DHA on $\mathrm{CH}_{4}$ yield (g/kg DMI) and $\mathrm{CH}_{4}$ intensity (g/kg FPCM), were additive. However, the interaction effect between nitrate and DHA on NDF digestibility indicated that negative effects of nitrate on apparent total-tract digestibility of nutrients were alleviated by DHA (Chapter 2,3), probably due to an altered feed intake pattern.

- The effects of nitrate as a $\mathrm{CH}_{4}$ mitigating feed additive on fiber degradation in the rumen can be detected by evaluating the change in the diurnal pattern of ${ }^{13} \mathrm{C}$ enrichment of exhaled $\mathrm{CO}_{2}$. A prerequisite for this detection method is that the main ration components differ in natural ${ }^{13} \mathrm{C}$ enrichment (e.g., $\mathrm{C} 3$ and $\mathrm{C} 4$ plants), and in content of the nutrients that are expected to be involved in a shift in fermentation (e.g., starch and fiber) or in degradability of a nutrient.

- Feed additives in the donor cow diet have a stronger effect on in vitro gas and $\mathrm{CH}_{4}$ production than the same additives in the incubation substrate (Chapter 4). This phenomenon should be considered in the planning of future studies on the mitigation potential of feed additives in vitro.

- DHA and nitrate significantly reduced milk fat and protein yield, respectively, and C12:0 reduced DMI (Chapter 4, 5) milk fat content, and FPCM production (Chapter 4). Therefore, the applied doses of these additives are not recommended for application in practice.

- In Chapter 5, rotational feeding of Agolin Ruminant ${ }^{\circledR}$ and $\mathrm{C} 12: 0$ did not result in a persistent decrease in $\mathrm{CH}_{4}$. However, there were indications that the concept of rotation may be effective. Future research should clarify if rotational feeding of Agolin Ruminant ${ }^{\circledR}$ with another additive could result in a persistent mitigation effect.

- The additives tested in this thesis are applied under specific circumstances. More mechanistic understanding is required to predict the response of the same additives when supplemented to other basal diets or animals in a different physiological state.

- Trade-offs in environmental impact, and effects of feed additives on animal health and performance, and in milk processing parameters and food safety are important aspects to consider in future research into mitigation strategies. 


\section{REFERENCES}

Aschenbach J. R., S. Bilk, G. Tadesse, F. Stumpff, and G. Gäbel. 2009. Bicarbonatedependent and bicarbonate-independent mechanisms contribute to non diffusive uptake of acetate in the ruminal epithelium of sheep. Am. J. Physiol. Gastroint. Liver Physiol. 296:1098-1107.

Beckie, H. J. 2006. Herbicide-Resistant Weeds: Management Tactics and Practices. Weed Technol. 20:793-814.

Benchaar, C., S. Calsamiglia, A. V. Chaves, G. R. Fraser, D. Colombatto, T. A. McAllister, and K. A. Beauchemin. 2008. A review of plant-derived essential oils in ruminant nutrition and production. Anim. Feed Sci. Technol. 145:209-228.

Benchaar, C., and H. Greathead. 2011. Essential oils and opportunities to mitigate enteric methane emissions from ruminants. Anim. Feed Sci. Technol. 166-167:338-355.

Benchaar, C., F. Hassanat, R. Martineau, and R. Gervais. 2015. Linseed oil supplementation to dairy cows fed diets based on red clover silage or corn silage: Effects on methane production, rumen fermentation, nutrient digestibility, $\mathrm{N}$ balance, and milk production. J. Dairy Sci. 98:7993-8008.

Boeckaert, C., B. Vlaeminck, V. Fievez, L. Maignien, J. Dijkstra, and N. Boon. 2008a. Accumulation of trans C18:1 fatty acids in the rumen after dietary algae supplementation is associated with changes in the Butyrivibrio community. Appl. Environ. Microbiol. 74: 6923-6930.

Boeckaert, C., B. Vlaeminck, J. Dijkstra, A. Issa-Zacharia, T. Van Nespen, W. Van Straalen, and V. Fievez. 2008b. Effect of dietary starch or micro algae supplementation on rumen fermentation and milk fatty acid composition of dairy cows. J. Dairy Sci. 91:4714-4727.

Castro-Montoya, J., S. De Campeneere, G. Van Ranst, and V. Fievez. 2012. Interactions between methane mitigation additives and basal substrates on in vitro methane and VFA production. Anim. Feed Sci. Technol. 176:47-60.

Cardozo, P.W., S. Calsamiglia, A. Ferret, and C. Kamel 2004. Effects of natural plant extracts on ruminal protein degradation and fermentation profiles in continuous culture. J. Anim. Sci. 82, 3230-3236.

Chapman, H. D. 2001. Use of anticoccidial drugs in broiler chickens in the USA: Analysis for the years 1995 to 1999. Poultry Sci. 80:572-580.

de Raphélis-Soissan, V., J. V. Nolan, J. R. Newbold, I. R. Godwin, and R. S. Hegarty. 2016a. Can adaptation to nitrate supplementation and provision of fermentable energy reduce nitrite accumulation in rumen contents in vitro? Anim. Prod. Sci. 56: 605-612. 
de Raphélis-Soissan, J. V. Nolan, J. R. Newbold, I. R. Godwin, and R. S. Hegarty. 2016b. Feeding frequency and rate of nitrate ingestion affect nitrite toxicity in sheep supplemented with dietary nitrate. In: Proceedings of the 31st biennial conference of the Australian Society of Animal Production 31, in press.

Dohme F, A. Machmüller, A. Wasserfallen, and M. Kreuzer. 2001. Ruminal methanogenesis as influenced by individual fatty acids supplemented to complete ruminant diets. Lett. Appl. Microbiol. 32: 47-51.

El-Zaiat, H. M., H. O. Patiño, Y. A. Solan, A. S. Morsy, R. C. Aroujo, H. Louvandini, and A. L. Abdalla. 2013. Additive effect of nitrate and cashew nut shell liquid in an encapsulated product fed to lambs on enteric methane emission and growth performance. Proc. of the $5^{\text {th }}$ Greenhouse Gases and Animal Agriculture conference, 2013, Dublin, Ireland.

European Food Safety Authority. 2009. Scientific opinion of the panel on contaminants in the food chain on a request from the European Commission on nitrite as undesirable substances in animal feed. EFSA J 1017:1-47.

Faciola A. P., and G. A. Broderick. 2014. Effects of feeding lauric acid or coconut oil on ruminal protozoa numbers, fermentation pattern, digestion, omasal nutrient flow, and milk production in dairy cows. J Dairy Sci. 97:5088-5100.

Fievez, V., C. Boeckaert, B. Vlaeminck, J. Mestdagh, and D. Demeyer. 2007. In vitro examination of DHA-edible micro-algae 2. Effect on rumen methane production and apparent degradability of hay. Anim. Feed Sci. Technol. 136:80-95.

Gould, D. H. 1998. Polioencephalomalacia. J. Anim. Sci. 76:309-314.

Greathead, H. 2003. Plants and plant extracts for improving animal productivity. Proc. Nutr. Soc. $62: 279-290$.

Guyader, J., M. Doreau, D. P. Morgavi, C. Gérard, C. Loncke, and C. Martin. 2016. Long-term effect of linseed plus nitrate fed to dairy cows on enteric methane emission and nitrate and nitrite residuals in milk. Animal 6:1-9.

Guyader, J., M. Eugène, B. Meunier, M. Doreau, D. P. Morgavi, M. Silberberg, Y. Rochette, C. Gerard, C. Loncke, and C. Martin. 2015. Additive methane-mitigating effect between linseed oil and nitrate fed to cattle. J. Anim. Sci. 93:3564-3577.

Haisan J., Y. Sun, L.L. Guan, K. A. Beauchemin, A. Iwaasa, S. Duval, D. R. Barreda, and M. Oba. 2014. The effects of feeding 3-nitrooxypropanol on methane emissions and productivity of Holstein cows in mid lactation. J. Dairy Sci. 97:3110-3119. 
Herrero, M., B. Henderson, P. Havlik, P. K. Thornton, R. T. Conant, P. Smith, S. Wirsenius, A. N. Hristov, P. Gerber, M. Gill, K. Butterbach-Bahl, H. Valin, T. Garnett, and E. Stehfest. 2016. Greenhouse gas mitigation potentials in the livestock sector. Nat. Clim. Chan. 6:452-461.

Hollmann, M., and D. K. Beede. 2012. Comparison of effects of dietary coconut oil and animal fat blend on lactational performance of Holstein cows fed a high-starch diet. J. Dairy. Sci. 95:1484-1499.

Hristov, A. N., C. Lee, T. Cassidy, M. Long, K. Heyler, B. Corl, and R. Forster. 2011. Effects of lauric and myristic acids on ruminal fermentation, production, and milk fatty acid composition in lactating dairy cows. J. Dairy Sci. 94: 382-395.

Hristov, A. N., J. Oh , F. Giallongo , T. W. Frederick, M. T. Harper, H. L. Weeks, A. F. Branco, P. J. Moate, M. H. Deighton, S. R. O. Williams, M. Kindermann, ans S. Duval . 2015. An inhibitor persistently decreased enteric methane emission from dairy cows with no negative effect on milk production. Proc. Nat. Acad. Sci. USA 112:663-668.

Hristov, A. N., J. Oh, J. Firkins, J. Dijkstra, E. Kebreab, G. Waghorn, A. Adesogan, W. Yang, J. Tricarico, C. Lee, P. J. Gerber, B. Henderson, and H. P. S. Makkar. 2013. Mitigation of methane and nitrous oxide emissions from animal operations: I. A review of enteric methane mitigation options. J. Anim. Sci. 91:5045-5069.

Latham, E. A., R. C. Anderson, W. E. Pinchak, and D. J. Nisbet. 2016. Insight on alterations to the rumen ecosystem by nitrate and nitrocompounds. Front. Microbiol. 7:228.

Lee, C., R. C. Araujo, K. M. Koenig, and K. A. Beauchemin. 2015. Effects of encapsulated nitrate on eating behavior, rumen fermentation, and blood profile of beef heifers fed restrictively or ad libitum. J. Anim. Sci. 93:2405-2418.

Lee, C., and K. A. Beauchemin. 2014. A review of feeding supplementary nitrate to ruminant animals: Nitrate toxicity, methane emissions, and production performance. Can. J. Anim. Sci. 94:557570.

Lichtenwalner, R. E., J. P. Fontenot, and R. E. Tucker. 1973. Effect of source of supplemental nitrogen and level of nitrate on feedlot performance and vitamin A metabolism of fattening beef calves. J. Anim. Sci. 37:837-847.

Livingstone, K. M., D. J. Humphries, P. Kirton, K. E. Kliem, D. I. Givens, and C. K. Reynolds. 2015. Effects of forage type and extruded linseed supplementation on methane production and milk fatty acid composition of lactating dairy cows. J. Dairy Sci. 98:4000-4011.

Lund, P., R. Dahl, H. J. Yang, A. L. F. Hellwing, B. B. Cao, and M. R. Weisbjerg. 2014. The acute effect of addition of nitrate on in vitro and in vivo methane emission in dairy cows. Anim. Prod. Sci. 54:1432-1435. 
Machmüller, A., F. Dohme, C. R. Soliva, M. Wanner, and M. Kreuzer. 2001. Diet composition affects the level of ruminal methane suppression by medium-chain fatty acids. Aus. J. Agric. Res. $52: 713-722$.

Moate, P. J., M. H. Deighton, S. R. O. Williams, J. E. Pryce, B. J. Hayes, J. L. Jacobs, R. J. Eckard, M.C. Hannah, and W. J. Wales. 2016. Reducing the carbon footprint of Australian milk production by mitigation of enteric methane emissions. Anim. Prod. Sci. 56:1017-1034.

Moate P. J., S. R. O. Williams, M. C. Hannah, R. J. Eckard, M. J. Auldist, B. E. Ribaux, J. L. Jacobs, and W. J. Wales. 2013. Effects of feeding algal meal high in docosahexaenoic acid on feed intake, milk production, and methane emissions in dairy cows. J. Dairy Sci. 96:3177-3188.

Newbold, J. R., S. M. Van Zijderveld, R. B. A. Hulshof, W. B. Fokkink, R. A. Leng, P. Terencio, W. J. Powers, P. S. J. Van Adrichem, N. D. Paton, and H. B. Perdok. 2014. The effect of incremental levels of dietary nitrate on methane emissions in Holstein steers and performance in Nelore bulls. J. Anim. Sci. 92:5032-5040.

Nolan, J. V., I. R. Godwin, V. de Raphélis-Soissan, and R. S. Hegarty. 2016. Managing the rumen to limit the incidence and severity of nitrite poisoning in nitrate-supplemented ruminants. Anim. Prod. Sci. In press DOI: http://dx.doi.org/10.1071/AN15324. .

Norsworthy, J.K., S. M. Ward, D. R. Shaw, R. S. Llewellyn, R. L. Nichols, T. M. Webster, K. W. Bradley, G. Frisvold, S. B. Powles, N. R. Burgos, W. W. Witt, and M. Barrett. 2012. Reducing the risks of herbicide resistance: best management practices and recommendations. Weed Sci. 60:31-62.

NRC. 2001. Nutrient Requirements of Dairy Cattle. 7th revised edition. Natl. Acad. Sci., Washington DC.

O’Brien, M., A. Navarro-Villa, P. J. Purcell, T. M. Boland, and P. O'Kiely. 2014. Reducing in vitro rumen methanogenesis for two contrasting diets using a series of inclusion rates of different additives. Anim. Prod. Sci. 54:141-157.

Olijhoek, D.W., A. L. F. Hellwing, M. Brask, M. R. Weisbjerg, O. Højberg, M. K. Larsen, J. Dijkstra, E. J. Erlandsen, and P. Lund. 2016. Effect of dietary nitrate level on enteric methane production, hydrogen emission, rumen fermentation, and nutrient digestibility in dairy cows. J. Dairy Sci. In press DOI: http://dx.doi.org/10.3168/ids.2015-10691.

Petersen S.O., A. L. F. Hellwing, M. Brask. O. Højberg, M. Poulsen, Z. Zhu, K. R. Baral, and P. Lund. 2015. Dietary nitrate for methane mitigation leads to nitrous oxide emissions from dairy cows. J. Environ. Qual. 44:1063-1070. 
Reynolds, C. K., D. J. Humphries, P. Kirton, M. Kindermann, S. Duval, and W. Steinberg. 2014. Effects of 3-nitrooxypropanol on methane emission, digestion, and energy and nitrogen balance of lactating dairy cows. J. Dairy Sci. 97:3777-3789.

Rigout, S., C. Hurtaud, S. Lemosquet, A. Bach, and H. Rulquin. 2003. Lactational effect of propionic acid and duodenal glucose in cows. J. Dairy Sci. 86:243-253.

Rius, A. G., J. A. D. R. N. Appuhamy, J. Cyriac, D. Kirovski, O. Becvar, J. Escobar, M. L. McGilliard, B. J. Bequette, R. M. Arkers, and M. D. Hanigan. 2010. Regulation of protein synthesis in mammary glands of lactating dairy cows by starch and amino acids. J. Dairy Sci. 93:31143127.

Romero-Perez, A., E. K. Okine, S. M. McGinn, L. L. Guan, M. Oba, S.M. Duval, M. Kindermann, and K.A. Beauchemin. 2014. The potential of 3-nitrooxypropanol to lower enteric methane emissions from beef cattle. J. Anim. Sci. 92:4682-4693.

Romero-Perez, A., E. K. Okine, S. M. McGinn, L. L. Guan, M. Oba, S.M. Duval, and K.A. Beauchemin. 2015. Sustained reduction in methane production from long-term addition of 3nitrooxypropanol to a beef cattle diet. J. Anim. Sci. 93:1780-1791.

Salter, A. M. 2013. Dietary fatty acids and cardiovascular disease. Animal 7:163-171.

Siri-Tarino, P. W., S. Chiu, N. Bergeron, and R. M. Krauss. 2015. Saturated fats versus polyunsaturated fats versus carbohydrates for cardiovascular disease prevention and treatment. Annu. Rev. Nutr. 35:517-543

Troy, S. M., C. A. Duthie, J. J. Hyslop, R. Roehe, D. W. Ross, R. J. Wallace, A. Waterhouse, and J.A. Rooke. 2015. Effectiveness of nitrate addition and increased oil content as methane mitigation strategies for beef cattle fed two contrasting basal diets. J. Anim. Sci. 93:1-9.

Tzompa-Sosa, D.A., H. J. F. van Valenberg, G. A. van Aken, and H. Bovenhuis. 2016a. Milk fat triacylglycerols and their relations with milk fatty acid composition, DGAT1 K232A polymorphism and milk production traits. J. Dairy Sci. 99:1-8.

Tzompa-Sosa, D. A., P. R. Ramel, H. J. F. van Valenberg, and G. A. van Aken. 2016b. Formation of $\beta$ polymorphs in milk fats with large differences in triacylglycerol profiles. J. Agric. Food Chem. 64:4152-4157.

Yáñez-Ruiz , D.R., A. Bannink, J. Dijkstra, E. kebreab, D. P. Morgavi, P. O’Kiely, C. K. Reynolds, A. Schwarm, K. J. Shingfield, Z. Yu, and A. N. Hristov. 2016. Design, implementation and interpretation of in vitro batch culture experiments to assess enteric methane mitigation in ruminants - a review. Anim. Feed Sci. Technol. 216:1-18.

Shingfield, K. J., M. Bonnet, and N. D. Scollan. 2013. Recent developments in altering the fatty acid composition of ruminant-derived foods. Animal 7:132-162. 
Van Middelaar, C.E., P. M. Berentsen, J. Dijkstra, and I. J. M. De Boer. 2013. Evaluation of a feeding strategy to reduce greenhouse gas emissions from dairy farming: The level of analysis matters. Agric. Sys. 121: 9-22.

Van Middelaar, C.E., J. Dijkstra, P. M. Berentsen, and I. J. M. De Boer. 2014. Cost-effectiveness of feeding strategies to reduce greenhouse gas emissions from dairy farming. J. Dairy. Sci. 97: 2427-2439.

Van Zijderveld, S. M., W. J. J. Gerrits, J. A. Apajalahti, J. R. Newbold, J. Dijkstra, R. A. Leng, and H. B. Perdok. 2010. Nitrate and sulfate: Effective alternative hydrogen sinks for mitigation of ruminal methane production in sheep. J. Dairy Sci. 93:5856-5866.

Van Zijderveld, S. M., J. Dijkstra, H. B., Perdok, J. R., Newbold, and W. J. J. Gerrits. 2011a. Dietary inclusion of diallyl disulfide, yucca powder, calcium fumarate, an extruded linseed product, or medium-chain fatty acids does not affect methane production in lactating dairy cows. J. Dairy Sci. 94:3094-3104.

Van Zijderveld, S. M., W. J. J. Gerrits, J. Dijkstra, J. R. Newbold, R. B. A. Hulshof, and H. B. Perdok. 2011b. Persistency of methane mitigation by dietary nitrate supplementation in dairy cows. J. Dairy Sci. 94:4028-4038.

Van Zijderveld, S.M. 2011. Dietary strategies to reduce methane emissions from ruminants. PhD thesis., Wageningen University, Wageningen, the Netherlands (132 pages).

Veerkamp, R. F. 1998. Selection for economic efficiency of dairy cattle using information on live weight and feed intake: A review. J. Dairy Sci. 81:1109-1119.

Walker G. P., F. R. Dunshea, and P. T. Doyle. 2004. Effects of nutrition and management on the production and composition of milk fat and protein: a review. Aus. J. Agric. Res. 55:10091028.

Zhou X., L. Meile, M. Kreuzer, and J. O. Zeitz. 2013. The effect of saturated fatty acids on methanogenesis and cell viability of Methanobrevibacter ruminantium. Archaea, 2013, Article ID 106916. doi:10.1155/2013/106916.

Zhou, Z., Z. Yu, and Q. Meng. 2012. Effects of nitrate on methane production, fermentation, and microbial populations in in vitro ruminal cultures. Biores. Technol. 103:173-179. 


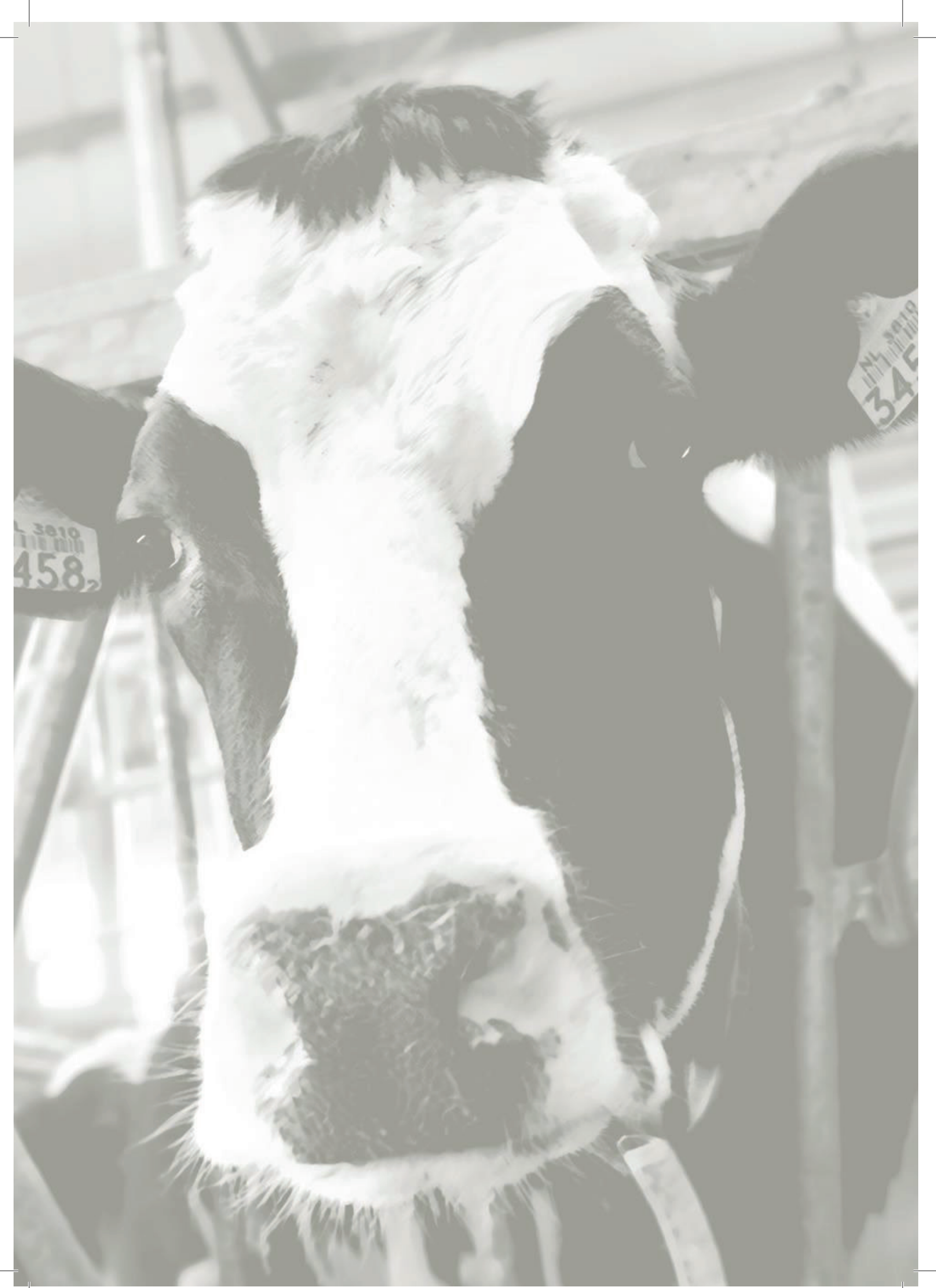


Chapter 7

Co-authored peer-reviewed publications

related to this thesis 


\section{CO-AUTHORED PEER-REVIEWED PUBLICATIONS RELATED TO THIS THESIS}

\section{6}

Dijkstra J., S. van Gastelen, E. C. Antunes-Fernandes, D. Warner, B. Hatew, G. Klop, S. C. Podesta, H. J. van Lingen, K. A. Hettinga, and A. Bannink. 2016. Relationships between milk fatty acid profiles and enteric methane production in dairy cattle fed grass- or grass silage-based diets. Anim. Prod. Sci. 56:541-548.

Ellis, J. L., I. K. Hindrichsen, G. Klop, R. D. Kinley, N. Milora, A. Bannink, and J. Dijkstra. 2016. Effects of lactic acid bacteria silage inoculation on methane emission and productivity of Holstein Friesian dairy cattle. J. Dairy Sci. 99:7159-7174.

Warner, D., B. Hatew, S. C. Podesta, G. Klop, S. van Gastelen, H. van Laar, J. Dijkstra, and A. Bannink. 2016. Effects of nitrogen fertilisation rate and maturity of grass silage on methane emission by lactating dairy cows. Animal 10:34-43.

\section{5}

Van Gastelen, S., E. C. Antunes-Fernandes, K. A. Hettinga, G. Klop, S. J. J. Alferink, W. H. Hendriks, and J. Dijkstra. 2015. Enteric methane production, rumen volatile fatty acid concentrations, and milk fatty acid composition in lactating Holstein-Friesian cows fed grass silage- or corn silage-based diets. J. Dairy Sci. 98:1915-1927.

Warner, D., S. C. Podesta, B. Hatew, G. Klop, H. van Laar, A. Bannink, and J. Dijkstra. 2015. Effect of nitrogen fertilization rate and regrowth interval of grass herbage on methane emission of zero-grazing lactating dairy cows. J. Dairy Sci. 98:3383-3393.

\section{4}

Heeren, J. A. H., S. C. Podesta, B. Hatew, G. Klop, H. van laar, A. Bannink, D. Warner, L. H. de Jonge, and J. Dijkstra. 2014. Rumen degradation characteristics of ryegrass herbage and ryegrass silage are affected by interactions between stage of maturity and nitrogen fertilisation rate. Anim. Prod. Sci. 54:1263-1267. 


\section{CURRICULUM VITAE}

Geronda Klop was born in Dordrecht, the Netherlands on the $22^{\text {nd }}$ of May 1987. She followed several years of secondary education (VWO) at Insula College, Dordrecht, the Netherlands. In 2004, she commenced intermediate vocational education (MBO) where she obtained a diploma in animal husbandry and a diploma in veterinary assistance in 2007. In 2010, she completed her BSc in Animal Husbandry at HAS Den Bosch University of applied sciences (HBO), 's-Hertogenbosch, the Netherlands. She followed the MSc programme Animal Sciences at Wageningen University, Wageningen, the Netherlands, where she did a minor thesis in the Soil Quality department and a major thesis in the Animal Nutrition Group. She graduated (Cum Laude) in June 2012, and thereafter she started the PhD project of which the results are described in this thesis. 


\section{OVERVIEW OF SCIENTIFIC PUBLICATIONS}

Peer-reviewed scientific publications

Klop, G., S. van Laar-van Schuppen, W. F. Pellikaan, W. H. Hendriks, A. Bannink, and J. Dijkstra. Changes in in vitro gas and methane production from rumen fluid from dairy cows during adaptation to feed additives in vivo. Animal (accepted).

Klop, G., A. Bannink, K. Dieho, W.J.J. Gerrits, and J. Dijkstra. 2016. Short communication: Using diurnal patterns of ${ }^{13} \mathrm{C}$ enrichment of $\mathrm{CO}_{2}$ to evaluate the effects of nitrate and docosahexaenoic acid on fiber degradation in the rumen of lactating dairy cows. J. Dairy Sci. 99:7216-7220.

Ellis, J. L., I. K. Hindrichsen, G. Klop, R. D. Kinley, N. Milora, A. Bannink, and J. Dijkstra. 2016. Effects of lactic acid bacteria silage inoculation on methane emission and productivity of Holstein Friesian dairy cattle. J. Dairy Sci. 99:7159-7174.

Dijkstra J., S. van Gastelen, E. C. Antunes-Fernandes, D. Warner, B. Hatew, G. Klop, S. C. Podesta, H. J. van Lingen, K. A. Hettinga, and A. Bannink. 2016. Relationships between milk fatty acid profiles and enteric methane production in dairy cattle fed grass- or grass silage-based diets. Anim. Prod. Sci. 56:541-548.

Klop, G., B. Hatew, A. Bannink, and J. Dijkstra. 2016. Feeding nitrate and docosahexaenoic acid affects enteric methane production and milk fatty acid composition in lactating dairy cows. J. Dairy Sci. 99:1161-1172.

Warner, D., B. Hatew, S. C. Podesta, G. Klop, S. van Gastelen, H. van Laar, J. Dijkstra, and A. Bannink. 2016. Effects of nitrogen fertilisation rate and maturity of grass silage on methane emission by lactating dairy cows. Animal 10:34-43.

Van Gastelen, S., E. C. Antunes-Fernandes, K. A. Hettinga, G. Klop, S. J. J. Alferink, W. H. Hendriks, and J. Dijkstra. 2015. Enteric methane production, rumen volatile fatty acid concentrations, and milk fatty acid composition in lactating Holstein-Friesian cows fed grass silage- or corn silage-based diets. J. Dairy Sci. 98:1915-1927.

Warner, D., S. C. Podesta, B. Hatew, G. Klop, H. van Laar, A. Bannink, and J. Dijkstra. 2015. Effect of nitrogen fertilization rate and regrowth interval of grass herbage on methane emission of zero-grazing lactating dairy cows. J. Dairy Sci. 98:3383-3393. 
Heeren, J. A. H., S. C. Podesta, B. Hatew, G. Klop, H. van laar, A. Bannink, D. Warner, L. H. de Jonge, and J. Dijkstra. 2014. Rumen degradation characteristics of ryegrass herbage and ryegrass silage are affected by interactions between stage of maturity and nitrogen fertilisation rate. Anim. Prod. Sci. 54:1263-1267

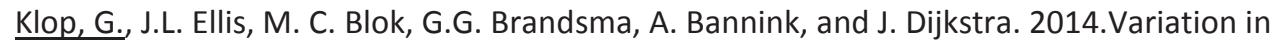
phosphorus content of milk from dairy cattle as affected by differences in milk composition. J. Agric. Sci. 152:860 - 869.

Klop, G., J. L. Ellis, A. Bannink, E. Kebreab, J. France, and J. Dijkstra. 2013. Meta-analysis of factors that affect the utilization efficiency of phosphorus in lactating dairy cows. J. Dairy Sci. 96:3936-3949.

Klop, G., G. L. Velthof, and J. W. van Groenigen. 2012. Application technique affects the potential of mineral concentrates from livestock manure to replace inorganic nitrogen fertilizer. Soil Use Man. 28:468-477.

\section{Contributions to conferences, symposia and other scientific output}

Goselink, R.M.A., G. Klop, J. Dijkstra, and A. Bannink. 2015. Phosphorus metabolism in dairy cattle : literature study on recent developments and gaps in knowledge. Wageningen UR Livestock report 910.

Klop, G., B. Hatew, A. Bannink, and J. Dijkstra. 2015. Effects of nitrate and docosahexaenoic acid on methane production in lactating dairy cows. Proceedings Joint Annual Meeting of the American Diary Science Association, Orlando, FI., USA.

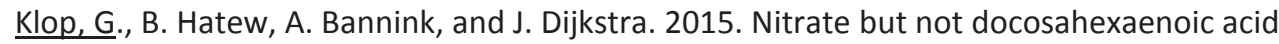
reduces methane production in lactating dairy cows. WIAS Science Day 2015, February 5, Wageningen, the Netherlands.

Dijkstra, J., J. France, A. Bannink, J. L. St-Pierre, E. Kebreab, R. M. A. Goselink, and G. Klop. 2014. A model of phosphorus utilization in lactating dairy cattle. Abstracts of the 8th International Workshop on Modelling Nutrient Digestion and Utilisation in Farm Animals, Cairns, Australia.

Van Gastelen, S., E.C. Antunes Fernandes, K. A. Hettinga, G. Klop, S. J. J. Alferink, and J. Dijkstra. 2014. Replacing grass silage with maize silage affects rumen fermentation 
characteristics and enteric methane production in dairy cattle. Proceedings of the 39th Animal Nutrition Research Forum. Utrecht, the Netherlands.

Podesta, S. C. , B. Hatew, G. Klop, H. van Laar, R. D. Kinley, A. Bannink, and J. Dijkstra. 2013. The effect of nitrogen fertilization level and stage of maturity of grass herbage on methane emission in lactating cows. Proceedings of the 5th Greenhouse Gases and Animal Agriculture Conference (GGAA2013), Dublin, Ireland.

Velthof, G.L., P. Hoeksma, J. J. Schröder, J. C. van Middelkoop, W. C. A. van; Geel, P. A. I. Ehlert, G. Holshof, G. Klop, and J. P. Lesschen. 2012. Agronomic potential of mineral concentrate from processed manure as fertiliser. Proceedings 716 of The International Fertiliser Society, 20th Annual Conference, Leek, United Kingdom.

Van Vuuren, A.M., J. Dijkstra, G. Klop, W. H. Hendriks, and A. A. Dijkhuizen. 2012. Challenges for future dairy nutrition. World Nutrition Forum. Marina Bay, Singapore. 


\section{TRAINING AND SUPERVISION PLAN ${ }^{1}$}

\begin{tabular}{lr}
\hline The Basic Package (3 ECTS) & \\
\hline WIAS Introduction Course & 2012
\end{tabular}

$\begin{array}{ll}\text { Course on philosophy of science and/or ethics } & 2014\end{array}$

\begin{tabular}{lr}
\hline Scientific Exposure (11 ECTS) & \\
\hline International conferences & 2013 \\
Greenhouse gases and Animal Agriculture conference, Dublin, Ireland & 2015 \\
ADSA-ASAS Joint Annual Meeting, Orlando, Florida, USA &
\end{tabular}

International Symposium on Dairy Cattle Nutrition, Wageningen, the Netherlands

2013, 2014, 2015

Seminars and workshops

Symposium on phosphorus nutrition in pigs and poultry, Wageningen, the Netherlands 2012

WIAS Science Day, Wageningen, the Netherlands $\quad 2014$

WIAS Science Day, Wageningen, the Netherlands $\quad 2015$

Symposium: Solutions for climate change from animal production, Wageningen, the 2014

Netherlands
Conference: Nutrition, Health and Welfare of Calves, Wageningen, the Netherlands

Presentations

'Phosphorus utilization in dairy cattle', Wageningen, the Netherlands, 26 November 2013,

oral presentation.

'Fosfor metabolisme in de koe - van het plafond naar de bodem', Hardenberg, the

Netherlands, 29 October 2014, oral presentation (in Dutch).

'Nitrate but not docosahexaenoic acid reduces methane production in lactating dairy cows',

Wageningen, the Netherlands, 5 February 2015, oral presentation.

'Fosfor in melkvee', Utrecht, the Netherlands, 9 June 2015, oral presentation (in Dutch).

'Nitrate but not docosahexaenoic acid reduces methane production in lactating dairy cows',

Orlando, Florida, USA, 16 July 2015, oral presentation.

Netherlands, 2 March 2016, oral presentation (in Dutch).

\begin{tabular}{ll}
\hline In-Depth Studies (7 ECTS) & \\
\hline Disciplinary and interdisciplinary courses & 2012 \\
Wageningen Business School course: Ruminant Nutrition & 2013 \\
Wageningen Business School course: Advances in Feed Evaluation & 2015 \\
Environmental Impact Assessment of Livestock Systems & 2012 \\
Advanced statistics courses & 2014 \\
Design of Experiments & 2012 \\
Statistics of the life sciences & \\
\hline Statutory Courses (3 ECTS) & 2013 \\
\hline Use of Laboratory Animals (Article 9) & 2014 \\
\hline Professional Skills Support Courses (3 ECTS) & 2014 \\
\hline Supervising MSc thesis work & 2015 \\
Scientific publishing & \\
Data management & \\
Writing Grant Proposals & \\
\hline
\end{tabular}




\section{Research Skills Training (12 ECTS)}

Two research assignments apart from PhD project

Phosphorus use efficiency in dairy cattle

Isotope study dairy cows

\begin{tabular}{lr}
\hline Didactic Skills Training (18 ECTS) & 2012,2014 \\
\hline Supervising practicals and excursions & $2013-2015$ \\
Supervising practical 'Introduction to Animal Sciences course' & $2013-2016$ \\
Supervising practical 'Applied Animal Biology course' & 2015 \\
Supervising theses & 2013 \\
6 MSc theses & $2013-2015$ \\
1 BSc thesis & \\
1 Internship & \\
\hline Management Skills Training (4 ECTS) & \\
\hline Membership of boards and committees & \\
WAPS council - Education Committee member for 2 years & \\
\hline TOTAL: 61 ECTS & \\
\hline${ }^{1}$ Completed in the fulfilment of the requirements for the education certificate of the Graduate School \\
Wageningen Institute of Animal Sciences (WIAS). \\
${ }^{2}$ One ECTS equals a study load of 28 hours.
\end{tabular}




\section{ACKNOWLEDGEMENTS}

Toch wel bijzonder om na 4 jaar dan op het punt aan te komen dat ik het dankwoord voor mijn proefschrift mag gaan schrijven. Mijn naam staat weliswaar op de kaft, maar dit proefschrift is met hulp van heel veel anderen tot stand gekomen en daarom wil ik graag van de gelegenheid gebruik maken om hen op deze plaats hartelijk te bedanken.

In de allereerste plaats wil ik de Heer Jezus Christus bedanken. Zonder Hem had ik dit nooit voor elkaar gekregen.

Uiteraard wil ik ook mijn promotor en co-promotoren hartelijk bedanken voor de begeleiding van de afgelopen jaren. Wouter, bedankt voor de begeleiding en de tips en adviezen op de momenten dat het promotietraject allemaal wat minder volgens plan verliep. Je gaf veel vrijheid en vertrouwen, maar als het nodig was kon ik altijd even binnenlopen voor advies. Bedankt daarvoor! En Mirian, jij ook bedankt!

Jan en André, bedankt voor de goede inhoudelijke begeleiding en feedback. Ik heb veel van jullie geleerd. Natuurlijk namen jullie het werk heel serieus, maar ik kan nog steeds lachen als ik terugdenk aan de discussies over o.a. stellingen als 'lactose is vet', 'alles binnen 10 meter van een koe is natuur', en dan was er nog het terugkerende gespreksonderwerp over iets met een maisdoolhof... ;-). Jullie allebei heel erg bedankt, het was leuk en leerzaam om met jullie samen te werken!

Walter en Wilbert, ook jullie hebben inhoudelijk een bijdrage geleverd aan dit proefschrift. Ik mocht altijd even binnenlopen met een vraag. Ook als soms bleek dat dat weer een paar nieuwe vragen opleverde en het dus iets meer tijd kostte dan gedacht. Bedankt!

Bayissa, also a special thank you for you. It was really fun to work with you in the same project. You showed me how to successfully defend a thesis from the Low Emission Feed project last year, and I hope to follow your example in that. Sabrina, ik heb goede herinneringen aan de tijd die we samen in dit project hebben gewerkt. Het einde van ons 'collega-zijn' was niet het einde van onze vriendschap. En wij weten allebei dat de beste 
resultaten van een project soms niet gepubliceerd worden. Bedankt voor al je support van de afgelopen jaren en ik vind het super dat je mijn paranimf wilt zijn!

Willem, ook jij bedankt dat je mijn paranimf wilt zijn. Ik kijk met veel plezier terug op onze samenwerking van de afgelopen jaren. En ook voor jou geldt dat je een heel betrokken collega was. Greet, jij verdient ook een speciaal bedankje voor al die keren dat je ons van eten/koffie hebt voorzien als het weer eens een keertje later werd met inkuilen dan gepland. En jullie allebei natuurlijk ook heel erg bedankt voor jullie gastvrijheid en betrokkenheid, ook buiten werktijden!

I also want to thank all my ANU colleagues from the past 4 years. I'm not going to mention everybody separately (as I don't want to forget anyone!), but thanks a lot to all of you for creating such a nice working environment. I wish all of you all the best for the future!

Een aantal collega's wil ik nog wel in het bijzonder bedanken voor hun support en gezelligheid: Marijke, je was de beste buurvrouw! Bedankt voor alle 'afleveringen' van Buurvrouw \& Buurvrouw. Ik denk er met veel plezier aan terug! Sanne, ook jij bedankt voor je gezelligheid en alle grappen die we hebben uitgehaald! Jij was de collega die me regelmatig aan het huilen maakte... van het lachen wel te verstaan :'-). Kasper, jij ook heel erg bedankt voor je gezelligheid en voor alle feedback op mijn schrijfsels. Was erg leuk om met je samen te werken! Henk, bedankt voor de 'ondertiteling' bij artikelen over chemische reacties die ik niet begreep. Sandra, ook jij was een heel leuke collega en ik vond het erg gezellig in Florida! Tetske en Yvonne, jullie kende ik al voor ik aan dit project begon. Het was leuk om samen met jullie te studeren en jullie zijn ook super leuke collega's geweest. Hopelijk blijven we elkaar in de toekomst tegenkomen. Jen, I already met you before I started my PhD. You were a great thesis supervisor during my MSc, a nice colleague during my PhD and also a good friend. Thanks for that! En Betty en Yvon, jullie zijn essentieel voor ANU. Ontzettend bedankt voor al jullie hulp en gezelligheid!

Al het onderzoek dat beschreven staat in dit proefschrift moest eerst uitgevoerd worden. Ook dat was niet mogelijk geweest zonder hulp van anderen. Ries, Teus, Willem, Rinie, Tonnie, Ronald, Bert, André, Sabine, Debbie, jullie hebben allemaal meegeholpen om dit 
project tot een goed einde te brengen. Bedankt voor jullie inzet en collegialiteit! Tamme, Sven, Marcel en Joswita, jullie verdienen ook een speciaal bedankje. Jullie technische assistentie was cruciaal en bovendien was het altijd erg gezellig om met jullie samen te werken! Ook de mensen van het ANU lab wil ik hartelijk bedanken: Michel, Jane-Martine, Erika, Xuan-Huong, Hans en Leon, bedankt voor het meedenken over de juiste procedures en/of jullie hulp op momenten dat er op meer dan één plek werk te doen was. Saskia, ik blijf het leuk vinden dat we in een intensieve proef met chronisch slaapgebrek toch geen enkele keer onenigheid hebben gehad. Hoewel het serieus onderzoek was moet ik toch ook terugdenken aan Donald Duck, een vrolijke hamster, vreselijke 'muziek(?)' en gezellige maaltijden. Bedankt voor je hulp, want zonder jou had ik die proef nooit kunnen uitvoeren. Het was gezellig! Harmen, ook jij bedankt voor de momenten dat je bij wilde springen!

Dit proefschrift had ook niet tot stand kunnen komen zonder de hulp van studenten. Kitty, Stefan en Sanne, jullie hebben allemaal een belangrijke bijdrage geleverd aan de uitvoering van het onderzoek en de analyses in het lab. Heel erg bedankt Het was ook erg plezierig om met jullie samen te werken, wat de saaiere klusjes vaak toch een stuk leuker maakte. Dus ook daarvoor hartelijk bedankt. Ik wens jullie allemaal het allerbeste toe! Abdulai and Jeffry, thank you very much for your assistance in conducting the research and the laboratory analyses. Both of you were a great help and a lot of fun to work with. I wish you all the best for the future!

Sander en Sander, jullie verdienen ook een plekje in dit dankwoord. Sander, bij jou heb ik de basics van voedingsonderzoek bij herkauwers geleerd. Ik denk met veel plezier terug aan de stages in Velddriel, Wageningen en Brussel. Het was niet alleen leerzaam, maar ook altijd gezellig om met jou samen te werken. En Sander, jij ook heel erg bedankt voor alles wat je me hebt geleerd tijdens mijn afstudeeropdracht voor de HAS. Ook dat was zowel leerzaam als gezellig! En tsja.. het blijft een feit dat jij al eerder wist dat ik een PhD zou gaan doen dan dat ik er zelf van overtuigd was...;-).

Voor mijn familie en vrienden was ik niet altijd even gezellig de afgelopen jaren, omdat ik vaak lange dagen en weekenden door moest werken. Bedankt voor jullie vriendschap, 
begrip, en voor de gezelligheid op de momenten dat ik dankzij jullie even afstand kon nemen van mijn werk.

Last, but not least: Pap, Mam, Eline, Peter, jullie verdienen een speciaal plekje hier. Bedankt voor jullie steun, gezelligheid, en gebeden. Ik hou van jullie!

\section{Geronda}




\section{COLOPHON}

The research described in this thesis is financially supported by the Dutch financers (Dutch Ministry of Economic Affairs, Product Board Animal Feed and the Dutch Dairy Board).

Cover design and lay-out: Geronda Klop

Pictures: Mirian Hendriks 